\title{
A Transcription for Soprano Saxophone and Piano of Chen Yi's "Chinese Folk Dance Suite", Originally for Violin and Orchestra
}

Tak Chiu Wong

Follow this and additional works at: https://researchrepository.wvu.edu/etd

\section{Recommended Citation}

Wong, Tak Chiu, "A Transcription for Soprano Saxophone and Piano of Chen Yi's "Chinese Folk Dance Suite", Originally for Violin and Orchestra" (2017). Graduate Theses, Dissertations, and Problem Reports. 6971.

https://researchrepository.wvu.edu/etd/6971

This Dissertation is protected by copyright and/or related rights. It has been brought to you by the The Research Repository @ WVU with permission from the rights-holder(s). You are free to use this Dissertation in any way that is permitted by the copyright and related rights legislation that applies to your use. For other uses you must obtain permission from the rights-holder(s) directly, unless additional rights are indicated by a Creative Commons license in the record and/ or on the work itself. This Dissertation has been accepted for inclusion in WVU Graduate Theses, Dissertations, and Problem Reports collection by an authorized administrator of The Research Repository @ WVU.

For more information, please contact researchrepository@mail.wvu.edu. 


\title{
A Transcription for Soprano Saxophone and Piano of Chen Yi's \\ Chinese Folk Dance Suite, Originally for Violin and Orchestra
}

Tak Chiu Wong

\author{
Doctoral Document submitted to the \\ College of Creative Arts \\ at West Virginia University \\ in partial fulfillment of the requirements \\ for the degree of
}

Doctor of Musical Arts
in
Music Performance

Michael Ibrahim, DMA, Committee Chairperson and Research Advisor Nina Assimakopoulos, MM

Yoav Kaddar, PhD

Andrew Kohn, PhD

David Taddie, PhD

School of Music
Morgantown, West Virginia 2017

Keywords: Saxophone, Violin, Reduction, Arrangement, Adaptation, Transcription, Copyright $@ 2017$ by Tak Chiu Wong 


\section{ABSTRACT \\ A Transcription for Soprano Saxophone and Piano of Chen Yi's Chinese Folk Dance Suite, Originally for Violin and Orchestra}

\section{Tak Chiu Wong}

Throughout the Western music tradition, transcription has been an important mechanism for the creation of new instrumental repertoire. This project intends to create new repertoire for the saxophone by transcribing an appropriate composition upon a non-western aesthetic. The works by Chinese-American composer Chen Yi are known for their merging of Oriental and Western aesthetics, and Chinese Folk Dance Suite is particularly well-suited for this endeavor.

A brief history of transcription is examined in the introductory chapter. The following two chapters investigate the life and music of Chen, including her musical style, unique instrumental resources, and works for the saxophone. The compositional background of Chinese Folk Dance Suite, including the origins and borrowed materials from Chinese tradition in each movement, is examined in chapter four. The last two chapters include a discussion of the methodology used in the transcription process and, finally, the transcription itself. A conclusion is provided in chapter seven. 
To my parents, my wife, and my son. 


\section{ACKNOWLEDGEMENTS}

I would like to express my appreciation to all those who helped and supported me during my musical journey.

First of all, I would like to express my deepest gratitude to my mentor, Dr. Michael Ibrahim, who has also served as the chair of my committee throughout the course of my studies at the West Virginia University. He has always been inspiring and encouraging of any of my artistic directions. Without his support, I would not have achieved what I have during my time at WVU, not to mention his mentoring and the endless time spent advising and proofreading this document.

I am fortunate to have had a supportive committee during my time at WVU. The other members include Prof. Nina Assimakopoulos, Dr. Yoav Kaddar, Dr. David Taddie, who has shared his extraordinary technological expertise in support of my recitals, and Dr. Andrew Kohn, who provided invaluable advice on this document.

This project would not have been possible without the support of Dr. Chen Yi. Her unique music was a direct inspiration for this project. Her generous approval and encouragement to my proposal, sharing her knowledge and original material, and advising during the process of this project, were inestimable.

I would also like to thank my other mentors since my formal music training began: Dr. Scott Turpen from the University of Wyoming, Mr. Jean-Yves Fourmeau from the CRR de Cergy-Pontoise, France, and Mr. Michael Campbell and Ms. Jennifer To from the Hong Kong Academy for Performing Arts.

Although neither of them received any musical training, my parents never wavered in their support throughout my musical studies. I am also fortunate in my parents-in-law, who provided generous support during my doctoral study. This document would not have been done without the help of my brother, who provided incessant technical support.

Last but not least, I wish to thank my beloved wife, Qian Xu, who has always been encouraging and supportive throughout my career in music. 


\section{TABLE OF CONTENTS}

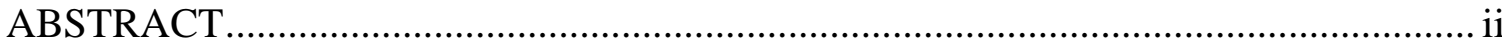

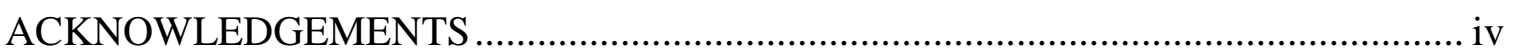

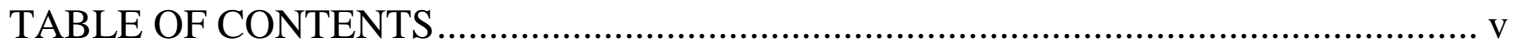

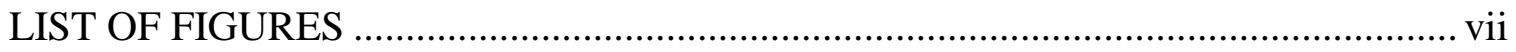

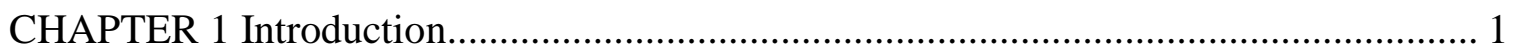

1.1. Terminology

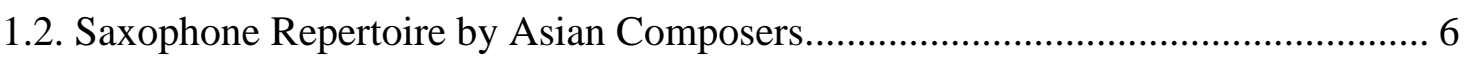

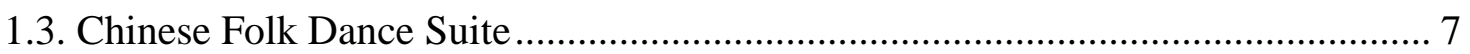

CHAPTER 2 Biography of Chen Yi......................................................................... 9

2.1. Childhood and Early Education ....................................................................... 9

2.2. The Influence of the Cultural Revolution .............................................................. 10

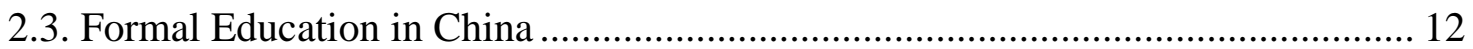

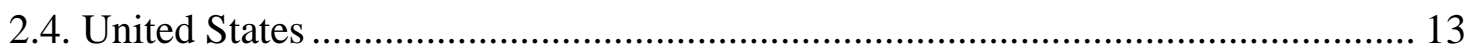

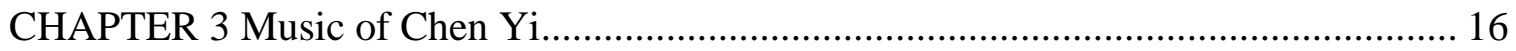

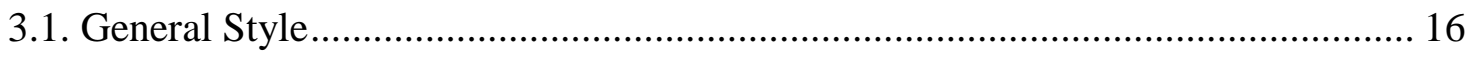

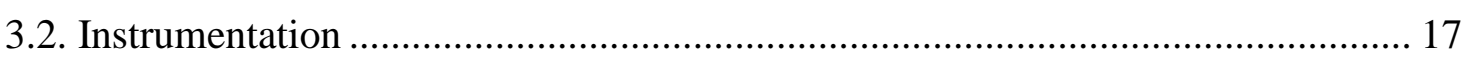

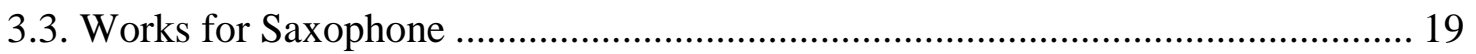

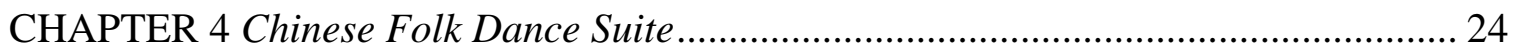

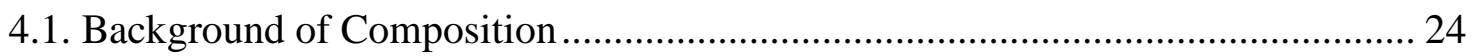

4.2. Origins and Borrowed Materials from Chinese Tradition ...................................... 25 
4.2.2. YangKo

4.3.2. Muqam 35

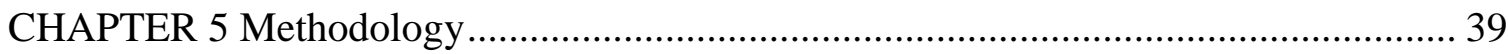

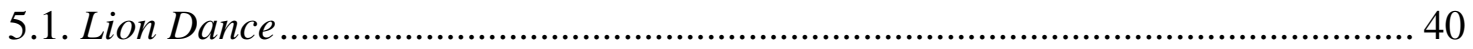

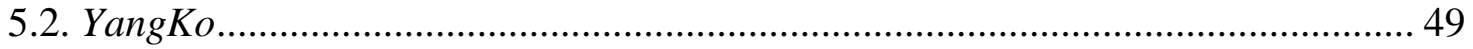

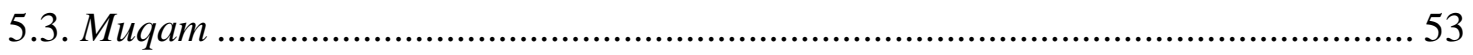

CHAPTER 6 Chinese Folk Dance Suite for Soprano Saxophone and Piano ................... 58

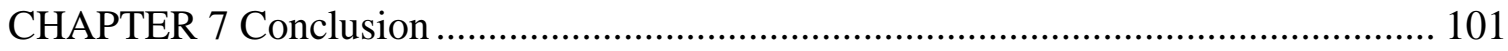

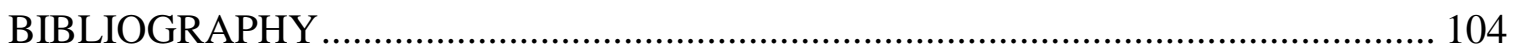

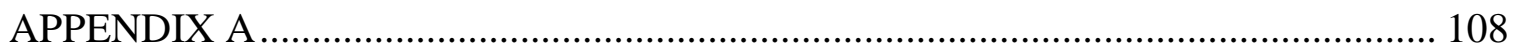

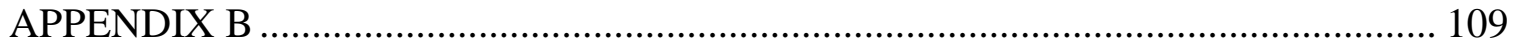

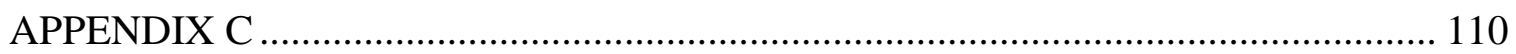




\section{LIST OF FIGURES}

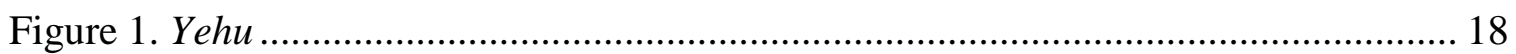

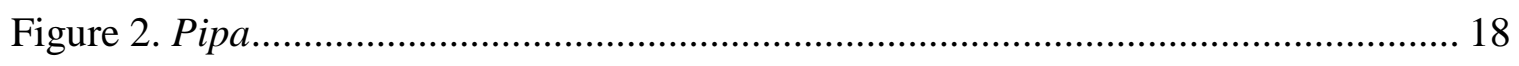

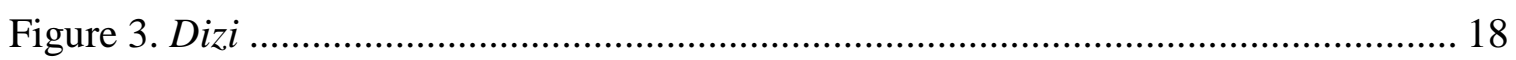

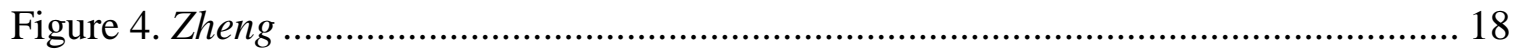

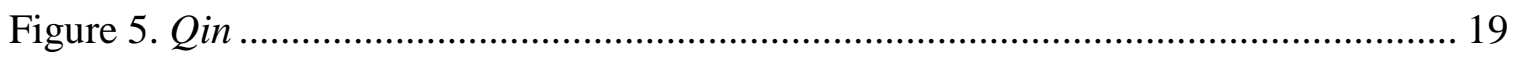

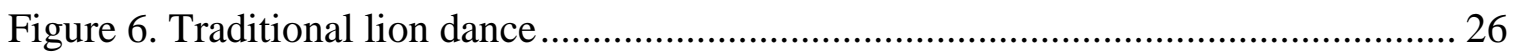

Figure 7. Lion dance percussion accompaniment ......................................................... 27

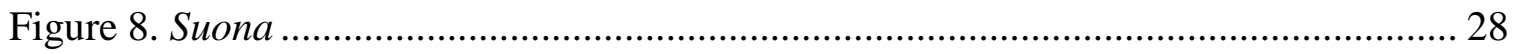

Figure 9. Motive a of Lion Dance and motive from Han Tian Lei.................................. 29

Figure 10. Motive b of Lion Dance and motive from Shi Zi Xi Qiu ................................. 30

Figure 11. Motives c and c' of Lion Dance, and motive from Shi Zi Xi Qiu.................... 30

Figure 12. Motives d of Lion Dance and motive from Shi Zi Xi Qiu ............................... 31

Figure 13. Motive e of Lion Dance and motives from Shi Zi Xi Qiu ................................ 31

Figure 14. YangKo dance with waist-drum dancing ...................................................... 32

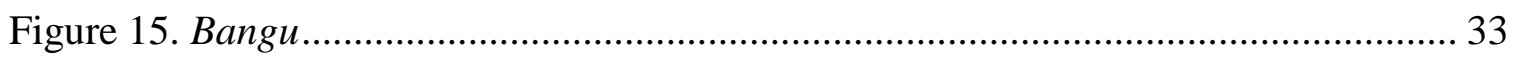

Figure 16. Luo gu jing technique, YangKo, mm. 13-16, full score.................................. 34

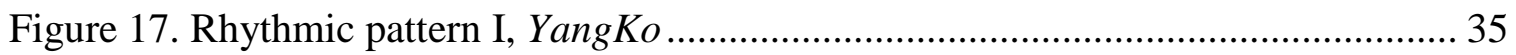

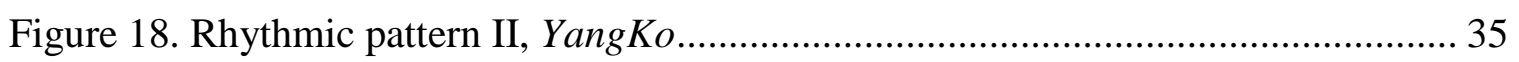

Figure 19. Traditional muqam performance ………………......................................... 37

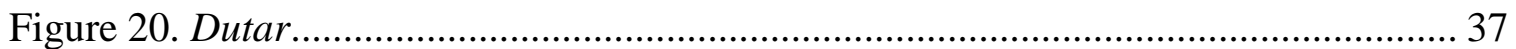

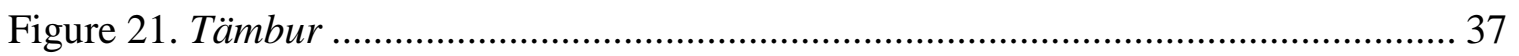

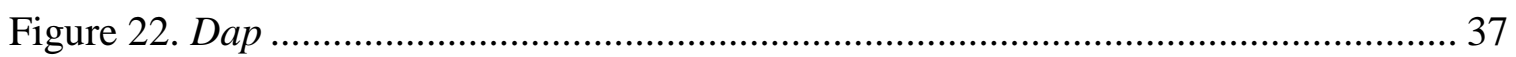

Figure 23. Second theme of Muqam, mm. 28-32 ………………………………...... 38

Figure 24. Beginning of Awagulia ............................................................................ 38

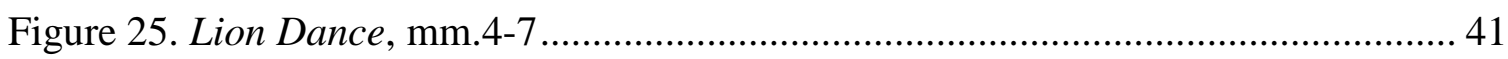

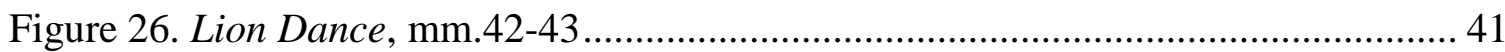

Figure 27. Soprano saxophone (in B-flat), Lion Dance, mm.64-78 ………………....... 42

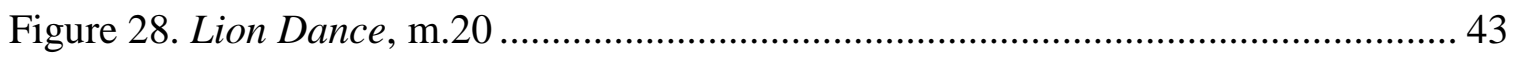

Figure 29. Lion Dance, mm.41-43 ......................................................................... 44 


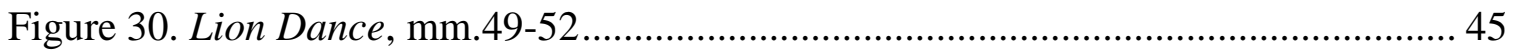

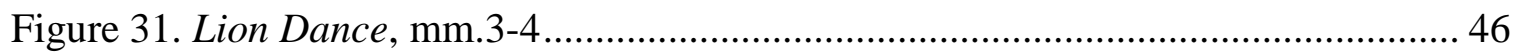

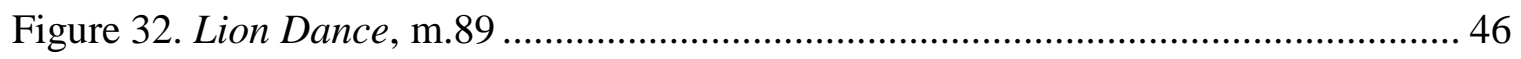

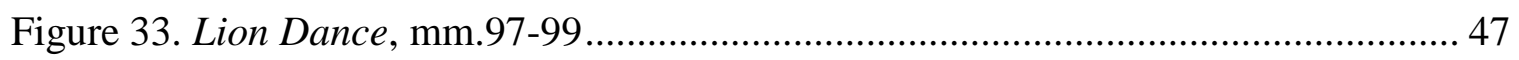

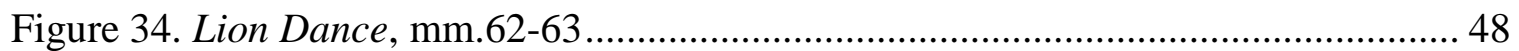

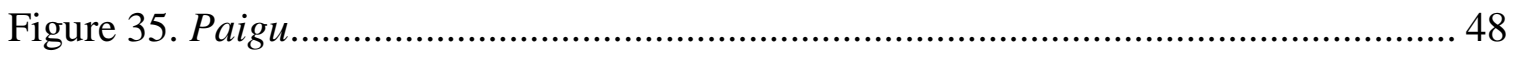

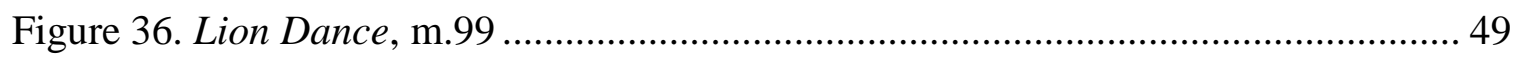

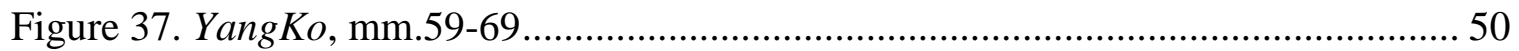

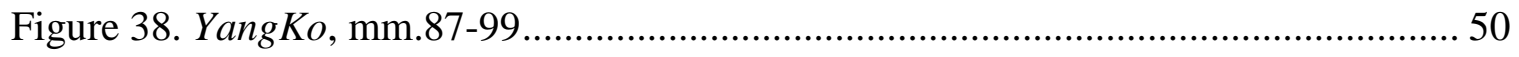

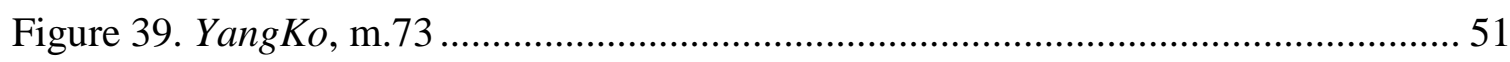

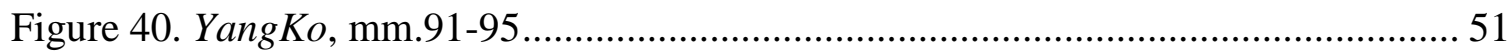

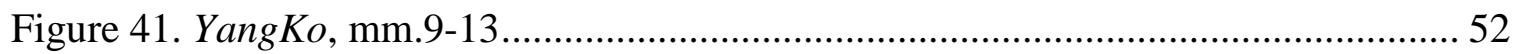

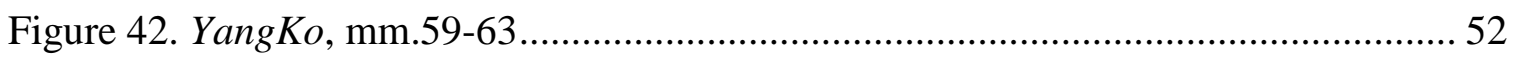

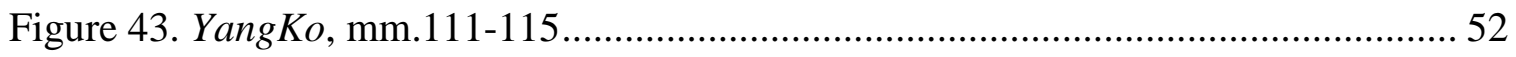

Figure 44. Texture Comparison, YangKo ............................................................... 53

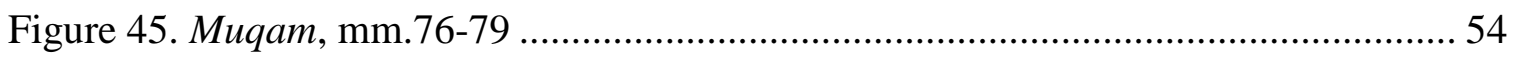

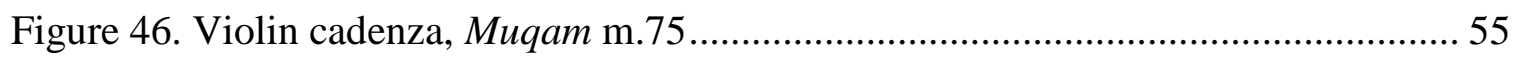

Figure 47. Saxophone cadenza (in B-flat), Muqam m.75 ......................................... 56

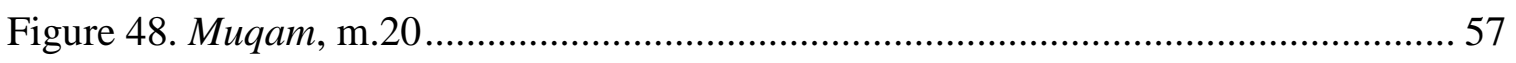




\section{CHAPTER 1}

\section{Introduction}

"The use of existing music as a basis for new music is pervasive in all periods and traditions," 1 claimed musicologist Peter Burkholder, who uses the term "musical borrowing" for "everything [ranging] from direct quotation to the use of an older work as a model without overt reference." ${ }^{2}$ In the broadest sense, the history of musical borrowing can be regarded as the history of improvisation, composition and performance. ${ }^{3}$ A more specific approach to musical borrowing, the reworking of significant portions of a composition from one medium to another, procedures we commonly refer to as arrangement or transcription, has been an important mechanism for the creation of new instrumental repertoire throughout the tradition of Western music.

Before the seventeenth century, vocal and instrumental music was often interchangeable and considered "apt for voices or viols." 4 Intabulations - that is, arrangements of existing polyphonic vocal music for keyboard or plucked string instruments - were a main practice in creating early instrumental repertoire between the fourteenth and sixteenth centuries. ${ }^{5}$ The Robertsbridge Codex, dated from approximately 1360, was one of the earliest surviving manuscripts written for keyboard instruments, and

\footnotetext{
1 J. Peter Burkholder, "Borrowing," Grove Music Online, accessed March 11, 2017, http://www.oxfordmusiconline.com/subscriber/article/grove/music/52918pg1.

2 J. Peter Burkholder, "The Uses of Existing Music: Musical Borrowing as a Field," Notes 50, no. 3 (1994): 861-62, accessed March 11, 2017, doi:10.2307/898531.

3 Burkholder, "Borrowing."

${ }^{4}$ Evlyn Howard-Jones, “Arrangements and Transcriptions," Music \& Letters 16, no. 4 (1935): 305, accessed February 7, 2017, http://www.jstor.org/stable/728727.

5 Howard Mayer Brown, "Intabulation," Oxford Music Online, accessed February 3, 2017, http://www.oxfordmusiconline.com/subscriber/article/grove/music/13823.
} 
contains intabulations of motets from the collection Roman de Fauvel. ${ }^{6}$ In the seventeenth century, it became common practice to arrange music from operas or stage works for keyboard instruments. Thus, in 1668, Jean-Henri d'Anglebert included a transcription of the overture from Lully's opera Mascarade de Versailles in his Pieces de Clavecin. ${ }^{7}$

By the mid-eighteenth century, original instrumental music was written for relatively specific instrumentations; for example, the concerto genre called for one or a small group of specific soloists and ensemble. Although written in an instrumental idiom, instrumental music was often adaptable and exchangeable. For example, J. S. Bach's Goldberg Variations can be played on organ, harpsichord or clavichord; Telemann's 12 Fantasias, $T W V$ 40:2-13 can be played on flute, recorder, oboe or violin. In the Baroque era, transcription was no longer the main practice in creating new instrumental repertoire, however, the practice did continue. J. S. Bach transcribed music from A. Marcello, B. Marcello, Telemann, Torelli, and Vivaldi, in his 16 Konzerte nach verschiedenen Meistern for keyboard, BWV 972-987.

A more exact and precise writing of notation continued with Haydn, Mozart, and especially Beethoven, whose music was expected to be performed as it was notated, except for the cadenzas in instrumental concertos. Composers throughout the Classical and Romantic eras continued to rework compositions for other instrumental groupings. The role of transcription, as a mechanism for creating new repertoire, would continue into the twentieth and the twenty-first centuries. While composers adapted music from one setting to another, modification was often made to make the new setting more idiomatic.

\footnotetext{
6 Thurston Dart and John Morehen and Richard Rastall, "Tablature," Oxford Music Online, accessed February 3, 2017, http://www.oxfordmusiconline.com/subscriber/article/grove/music/27338.

7 David Ledbetter and C. David Harris, “D’Anglebert, Jean Henry," Oxford Music Online, accessed February 5, 2017, http://www.oxfordmusiconline.com/subscriber/article/grove/music/07165.
} 
The development of the modern piano also led to further instances of transcribed works. First, because of the instrument's ability to reproduce polyphonic and contrapuntal musical material, composers and publishers arranged opera arias and orchestral works for piano. Secondly, a Bach revival lead to a new interest in arranging and performing J. S. Bach's keyboard music on the modern piano. Lastly, publishers and composers created piano reductions of concertos for private performances. ${ }^{8}$ Nineteenth century composers also created virtuosic transcriptions as concert music. Liszt was an important figure in contributing to this genre for piano. This type of musical creation spanned throughout his entire creative life, since the first version of Grande fantaisie sur la tyrolienne de l'opéra La fiancée de Auber written in 1829 , to Tarentelle de César Cui written in $1885 .{ }^{9}$ Other notable transcriptions included La Campanella, from Paganini's Violin Concerto No. 2. Liszt also wrote solo piano reductions of Berlioz's Symphonie Fantastique and Beethoven's complete symphonies.

Twentieth and twenty-first century composers continued the practice of creating new repertoire through transcription. Converse to the practice of reducing orchestral works to the piano, some composers explored orchestrating solo or chamber works into large ensemble settings. Ravel's orchestration of Mussorgsky's Pictures at an Exhibition is frequently programed and recorded. Other examples include Schoenberg's orchestral setting of Brahms's Piano Quintet; and Webern's Ricercar a 6 from J. S. Bach's Art of Fugue. Transcription also remains an essential practice in developing initial works for ensembles such as the reed quintet, brass ensemble, and wind band.

\footnotetext{
${ }^{8}$ Howard-Jones, “Arrangements and Transcriptions," 307-308.

9 James F. Penrose, “The Piano Transcriptions of Franz Liszt," The American Scholar 64, no. 2 (1995): 273 , accessed February 5, 2017, http://www.jstor.org/stable/41212325.
} 
In numerous cases, composers have adapted their own works for multiple settings, such as Brahms's viola version of his clarinet sonatas; and, Stockhausen's multiple versions of In Freundschaft, originally for clarinet. Self-adaptation can be found in many of Handel's works; more than fourteen examples of self-adaptation can be found in his masque Acis and Galatea. ${ }^{10}$ In some instances, the adaptation was made by performers with the approval and oversight from the composers, for example, the cello setting of Beethoven's Horn Sonata, Op.17; Berio's Sequenza XIVb for double bass originally written for cello; and, Khachaturian's Flute Concerto, originally for violin, and many others.

\subsection{Terminology}

The process of adapting an existing musical composition can involve various levels and degrees of restructuring the original work. The terminology used to define creations within this range can be ambiguous, interchangeable and is by no means universally accepted. ${ }^{11}$ Arrangement and transcription are two of the most commonly used terms. Terminologies like Übertragung (adaptation), and Bearbeitung (re-working or working over), are also commonly used to describe these practices. ${ }^{12}$

Musicologist Malcolm Boyd defines an arrangement as "any piece of music based on or incorporating pre-existing material: variation form, the contrafactum, the parody mass, the pasticcio, and liturgical works based on a cantus firmus all involve some measure of arrangement. In the sense in which it is commonly used among musicians, however, the word may be taken to mean either the transference of a composition from one medium to

\footnotetext{
10 John T. Winemiller, "Recontextualizing Handel's Borrowing," The Journal of Musicology 15, no. 4 (1997): 455, accessed February 5, 2017, doi:10.2307/764003.

${ }^{11}$ Malcolm Boyd, "Arrangement," Oxford Music Online, accessed February 9, 2017, http://www.oxfordmusiconline.com/subscriber/article/grove/music/01332.

12 Howard-Jones, “Arrangements and Transcriptions," 305.
} 
another or the elaboration (or simplification) of a piece, with or without a change of medium. ${ }^{" 13}$ Under this broad definition, the terms and their usages vary differently. Pianist Evlyn Howard-Jones claimed that an arrangement is "playing of the notes in another medium, for example, to play the Bach Flute Sonatas on the Violin"; while transcription is a "recreation or making-over with regard to imaginative and creative, definite re-making of the orchestral and vocal material into a piece. It is exemplified by the Liszt Tristan Liebestod." ${ }^{14}$ In contrast to the previous view, music critic Clinton Gray-Fisk thought that a "real (strict) transcription is, or should be, an attempt to transfer a work from one medium to another as accurately as circumstances may permit," while a "free transcription is akin to that of arrangement." 15

As an example of an organization that has grappled with this terminology, in 1966, the American Choral Directors Association (ACDA) created the Committee on Choral Editing Standards, tried to define the labelling problems of arrangement and transcription. ${ }^{16}$ According to the committee, an arrangement means a "re-working of a piece so that the performing forces, the musical content or the form are different from those of the original," 17 and usually "entails substantial re-conception of the original piece." 18 Transcription, however, means to "re-write in another manner, and usually means a re-scoring of a work for performing forces other than those for which it was originally

\footnotetext{
13 Boyd, "Arrangement."

14 Howard-Jones, "Arrangements and Transcriptions," 305.

15 Clinton Gray-Fisk, “'Improving' the Classics," The Musical Times 69, no. 1026 (1928): 733, accessed February 9, 2017, doi:10.2307/916657.

16 Ronald Broude, “Arrangement, Transcription, Edition: Some Problems in Terminology," The Choral Journal 18, no. 1 (1977): 25-27, accessed February 9, 2017, http://www.jstor.org/stable/23544286.

17 Ibid, 25.

18 Ibid.
} 
composed." ${ }^{19}$ In this study, the term arrangement and transcription is used as described by the Committee on Choral Editing Standards.

\subsection{Saxophone Repertoire by Asian Composers}

Adolphe Sax, the inventor of saxophone, understood the necessity of developing new literature for the instrument to flourish. After its patent in 1846, he commissioned and published almost 200 compositions. ${ }^{20}$ According to the bibliographical index, Londeix Guide to the Saxophone Repertoire, 1844-2012 by Jean-Marie Londeix and Bruce Ronkin, more than 29,000 works were written for the saxophone by 2012 , excluding orchestral works which included one or more saxophone parts. Saxophone repertoire grew with 11,000 new works being written between 2003 to $2012 .{ }^{21}$ Many of these 30,000 works for saxophone were created by adapting works for other instruments with approval from the original composers. Some notable examples include Berio's Sequenza $I V b$, originally written for oboe; Denisov's Saxophone Concerto, originally written for viola; and John Adams's Fearful Symmetries for saxophone quartet, originally written for orchestra.

Since the second half of the twentieth century, Asian musicians have been a new force in western classical music, both in its creation and performance. Several examples include conductor Seiji Ozawa, pianist Lang Lang, violinist Midori Gotō, and flutist Jasmine Choi. Oriental aesthetics and philosophies influence Asian composers to compose in different way. Composers such as Chou Wen-Chung, Toru Takemitsu, and Isang Yun composed in highly personal styles that drew upon vast influences from both

\footnotetext{
${ }^{19}$ Ibid, 26.

${ }^{20}$ Thomas Liley, "The Repertoire Heritage," in The Cambridge Companion to the Saxophone, ed. Richard Ingham (Cambridge: Cambridge University Press, 1998), 51.

${ }_{21}^{2}$ Jean-Marie Londeix, introduction to Londeix Guide to The Saxophone Repertoire 1844-2012, ed. Bruce Ronkin (Glenmoore: Roncorp Publication, 2012), iv-v.
} 
Western tradition and their own cultural background. These composers did not write significantly for the saxophone. This project intends to create new repertoire by transcribing suitable composition for the saxophone in non-western aesthetics, and Chen Yi's $^{22}$ Chinese Folk Dance Suite is idiomatically suitable for this new setting.

\subsection{Chinese Folk Dance Suite}

Chinese Folk Dance Suite is scored for solo violin and orchestra. There are three movements in this work, featuring distinct folk dances from different parts of China. They are titled Lion Dance, YangKo, and Muqam respectively. It is one of the most popular solo works for a melodic instrument by $\mathrm{Chen} \mathrm{Yi}$, and is an idiomatically suitable piece to adapt to the saxophone for several reasons. First, in the first movement Lion Dance, the solo violin line imitates the spirit of the Chinese double-reed instrument Souna. The soprano saxophone has a similar timbre and dynamic range to the Souna. Secondly, the register of the violin is similar to the soprano saxophone. The lowest note on soprano saxophone is Ab3, only a half-step above the G3 on violin. ${ }^{23}$ With the consideration of using altissimo register, soprano saxophone can play up to $\mathrm{C} 7$, covering most of register on violin. Finally, the Chinese Folk Dance Suite was written in a conventional Western language and technique; with the main musical elements derived from Chinese traditional music, this work embodies a unique musical language rarely found in saxophone repertoire.

\footnotetext{
${ }^{22}$ Chen is family name; Yi is personal name. Chen Yi can be referred to as Dr. Chen, Prof. Chen, Ms. Chen, or Chen Yi, but not Dr. Yi, Prof. Yi, or Ms. Yi.

"Chen Yi," Theodore Presser Company, accessed December 18, 2016, http://www.presser.com/composer/chen-yi.

${ }^{23}$ Scientific Pitch Notation was used in this document, where C4 corresponds to middle C on the piano. Robert W. Young, "Terminology for Logarithmic Frequency Units," Journal of the Acoustical Society of America, 11, no. 1 (1939): 134-139, accessed April 14, 2017, doi:10.1121/1.1916017.
} 
This project aims to create a transcription of Chen Yi's Chinese Folk Dance Suite, originally written for solo violin and orchestra, for soprano saxophone and piano. This setting will be scored for soprano saxophone and piano instead of soprano saxophone and orchestra in order to increase the opportunity for performance among the saxophone community. This setting will help to further the literature for the saxophone, enhancing the diversity of musical aesthetics. However, the possibility of performing this work in the orchestral setting with solo saxophone part can also be considered.

There are seven chapters included in this project. After the first introductory chapter, chapters two and three discuss the life and works of Chen Yi. Chapter four presents background information of Chinese Folk Dance Suite. Chapter five discusses the methodology of the process of transcription. Chapter six is the transcription, and chapter seven is the conclusion of the research project. Unless indicated otherwise, excerpts of the soprano saxophone part are notated in concert pitch but notated in B-flat in the transcription in chapter six. 


\section{CHAPTER 2}

\section{Biography of Chen Yi}

\subsection{Childhood and Early Education}

Chen Yi was born in Guangzhou, China, on April 4, 1953 to a family of medical doctors who appreciated Western classical music. Chen's mother played piano at a professional level. Chen's father played violin, and enjoyed singing various songs at home ranging from European folk songs to Hollywood movie music. ${ }^{24}$

Chen has two siblings, who both became professional musicians. Chen's older sister, Chen Min, was a piano prodigy, and began performing at three years. She now serves as pianist of the China Philharmonic Orchestra. Chen's younger brother, Chen Yun, is a violinist. He studied at the Sydney Conservatory of Music. He is currently the concertmaster of the China Philharmonic Orchestra, and teaches violin performance at the at Central Conservatory of Music in Beijing, China, where he coordinates the chamber music division of the string department.

Chen began her music education with regular private piano lessons at the age of three, and then violin lessons at the age of four. Her early teachers included Li Suxin on piano and Zheng Rihua on violin. Chen studied most of the standard violin repertoire, including works by J. S. Bach, Beethoven, Brahms, Mendelssohn, Mozart, Paganini and Sibelius. ${ }^{25}$ She also took private theory and music history lessons with Zheng Zhong, the brother of her violin teacher, Zheng Rihua, who had an influence on her childhood musical development.

${ }^{24}$ John de Clef Piñeiro, "An Interview with Chen Yi," The New Music Connoisseur 9, no. 4 (2001): 28.

${ }^{25}$ Ibid. 
Chen's childhood was surrounded by music, art, and literature. Her family frequently attended symphonic concerts and ballets. She also attended performances of folk songs and dances by visiting performance groups from Japan and the Congo. She played music from her father's large collection of western classical music, and read opera librettos and other literature from both Chinese and European writers. Chen was familiar with musical styles and different art forms from both Chinese traditions and European culture at a young age. This cultural background would be significant for her future development as a musician and composer.

\subsection{The Influence of the Cultural Revolution}

The Cultural Revolution began in 1966 and dramatically affected Chen and her family's life. The Chen family were urban intellectuals who were victim to cruel political persecution during this time. Forced apart, Chen's father was sent to the countryside, her mother was imprisoned in a hospital, her older sister was sent to a farm in the North, and her younger brother was sent to the home of their violin teacher Zheng Rihua. From 1968 to 1970 , Chen was sent to a suburban district of her home town Guangzhou, and forced to perform heavy labor as a punishment. Chen recalls:

I had to walk all the way up to the big mountain. I sometimes had to get up at 4 a.m. just to avoid the heat of the sun. There were days when I also had to carry a hundred pounds of stone and mud twenty-two times, from the foot of the mountain to the very top. ${ }^{26}$

This extremely difficult time would have a lasting effect upon Chen's values and her musical aesthetic. Although schools were closed, Chen did not stop studying and practicing music. In her spare time, she practiced her violin with a heavy metal mute

${ }^{26}$ Ibid., 29. 
intended to reduce the volume. Music helped her to overcome the emotional distress that was placed upon her due to her family's separation. She played violin publicly to entertain farmers, children, and soldiers. Although only revolutionary songs were allowed, she added double-stops and fast flourishes which she had learned from studying Paganini. It was at this time that she realized that Western music techniques could be applied to Chinese music. Within this framework, her improvisation was one of her first experiences as a composer. ${ }^{27}$ The resulting music was a natural integration of both Chinese and Western cultures. ${ }^{28}$ Chen later recalled that with this experience she "learned to overcome hardship, to bear anger, fear, and humiliation under political pressure, to get close to uneducated farmers on a personal and spiritual level, and to share her feelings and thinking with them, to learn to hope, to forgive, to survive, and to live optimistically, strongly and independently, and to work hard in order to benefit more human beings in society."29

Jiang Qing, the third wife of Mao Zedong, attempted to add Western instruments to the traditional ensemble of the Chinese opera, in order to reform the traditions to a new model of proletarian art for future opera productions. Under such ideals, Chen was called to join the Beijing Opera Troupe in her hometown Guangzhou in 1970, and served as concertmaster in the orchestra, a position she kept until $1978 .{ }^{30}$ Chen worked closely with the mixed ensemble comprising Chinese and Western instruments, by orchestrating and composing music for them. She eventually mastered the use of range, techniques,

\footnotetext{
${ }^{27}$ Dee Wedemeyer, “Arts Abroad; A Chinese-Born Composer and Her Own Long March,” New York Times, March 27, 2001, accessed December 28, 2016, http://www.nytimes.com/2001/03/27/arts/arts-abroad-a-chinese-born-composer-and-her-own-long-march.ht $\mathrm{ml}$.

${ }^{28}$ Piñeiro, "An Interview with Chen Yi," 28.

${ }^{29}$ Ibid., 29.

${ }^{30}$ Ibid.
} 
timbres and expressive effects of each of these Chinese instruments. She became very interested in timbre and aimed to combine Western and Chinese instruments, and was able to apply Western structural techniques in organizing the musical material. She also discovered that to "understand and master the syntax of Chinese language is the key to creating a good melody of Chinese opera." 31

\subsection{Formal Education in China}

When the Cultural Revolution ended in 1976, the educational systems were restored. In 1978, Chen Yi, along with her brother Chen Yun, was among the class of two hundred admitted to the Central Conservatory out of eight thousand applicants. Chen was admitted as a violinist; she later declared composition as her major. The composition class consisted of composers such as Chen Qigang, Cong Su, Tan Dun, and Zhou Long, her future husband, who would all become some of the most influential Chinese composers in their generation. ${ }^{32}$

Chen's studies in Western music included functional harmony, counterpoint, form and analysis, orchestration, ear training, and sight-singing. Chinese music was another important part of her education, including the study of folk songs, musical storytelling, local theater, and traditional instrumental music. She memorized folk songs in the local dialect, and was able to compose melodies in various local styles. ${ }^{33}$

During Chen's undergraduate studies (from 1978 to 1982) and graduate studies (from 1983 to 1986), she studied composition with Wu Zuqiang and Alexander Goehr, a visiting professor from Cambridge University. Wu's rigorous training and open-minded

\footnotetext{
${ }^{31}$ Xin Guo, "Chinese Musical Language Interpreted by Western Idioms: Fusion Process in The Instrumental Works by Chen Yi" (PhD diss., Florida State University, 2010).

32 Wedemeyer, "Arts Abroad."

${ }^{33}$ Piñeiro, "An Interview with Chen Yi," 29.
} 
musical thought had a significant influence on Chen's compositional style, in particular on her interest in motivic development, music analysis, and striking a balance between compositional technique and human emotion, as well as a passion for Chinese cultural heritage. He also encouraged Chen to develop her own style: especially to combine Chinese musical culture and western techniques. Under the instruction of Goehr, Chen studied twentieth century compositional techniques extensively. Contemporary music was banned in China for three decades; no recordings or scores were available until Chou Wen-Chung's visit in $1977 .{ }^{34}$ The twentieth-century music further opened Chen's notion of music from tertian tonality, and she developed her own musical language and style during this period. Chen graduated in 1986, as the first woman to receive a Master of Music degree in composition in China.

\subsection{United States}

In 1986, Chen traveled to the United States and pursued her doctoral study at Columbia University. She studied composition with Chou Wen-Chung and Mario Davidovsky for six years.

While at Columbia University, Chen receive her first major commission outside of China in 1992, to write a piano concerto for the Brooklyn Philharmonic Orchestra, commissioned by Dennis Russell Davies. Davies heard her Symphony No. 1 in Germany in 1987. This composition later became a part of her doctoral dissertation. She received her Doctoral of Musical Art degree in composition in 1993.

Soon after her graduation, Chen was appointed the composer-in-residence for Women's Philharmonic, the vocal ensemble Chanticleer, and the Aptos Creative Arts

\footnotetext{
${ }^{34}$ Guo, "Chinese Musical Language Interpreted by Western Idioms."
} 
Center in San Francisco with the support of the New Residencies Program from the organization Meet the Composer. ${ }^{35}$ She held this position until 1996, when she joined the composition faculty of the Peabody Conservatory at John's Hopkins University. In 1998, she became the Cravens/Millsap/Missouri Distinguished Professor in Composition at the University of Missouri, Kansas City, a position which she holds today. Chen was also appointed as the Cheungkong Scholar Visiting Professor at the Central Conservatory of Music by the China Education Ministry in 2006, and Distinguished Visiting Professor at the Tianjin Conservatory, China, in 2012. ${ }^{36}$

Chen's music has been recorded, performed, and commissioned by the world's leading musicians and ensembles, including Yehudi Menuhin, Yo-Yo Ma, Evelyn Glennie, the Ying Quartet, the Prism Saxophone Quartet, the National Symphony Orchestra (United States), the Los Angeles Philharmonic, the St. Paul Chamber Orchestra, the Sächsische Staatskapelle Dresden, the Austrian Radio Symphony Orchestra, the BBC Philharmonic, the Halle Orchestra, the NHK Symphony Orchestra, the Singapore Symphony Orchestra, and the China National Symphony Orchestra. Her music has been recorded on labels including BIS, Teldec, Albany, and Naxos. ${ }^{37}$

She has received fellowships from the National Endowment for the Arts and the Guggenheim Foundation. In 2001, she received the Charles Ives Living Award, a \$225,000 prize awarded every three years. ${ }^{38}$ Her other honors include the Lili Boulanger Award, the CalArts/Alpert Award, the ASCAP Concert Music Award, the Elise Stoeger Award from Chamber Music Society of Lincoln Center, the Barlow Commission Award, and the

\footnotetext{
${ }^{35}$ Piñeiro, "An Interview with Chen Yi," 27.

36 "Chen Yi," Theodore Presser Company.

${ }^{37}$ Ibid.

38 “Awards," American Academy of Arts and Letters, accessed December 18, 2016, http://artsandletters.org/awards.
} 
Chamber Music America Classical Commissioning Program Award, among others. Chen has received Honorary Doctorates from Lawrence University (Wisconsin), Baldwin-Wallace College (Ohio), The University of Portland (Oregon), and The New School (New York City). ${ }^{39}$ As a strong advocate of new music, Chen has served on the advisory boards of several organizations such as the Fromm Music Foundation at Harvard, the John Simon Guggenheim Memorial Foundation, the American Music Center, New Music USA, and the American Composers Orchestra. ${ }^{40}$

39 "Chen Yi," Theodore Presser Company.

40 Ibid. 


\section{CHAPTER 3}

\section{Music of Chen Yi}

\subsection{General Style}

Chen Yi has composed over 130 works including solo pieces, chamber music, vocal music, and orchestral music. ${ }^{41}$ She is especially known for her ability to merge Oriental and Western aesthetics. She considers her music to be a "fusion and merger, a marriage of the consonant and dissonant, the tonal and atonal." ${ }^{42}$ She regards composition to be "a composer's cultural and psychological makeup,"43 and that her musical language is a "unique combination and a natural hybrid of all influences from her background."44 She considers her composition as primarily twentieth century music, and has written in a "Western music idiom with a Chinese color."45

Chinese culture - language, philosophy, literatures, and music - make up indispensable elements and serve as a driving force behind Chen's music. As a scholar of Chinese folk music, Chen makes use of scales and folk tunes from Chinese traditional music.

Beginning with her formal musical training from the Central Conservatory of Music in China, Chen studied western music including counterpoint, fugue, tonal harmony, form and analysis, orchestration, and twentieth century music. ${ }^{46}$ Tertian and non-tertian

41 “Chen Yi," New Music USA Online Library, accessed February 16, 2017, http://library.newmusicusa.org/ChenYi.

42 Piñeiro, "An Interview with Chen Yi," 30.

43 Ibid, 28.

${ }^{44}$ Ibid.

${ }^{45}$ Ibid, 30.

${ }^{46}$ Piñeiro, "An Interview with Chen Yi,"29. 
harmony, symmetrical pitch constructions, pitch class set technique, and even aleatoric elements can also be found in her works.

\subsection{Instrumentation}

Chen writes for both Chinese instrumental ensemble and mixed ensemble with Western and Chinese instruments. Western instruments are sometimes played in an unconventional manner in order to imitate the timbre and sound of Chinese instruments. For instance, in her Viola Concerto "Xian Shi," the character and timbre of the viola are used to imitate the nasal tone of yehu (椰胡) (Figure 2), a bowed two-string instrument with a resonator made from a coconut shell. ${ }^{47}$ She also combines right-hand and left-hand pizzicato on the viola in this composition, to achieve a rapid tremolo to imitate the playing of pipa (琵琶) (Figure 1), a Chinese plucked string instrument, also known as the Chinese lute. ${ }^{48}$ Extensive use of sliding tone, specific vibrato, and ornamentation can also be found in Chen's music, to further imitate the character of Chinese traditional instrumental music. In her Near Distance, the flute parts involve wide vibrato in the low register to imitate the sound of the Chinese bamboo flute dizi (笛子) (Figure 3). ${ }^{49}$ Chen often imitated the characters of the Chinese traditional plucked string instruments $z h e n g^{50}$ (古筝) (Figure 4) and $q_{i n}^{51}$ (古琴) (Figure 5) in her piano works. For example, in her

\footnotetext{
47 Fanqin Meng, "A Research and Performance Guide of the Viola Concerto Xian Shi" (DMA diss., University of Wisconsin-Madison, 2016).

${ }^{48}$ Meng, "A Research and Performance Guide of the Viola Concerto Xian Shi."

49 Guo, "Chinese Musical Language Interpreted by Western Idioms."

50 Mei Han, "Zheng," Oxford Music Online, accessed February 20, 2017, http://www.oxfordmusiconline.com/subscriber/article/grove/music/46543.

51 Ming-Yueh Liang and Joseph S. C. Lam, "Qin," Oxford Music Online, accessed February 20, 2017, http://www.oxfordmusiconline.com/subscriber/article/grove/music/47071.
} 
piano work Guessing, she used repeated pentatonic fragmental running note patterns to imitate the playing of zheng. ${ }^{52}$

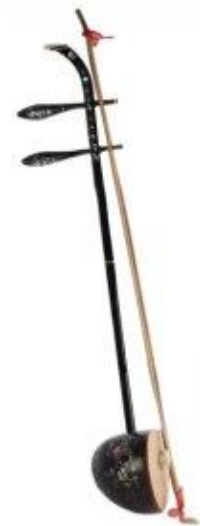

Figure 1. Yehu

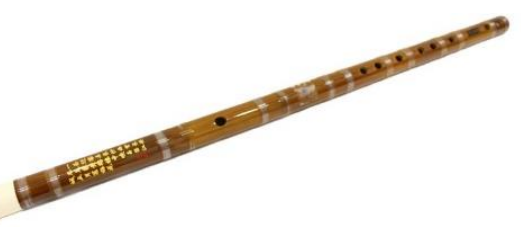

Figure 3. Dizi

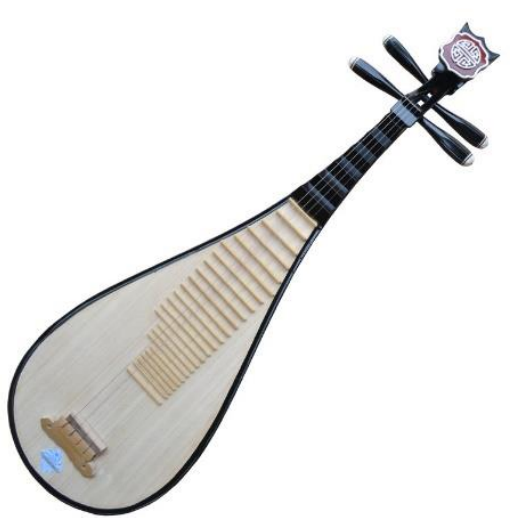

Figure 2. Pipa

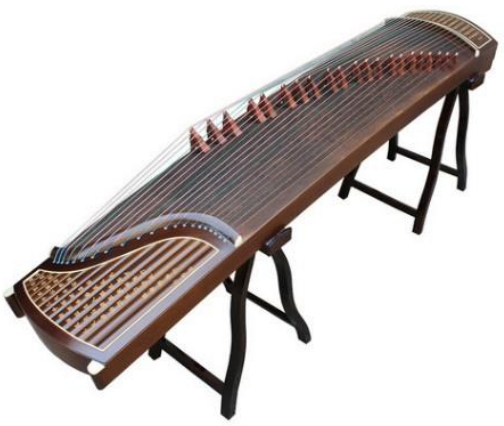

Figure 4. Zheng

52 Qing Nadia Feeken, "The Complete Solo Piano Works of Chen Yi - A Recording, Analysis, and Interpretation" (DMA diss., Arizona State University, 2012). 


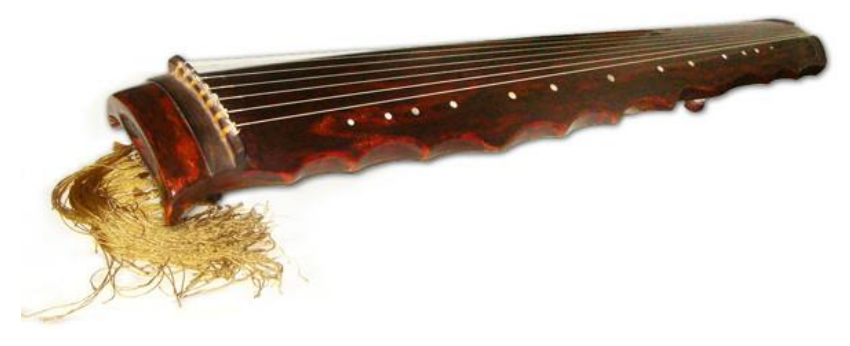

Figure 5. Qin

The techniques used in Beijing Opera are also frequently applied in Chen's music. They include the Beijing Opera's form of singing and luo gu jing (鑼鼓經) technique. She admired Schoenberg's Sprechstimme, in which she discovered a combination of speaking and singing that is similar to the Beijing Opera's reciting style. ${ }^{53}$ In her As in a Dream for soprano, pipa, and zheng, the singing pitches were designed according to reciting tones, speech-like intonations, gestures of Chinese music style, and influences from Western atonality. ${ }^{54}$ Luo gu jing is a traditional Chinese vocables and oral notation system for percussion ensemble for educational purposes. Spoken syllables are applied in representing corresponding sounds of percussion instruments. Percussionists learn music orally and aurally by singing and memorizing different patterns of syllables. ${ }^{55}$ Chen applied the technique of luo gu jing in YangKo, the second movement of Chinese Folk Dance Suite, where orchestral musicians sing unpitched syllable patterns in accompaniment with the violin solo, resulting in a chanting percussive sonority.

\subsection{Works for Saxophone}

\footnotetext{
53 Po Kwan Law, "The A Cappella Choral Music of Chen Yi: 1985-2010” (DMA diss., University of Illinois at Urbana-Champaign, 2013).

${ }^{54}$ Songwen Li, "East Meets West: Nationalistic Elements in Selected Piano Solo Works of Chen Yi" (DMA diss., University of North Texas, 2001).

55 Guangming Li, "Onomatopoeia and Beyond: A Study of the Luogu Jing of the Beijing Opera" (PhD diss., University of California, Los Angeles, 2001).
} 
Chen has included the saxophone in several of her original works. To date, they include three solo works, four chamber works, one concerto, and six large-ensemble works. ${ }^{56}$

The six large-ensemble works are Spring Festival (1999), KC Capriccio (2000), Tu (2003), Suite from China West (2005), Dragon Rhyme (2010), and Wind (2011). Spring Festival was Chen's first work that includes saxophone. It was written for middle school bands with one optional alto saxophone part; Four works - Tu, Suite from China West, Dragon Rhyme, and Wind - were written for professional wind ensemble; and $K C$ Capriccio was written for wind ensemble and mixed choir. As is common in wind ensemble, the instrumentation usually includes a saxophone quartet (AATB, or occasionally SATB). Suite from China West and Dragon Rhyme included an AATB saxophone quartet; $T u$ included a SATB saxophone quartet; while Wind and $K C$ Capriccio included an ATB saxophone trio. ${ }^{57}$

Commissioned by the Stuttgart Chamber Orchestra, Ba Yin was written for saxophone quartet and string orchestra, and was premiered by the Rascher Saxophone Quartet and the Stuttgart Chamber Orchestra on October 27, 2001 with conductor Dennis Russell Davies in Stuttgart, Germany. ${ }^{58}$ This three-movement concerto is the only saxophone concerto by Chen. It is also her first solo composition to include saxophone. Ba Yin means eight sounds in Chinese, and refers to the eight kinds of instruments in ancient China, categorized by material: metal, stone, silk, bamboo, gourd, clay, leather and

\footnotetext{
56 “Chen Yi," New Music USA Online Library, accessed February 16, 2017, http://library.newmusicusa.org/ChenYi.

57 Ibid.

58 "Chen Yi, Ba Yin," New Music USA Online Library, accessed February 16, 2017, http://library.newmusicusa.org/library/composition.aspx?CompositionID=345889.
} 
wood. ${ }^{59}$ The music was inspired by the performances of common villagers on old traditional instruments in various ensembles. ${ }^{60}$ A version accompanied by wind ensemble was adapted in 2015. This version was written and premiered by the Prism Saxophone Quartet and the University of Missouri-Kansas City Wind Symphony on October 4, 2015.

Her four chamber compositions which include saxophone are Happy Birthday to PRISM (2004), The Han Figurines (2006), Septet for Erhu, Pipa, Percussion and Saxophone Quartet (2008), and Not Alone (2014).

Happy Birthday to PRISM is a short work for saxophone quartet which lasts approximately one minute. It was written for the Prism Saxophone Quartet on its 20th anniversary celebration in 2004 .

The Han Figurines was scored for violin, clarinet, tenor saxophone, double bass, piano, and percussion. It was commissioned by the Opus 21 Ensemble and Fontana Chamber Arts, and premiered at the Kerrytown Concert House in Ann Arbor, Michigan on May 11, 2006. The sextet was inspired by Chinese clay figurines of the Later Han dynasty (25-220 A.D.) of China. ${ }^{61}$

Septet for Erhu, Pipa, Percussion and Saxophone Quartet was commissioned and premiered by the Prism Saxophone Quartet and the Music From China Ensemble. It is also the only composition of Chen's for saxophone and non-Western instruments. It was premiered in Philadelphia on February 27, 2009. Chen was inspired by the imaginative figures in the murals carved in the Mogao Caves in the ancient Chinese city Dunhuang. ${ }^{62}$

\footnotetext{
59 Ibid.

60 Ibid.

61 “Chen Yi, The Han Figurines," New Music USA Online Library, accessed February 16, 2017, http://library.newmusicusa.org/library/composition.aspx?CompositionID=345908.

62 "Chen Yi, Septet for Erhu, Pipa, Percussion and Saxophone Quartet," New Music USA Online Library, accessed February 16, 2017, http://library.newmusicusa.org/library/composition.aspx?CompositionID=345933.
} 
Written in 2013, Not Alone was commissioned and premiered by the Prism Saxophone Quartet and Nai-Ni Chen Dance Company for a dance performance with saxophone quartet, and premiered at the Peridance Center, New York City on April 26, 2014. This composition was awarded the New Music USA 2013 Live Music For Dance Award. The music was inspired by ancient Chinese poet Li Bai's poem Drinking Alone under the Moon with the Shadow. ${ }^{63}$

Chen has written three solo works for saxophone, Monologue (Impressions on the True Story Of Ah Q) (1993/2008), Chinese Ancient Dances (2004/2010), and The soulful and the perpetual (2012). Only The soulful and the perpetual is an original work for saxophone, while the other two are transcribed from Chen's works for other instruments.

Monologue (Impressions on the True Story of $A h Q$ ) was originally written for solo clarinet. It was commissioned by Inter-Artes in London and premiered at a concert entitled The World of Lu Xun in April 23, 1993 in Birmingham, United Kingdom. The work was transcribed for solo alto saxophone by American saxophonist Jeffrey Heisler in $2008 .{ }^{64} \mathrm{Lu}$ Xun was one of the most influential Chinese authors in the twentieth century. Monologue (Impressions on the True Story Of $A h Q$ ) was a "meditation of introspection"65 inspired by Lu's The True Story of Ah $Q$. The work is one of Chen's most frequently performed composition by clarinetists and saxophonists.

Chinese Ancient Dances was originally written for clarinet and piano in 2004. It was co-commissioned by the Chamber Music Society of Lincoln Center and Virginia Arts. This

\footnotetext{
63 “Chen Yi, Not Alone," New Music USA Online Library, accessed February 16, 2017, http://library.newmusicusa.org/library/composition.aspx?CompositionID=350488.

64 "Chen Yi, Monologue (Impressions on the True Story of Ah Q)," New Music USA Online Library, accessed February 16, 2017, http://library.newmusicusa.org/library/composition.aspx?CompositionID=345918.

65 "Chen Yi, Monologue," New Music USA Online Library.
} 
two-movement composition was premiered by David Shifrin and Andre-Michel Schub at Lincoln Center in New York City. The premiere performance was dedicated to the celebration of the 70th birthday of Chen's mentor Mario Davidovsky. Chen adapted the piece for soprano saxophone and piano in 2010 at the request of American saxophonist Carrie Koffman. ${ }^{66}$

The soulful and the perpetual is scored for alto saxophone and piano in two movements. It was commissioned and premiered by American saxophonist Jessica Heller Knopf in July 2012 at the 16th World Saxophone Congress in St. Andrews, Scotland. The first movement The Soulful is lyrical in moderate tempo; the second movement The Perpetual is a perpetual motion, in which consistent melodic materials are sustained and led to a final climax. ${ }^{67}$

With the approval from Chen, the transcription of Chinese Folk Dance Suite for soprano saxophone and piano will serve as a new work by Chen that features the saxophone. The compositional background, formal analysis, and methodology in the adaptation will be examined in next two chapters.

\footnotetext{
66 "Chen Yi, Chinese Ancient Dances," New Music USA Online Library, accessed February 16, 2017, http://library.newmusicusa.org/library/composition.aspx? CompositionID=345895.

67 "Chen Yi, The Soulful and The Perpetual," New Music USA Online Library, accessed February 16, 2017, http://library.newmusicusa.org/library/composition.aspx?CompositionID= 349931 .
} 


\section{CHAPTER 4}

\section{Chinese Folk Dance Suite}

\subsection{Background of Composition}

Commissioned and written in 2000, Chinese Folk Dance Suite was dedicated to Serge and Natalie Koussevitzky, and was premiered by the Women's Philharmonic with violin soloist Terrie Baune, conducted by Apo Hsu, in March 2001. The commission was supported by an award from the Serge Koussevitzky Music Foundation. ${ }^{68}$ The first and only commercial recording of the complete work to date was released by BIS records in the album Chen $Y i$ - Momentum in 2003. The soloist was Lin Cho-Liang and was accompanied by the Singapore Symphony Orchestra under direction of the director Shui Lan. ${ }^{69}$ Each of the three movements features a distinct folk dance from different parts of China. They are Lion Dance, YangKo, and Muqam respectively.

In 2005, Chen has adapted the second movement YangKo for solo violin and two percussionists for the dance program The Network For New Music with the Phrenic New Ballet in Philadelphia. ${ }^{70}$ This project was recorded by the American violinist Linda Wang in her album The Stream Flows on the label Equilibrium in 2013. ${ }^{71}$

The three dances in Chen Yi's Chinese Folk Dance Suite are stylistically distinctive and independent, which quotations and adoptions of Chinese folk music applied in these three movements. In China, Han Chinese is the majority culture which covers 94 percent

\footnotetext{
${ }^{68}$ Yi Chen, preface to Chinese Folk Dance Suite, by Yi Chen (King of Prussia: Theodore Presser Company, 2000).

${ }^{69}$ Singapore Symphony Orchestra, Chen $Y i-M o m e n t u m$, Conducted by Lan Shui, Åkersberga: BIS, 2002, Compact Disc.

${ }^{70}$ Yi Chen, preface to YangKo: for Solo Violin and 2 Percussionists, by Yi Chen (King of Prussia: Theodore Presser Company, 2006).

${ }^{71}$ Linda Wang, The Stream Flows, Scottsdale: Equilibrium, 2013, Compact Disc.
} 
of the total population, while the remaining 6 percent are comprised of more than 50 non-Han minorities. ${ }^{72}$ These 50 ethnically distinctive minorities make up the large diversity of Chinese culture. Although Han Chinese share similar cultural traditions, musical diversity did occur geographically within the Han culture: for example, within Confucian ritual music, the traditions of playing the qin (fig.3.5), and in Chinese opera. This geographic divide can be grouped broadly into North and South, in which the North Han associates with the tradition of Beijing opera and wind-and-percussion music; while the South Han associates with the tradition of Kunqu (崑曲) opera and silk-and-bamboo music. ${ }^{73}$ The diversity can be further classified: for instance, musicologist Qiao Jianzhong divides the musical culture into twelve areas. ${ }^{74}$

\subsection{Origins and Borrowed Materials from Chinese Tradition}

\subsubsection{Lion Dance}

The lion dance (舞獅) is a traditional dance form in China, where a lion costume is worn to imitate the spirit and motion of lions. The history of the tradition begins as early as the Han dynasty (206 B.C.-220 A.D.). It is usually performed during the Chinese New Year and other Chinese traditional joyous festivals. It may also be used to honor special guests by Chinese communities, or be performed at opening ceremonies, wedding ceremonies, or special celebrations. The dance is usually performed by two dancers, with one holding the head, operating the facial expression, and leading the action of the lion costume, and the other following and cooperating to depict the bodily motion of a lion

\footnotetext{
72 Alan R. Thrasher, "China, §I: Introduction: Historical, regional and study perspectives," Oxford Music Online, accessed February 26, 2017, http://www.oxfordmusiconline.com/subscriber/article/grove/music/43141pg1.

${ }^{73}$ Ibid.

${ }^{74}$ Ibid.
} 
(Figure 6). In the late twentieth century, the lion dance became a sport activity and is performed by Chinese emigrant communities in Malaysia, the United Kingdom, and the United States. ${ }^{75}$

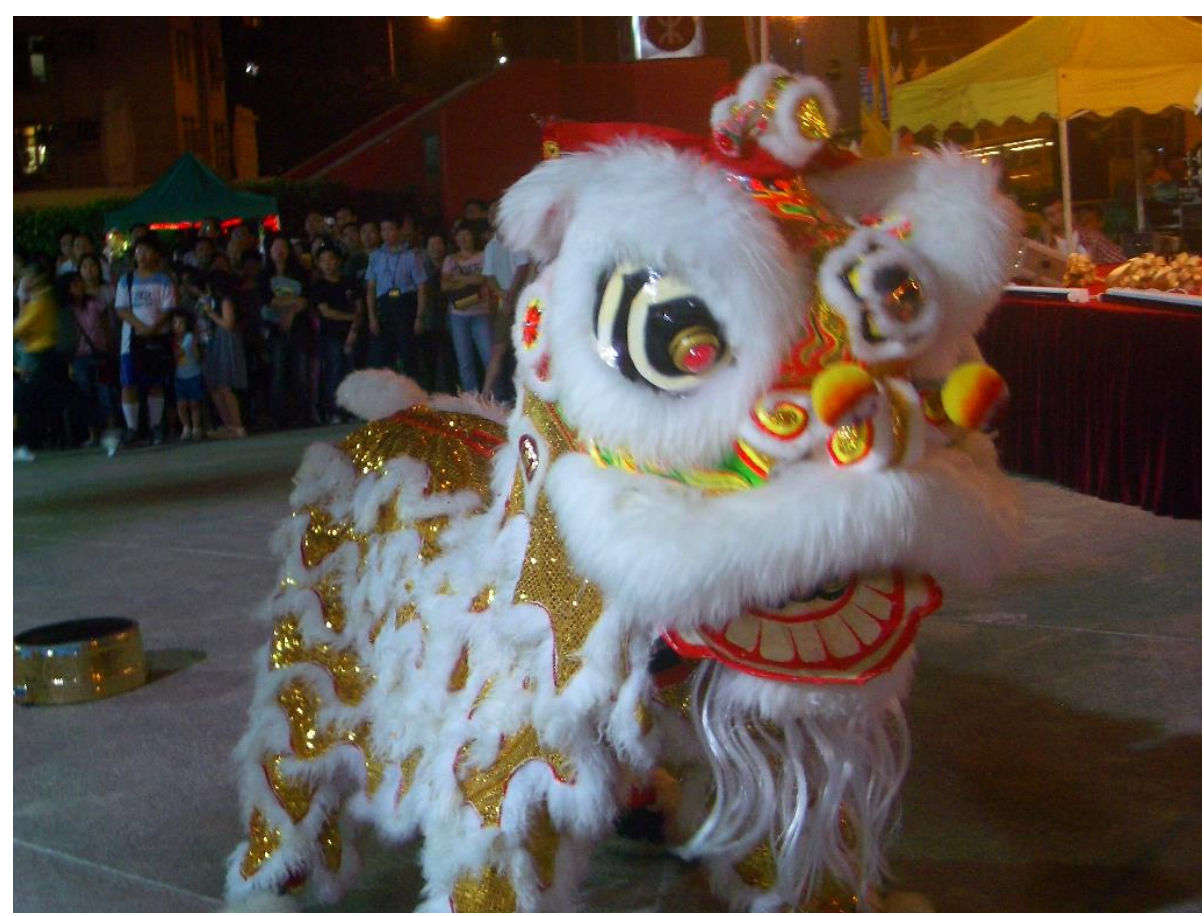

Figure 6. Traditional lion dance

The lion dance is usually accompanied solely by percussion music composed of Chinese bass drums, Chinese gongs, and Chinese cymbals (Figure 7). Several rhythmic patterns are applied in order to create different moods while the "lion" interacts with the music. Melodic instruments can be added as extra musical elements. ${ }^{76}$

\footnotetext{
${ }^{75}$ Lion dance is commonly known for native Chinese people. Cited by authority of the author. ${ }^{76}$ Ibid.
} 


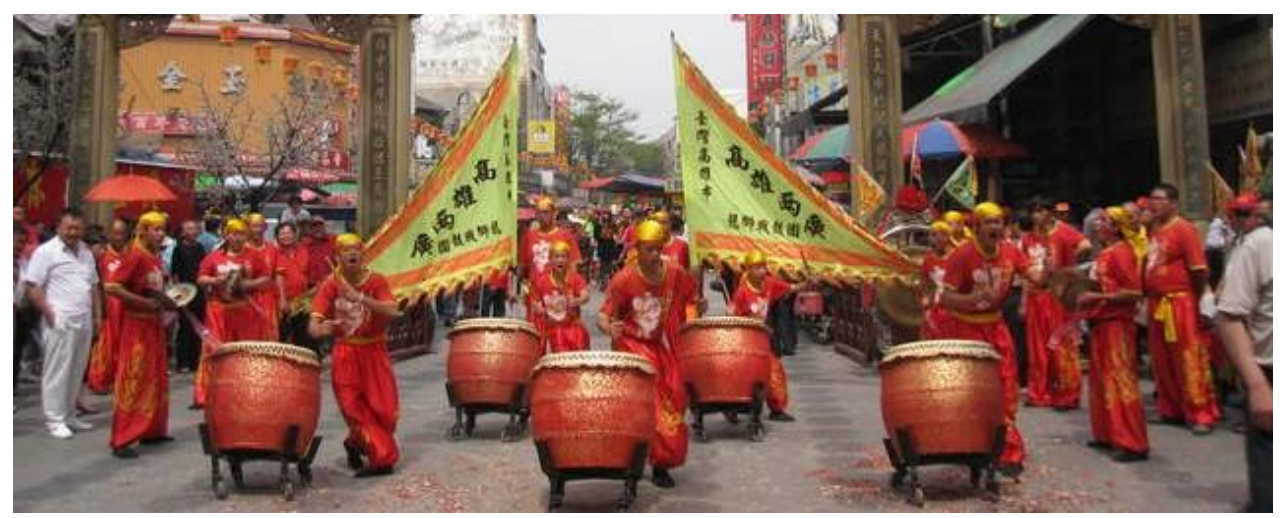

Figure 7. Lion dance percussion accompaniment

In Lion Dance, Chen Yi followed the tradition of percussion ensemble by using them to create a "dynamic and rhythmic texture responding to the solo part,"77 with the solo violin part imitating melodies and the sound of the suona (嗩呐) (Figure 8), a Chinese shawm. ${ }^{78}$ Although the lion dance was a national part of the Han heritage, Chen also featured music especially from the southern province of Guangdong in this movement. Two folk tunes, Han Tian Le (旱天雷 [dry thunderstorm]), from Guangdong and Shi Zi Xi Qiu (沿子䖒球 [lion play the ball]), from the Guangdong city of Chouzhou respectively are adopted in Lion Dance. ${ }^{79}$ Guangdong is a province in southern China.

\footnotetext{
77 Chen, preface to Chinese Folk Dance Suite.

78 Ibid.

79 Yi Chen, phone interview by author, February 26, 2017.
} 


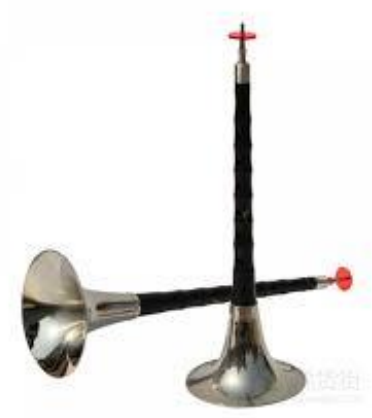

Figure 8. Suona

The Han Tian Lei melody was written by Yen Lao-Lei (嚴老烈) and was first published in the folk-song collection String Music Essential (弦歌必讀) in 1921. It was an arrangement of San Ji Lang (三汲浪) from the Cantonese opera San Bao Fo (三寶佛) for yangqin (洋琴), a Chinese hammered dulcimer. ${ }^{80}$ The original melody of San Ji Lang was plain. Yen added ornamentations with sixteenth-note and octave leaps, with fast tempo, in order to recreate the exciting mood of hearing a thunderstorm after drought. This work is now regarded as a standard repertoire in Guangdong music.

There are five motives (motives a through e) in Lion Dance, all of them are extracted from Han Tian Lei and Shi Zi Xi Qiu. An eight-note motive from Han Tian Lei is extracted and modified to become the opening theme and motive a (Figure 9) in Lion Dance. The first four notes (motive 1) and last four notes (motive 2) of Han Tian Lei are reordered to form the framework of motive a. Chen keeps the gesture of both original motives from Han Tian Lei with modified interval relationships. In motive 1, the intervals minor $3^{\text {rd }}$, major $2^{\text {nd }}$, and major $2^{\text {nd }}$, is modified to major $2^{\text {nd }}$, minor $3^{\text {rd }}$, and minor $3^{\text {rd }}$, becomes the second half of motive a. In motive 2 , the intervals minor $3^{\text {rd }}$,

\footnotetext{
${ }^{80}$ Alan R. Thrasher, "Yangqin," Oxford Music Online, accessed February 28, 2017, http://www.oxfordmusiconline.com/subscriber/article/grove/music/45375.
} 
perfect $4^{\text {th }}$, and minor $3^{\text {rd }}$, is modified to minor $3^{\text {rd }}$, minor $6^{\text {th }}$, and minor $3^{\text {rd }}$, becomes the first half of motive a.

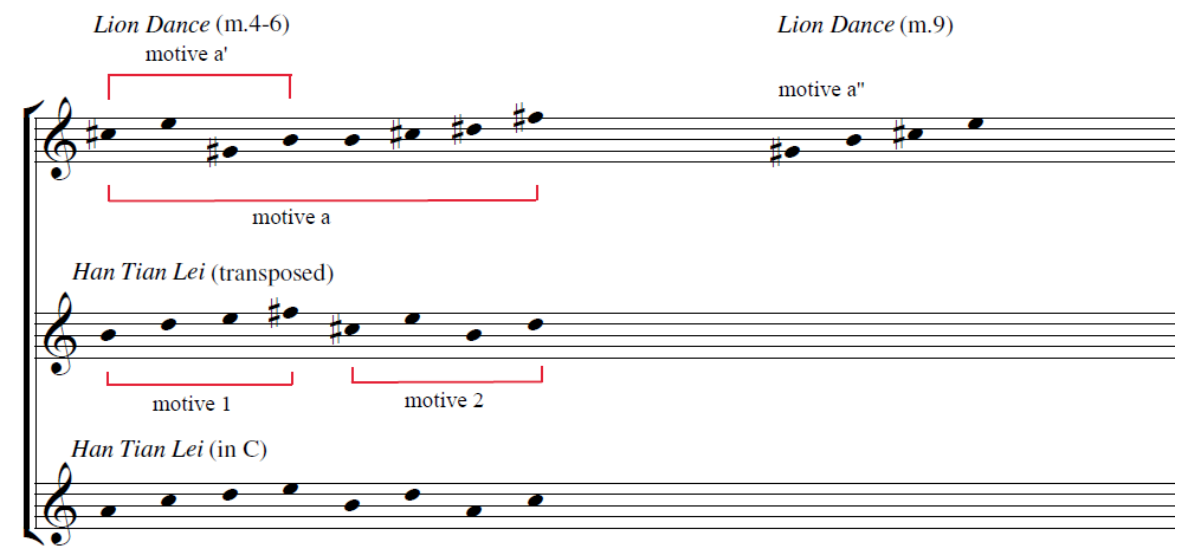

Figure 9. Motive a of Lion Dance and motive from Han Tian Lei

Shi Zi Xi Qiu was a work of standard literature in Chaozhou Xianshi (潮州弦詩)

[string] music. As indicated by the name, Chaozhou Xianshi music has been performed by string instrumental ensembles in the Chaozhou area, which has over six hundred years of history. ${ }^{81}$ The ensemble comprises of Chinese stringed instruments including yehu, zheng, pipa, erxian (二弦), sanxian (三弦), and yangqin. Fragments of Shi Zi Xi Qiu were extracted and varied to form motives b through e in Lion Dance.

The first five notes and last three notes of motives b remain unchanged from Shi Zi Xi Qiu. Chen modified the sixth and seventh note from D and G, to D-flat and E-flat, to create a motive with more chromatic notes (Figure 10).

\footnotetext{
${ }^{81}$ Meng, "A Research and Performance Guide of The Viola Concerto Xian Shi."
} 


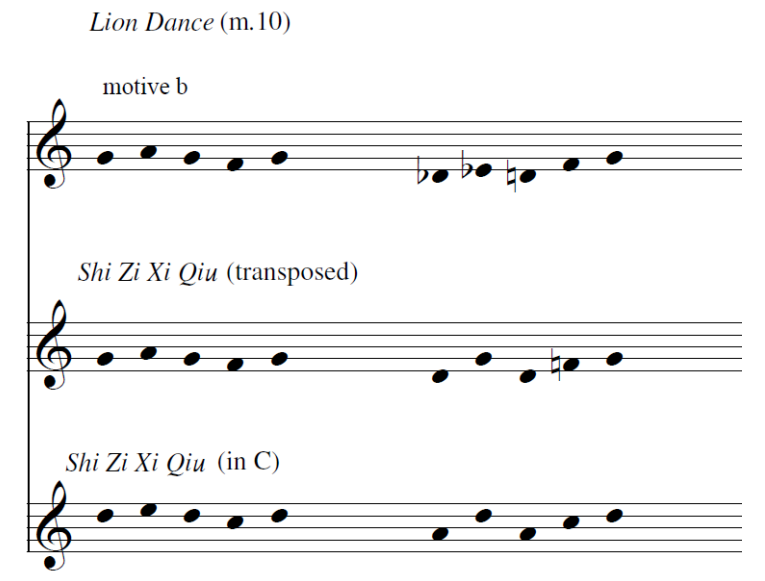

Figure 10. Motive b of Lion Dance and motive from Shi Zi Xi Qiu

Motive c is slightly adapted by omitting one note from Shi Zi Xi Qiu. The first four notes of motive c are reordered to form motive c' (Figure 11).

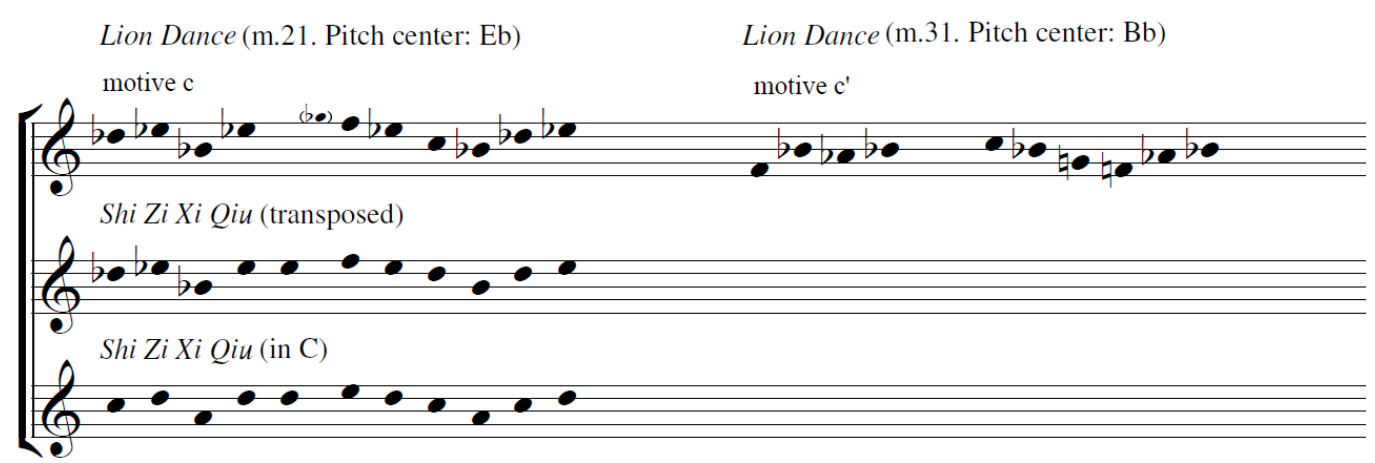

Figure 11. Motives c and c' of Lion Dance, and motive from Shi Zi Xi Qiu

Motives d (Figure 12) and e (Figure 13) are directly quoted from Shi Zi Xi Qiu. Motive $\mathrm{d}$ is slightly varied in the first appearance. 


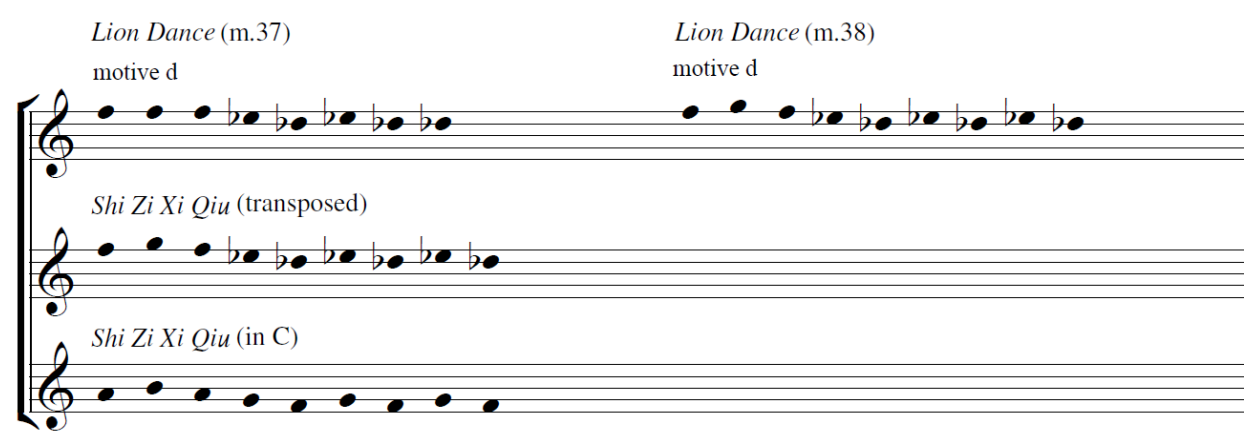

Figure 12. Motives d of Lion Dance and motive from Shi Zi Xi Qiu

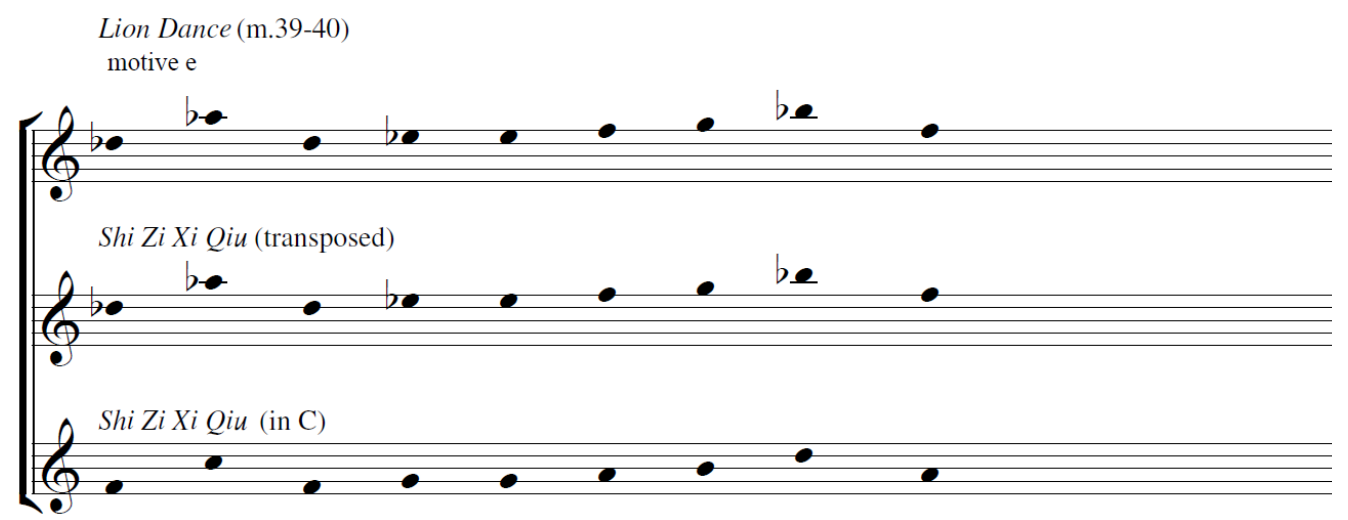

Figure 13. Motive e of Lion Dance and motives from Shi Zi Xi Qiu

The melodic material is written in a pentatonic setting related to Han Chinese folk tunes. Chen noted that twelve-tone technique had significant influence in this movement, however, it was written in manner of free atonality instead of serial technique. ${ }^{82}$

\subsubsection{YangKo}

YangKo (秧歌) dance, also spelled as yangge dance, means "song of rice". It originated as a religious activity to greet gods and dispel evils in farmland in ancient China as early as the Song dynasty (960-1279 A.D.). The YangKo dance usually combines singing with waist-drum dancing in groups and became a tradition in celebrating the Lunar New Year and the Lantern Festival, the fifteenth day after the Lunar New Year

${ }^{82}$ Yi Chen, phone interview by author. 
day. On these specific days, it was customary for people to go to their neighborhood after dinner to dance in the courtyards to greet a happy new year. The house host would prepare firecrackers and home-made rice wine to welcome the dancers' arrival. The combined sounds of songs, drums, and firecrackers were blended to create a festival atmosphere. The YangKo dancers usually dance with a red waist-drum. It would be tied to the waist of the dancers, and they would beat the drum with drumsticks while dancing. Although originating in central China, YangKo became a national recreational activity in snow season or on holidays in the late twentieth century (Figure 14). ${ }^{83}$

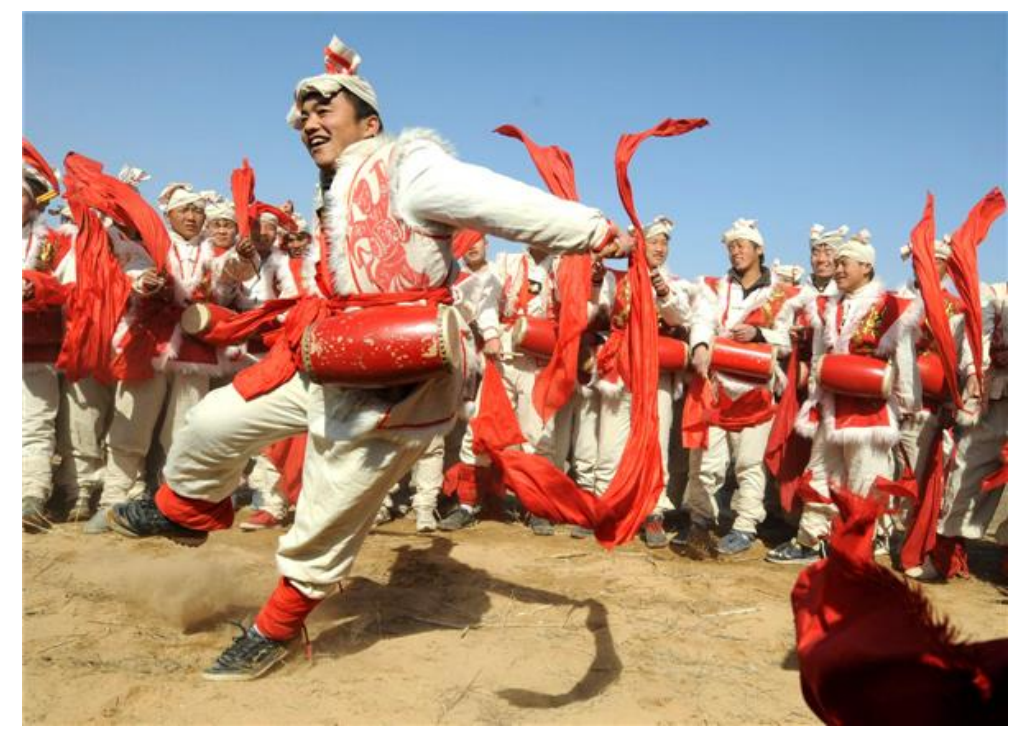

Figure 14. YangKo dance with waist-drum dancing

Chen features musical material from central China in YangKo. She was inspired by a YangKo performance she saw from television in China, in which a young female singer sang a "sweet" melody with accompaniment by a group of YangKo dancers. Chen created an imagined scene from this television program, with the solo violin part imitating the singing melody, the orchestral percussion parts imitating a close YangKo dance group, and unpitched whisper syllables, hummed by members of the orchestra, imitating a

\footnotetext{
${ }^{83}$ YangKo dance is commonly known for native Chinese people. Cited by authority of the author.
} 
distant YangKo dance group. ${ }^{84}$ The solo violin melodies were composed in a Han musical style and luo gu jing technique was applied to the orchestral whispering writing. There was no quotation or use of any folk tunes in this movement. ${ }^{85}$

As mentioned in chapter three, luo gu jing technique is a traditional Chinese solmization and oral notation system used by percussion ensembles for training purposes. The idea of luo gu jing was applied to imitate a distant sound of a percussion ensemble. For instance, "Tsa" and "Chi" imitates the sound of Chinese cymbals, "Diong" imitates a combined sound of the bass drums from both Chinese tradition and the drumset, "Da" imitates the sound of bangu (板鼓) (Figure 15), a small single headed drum from Beijing Opera. "Yi" was originally an indication of rest for bangu, and Chen made use of this syllable to create an extra layer and color to the orchestral whispering part (Figure 16). ${ }^{86}$

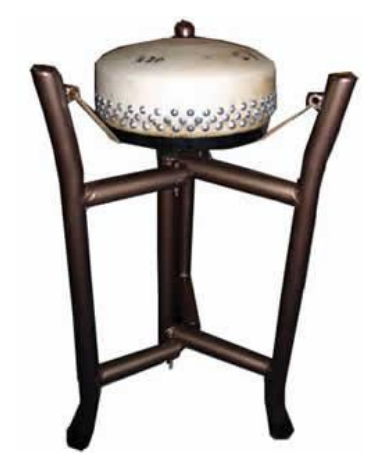

Figure 15. Bangu

${ }^{84}$ Chen, phone interview by author.

${ }^{85}$ Ibid.

${ }^{86}$ Ibid. 
13

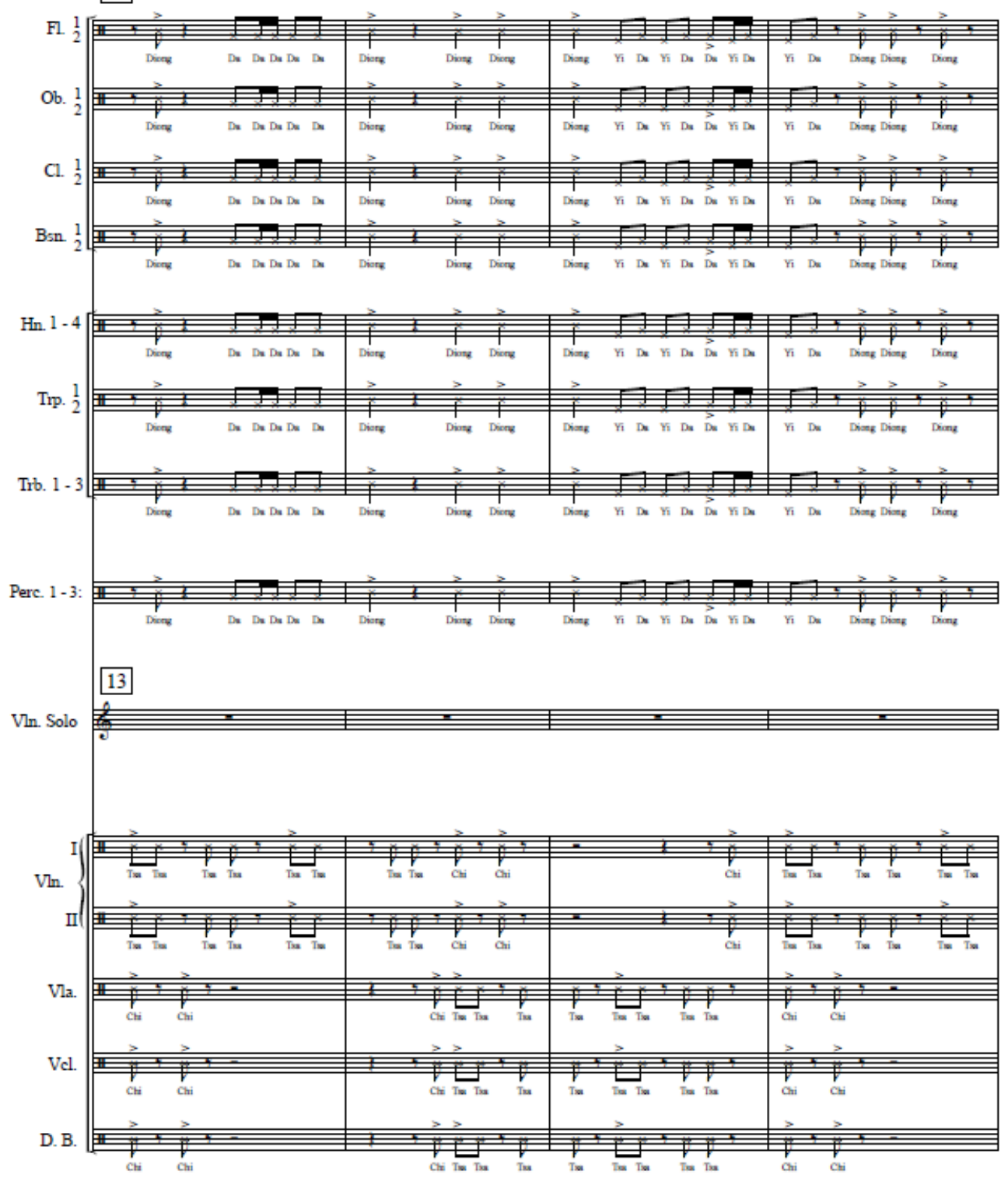

Figure 16. Luo gu jing technique, YangKo, mm. 13-16, full score

The solo violin part presents long lyrical melodies throughout this movement in different registers. Two rhythmic patterns (I and II) are presented by percussions and luo gu jing singing by orchestral players. The rhythmic pattern I (Figure 17) is repeated every three measures, while rhythmic pattern II (Figure 18) is repeated every five measures, 
creating a rich layer of rhythmic texture without resulting repeating gestures. This sonority was influenced by minimalism. ${ }^{87}$

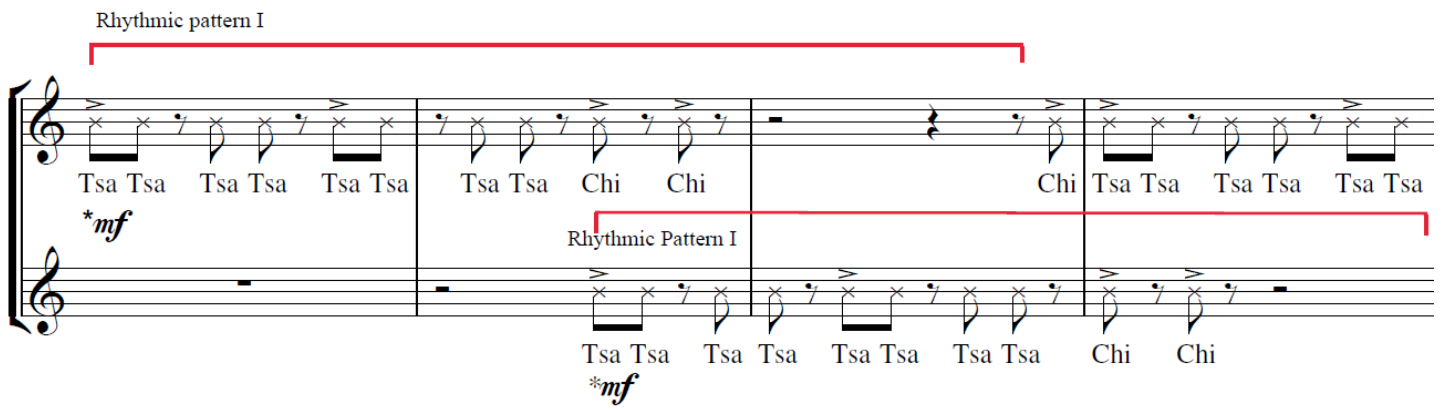

Figure 17. Rhythmic pattern I, YangKo

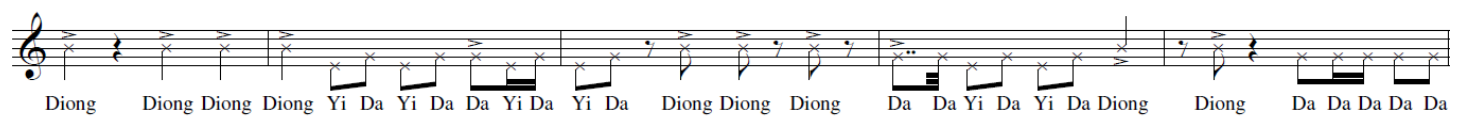

Figure 18. Rhythmic pattern II, YangKo

\subsubsection{Muqam}

Muqam is a form of music in Xinjiang, an autonomous region in northwestern China, which was dominated by Uyghur people, one of the ethnic minorities in China. The word "Muqam" is an Arabic word and one of its meanings is "homeland." 88 Although they now live in western China, Uyghur people originated from Western Eurasia, with a culture highly distinctive from that of the Han Chinese people. As a result, muqam was a merging of influences from Eastern and Central Asia, Middle East, and North Africa. ${ }^{89}$ There are four types of muqam, and Twelve Muqam is the most prestigious among them. Twelve Muqam is a large-scale suite consisting of vocal music, instrumental music, and dance

\footnotetext{
${ }^{87}$ Chen, phone interview by author.

88 Jizeng Mao, "Wei wu er zu ren ming de jiao au: mu ka mu [The Pride of the Uyghurs - Muqam]," Beishi GuoYue 193 (2003).

89 Journal article provided by Chen Yi.

Jizeng Mao and Turghun Jiang, “Twelve Muqam,” Music Weekly (2007).
} 
music. The total performance time of the whole suite lasts over twenty hours. ${ }^{90}$ Under the support of the Abdurashit Khan of the Yerqiang Kingdom (1526-1560), his concubine Amanni Shahan was credited as the "Mother of Twelve Muqam," because she collected, preserved, and organized muqam music in different traditions of the Tian Shan mountains region, and formed the prototype of the Twelve Muqam. Playing the muqam is not limited to professional musicians but widely common among Uyghur people, including kings, monks, and beggars. It was also respected as a spiritual or even physical need for Uyghurs (Figure 19). ${ }^{91}$ In 2005, The United Nations Educational, Scientific and Cultural Organization proclaimed the Uyghur muqam as a part of the Intangible Heritage of Humanity. $^{92}$

\footnotetext{
90 Ibid.

91 Rachel Harris and Yasin Muhpul, "Music of the Uyghurs," London Uyghur Ensemble, accessed March 2, 2017, http://www.uyghurensemble.co.uk/en-html/nf-research-article1.html.

92 "Uyghur Muqam of Xinjiang," The United Nations Educational, Scientific and Cultural Organization, accessed March 2, 2017, http://www.unesco.org/culture/ich/en/RL/uyghur-muqam-of-xinjiang-00109.
} 


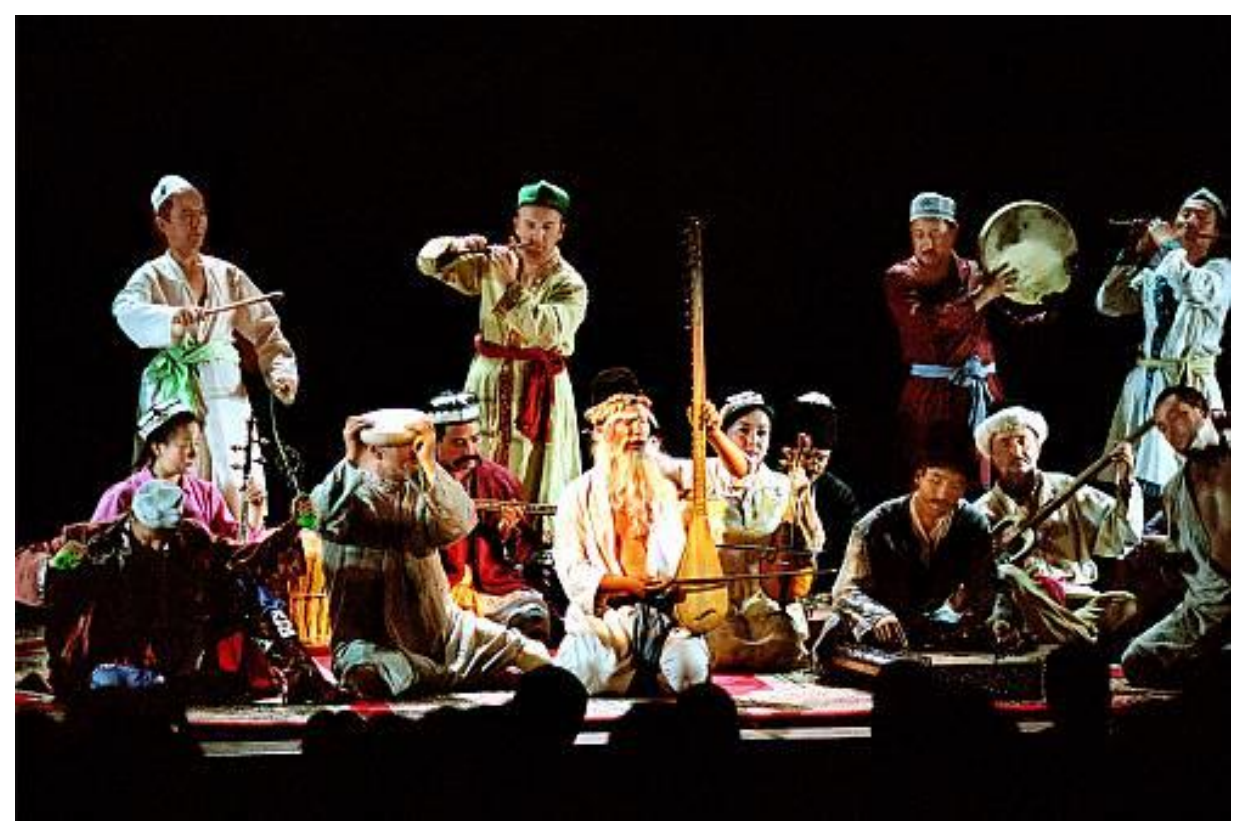

Figure 19. Traditional muqam performance

Muqam is typically performed by a small ensemble of singers, and accompanied by dutar (a plucked string instrument) (Figure 20), tämbur (a low-register plucked string instrument) (Figure 21), and dap (a frame drum) (Figure 22). ${ }^{93}$ Simultaneously tutti singing and playing with slight variations of the same melody is a common practice in muqam music. Compound meters like 5/8 and 7/8 are commonly used in muqam.

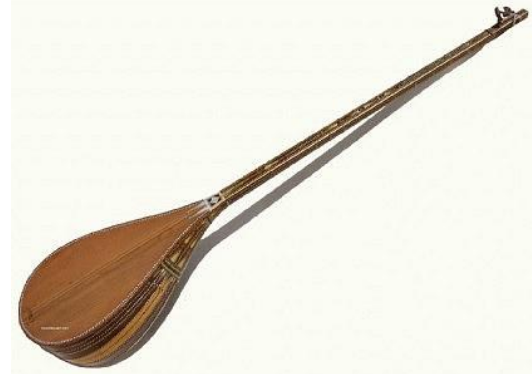

Figure 20. Dutar

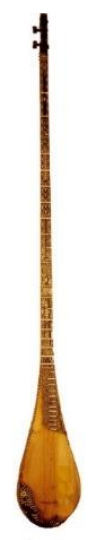

Figure 21. Tämbur

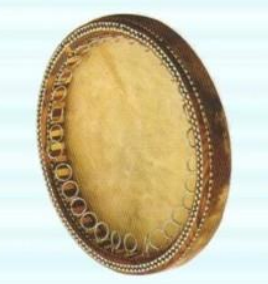

Figure 22. Dap

\footnotetext{
${ }^{93}$ Harris and Muhpul, "Music of the Uyghurs."
} 
Chen was inspired by Twelve Muqam in writing this movement. Her first theme is written in the style of muqam music in $7 / 8$ meter. Chen recalled that her writing was a result of a mixing of several muqam melodies which she studied for a long time. ${ }^{94}$ It was written in heterophonic texture in which solo violin and orchestra played simultaneously.

The second theme (Figure 23) was adapted from Awaguli (阿瓦日古麗) (Figure 24), ${ }^{95}$ a folk song from Ili, an autonomous prefecture in northern Xinjiang. ${ }^{96}$ It was arranged and published by composer Shi Fu (石夫) in $1957 .{ }^{97}$ Awagulia was written in triple meter. Chen modified the melody to a 7/8 meter while keeping the original melodic contour. Pitches remain the same with slightly alternated ornamentations, as seen in Figure 23 and 24.

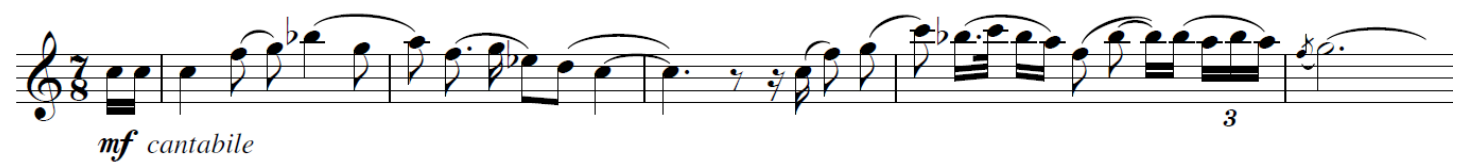

Figure 23. Second theme of Muqam, mm. 28-32

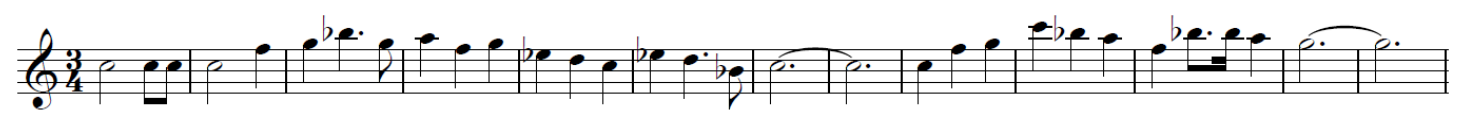

Figure 24. Beginning of Awagulia

94 Chen, phone interview by author.

95 Ibid.

96 Zhaoxiong Peng, "Awaguli," Collection of Sheet Music, accessed March 2, 2017, http://www.qupu123.com/Mobile-view-id-201789.html.

97 Ibid. 


\section{CHAPTER 5}

\section{Methodology}

This chapter examines the process and methodology in creating a transcription of Chinese Folk Dance Suite from an orchestral setting with solo violin to soprano saxophone and piano. The intention is to balance preserving the original setting with making an idiomatic revision for both the saxophone and piano. Therefore, musical elements, such as rhythm, pitch, dynamics, articulation, and tempi, have remained largely unchanged. There are two components to this transcription, the solo part for violin and the reduction of the orchestra. It is possible for saxophonists to perform the current version in orchestral setting by replacing the solo violin part with soprano saxophone.

A formal analysis had been done before beginning the transcription process. The choices of register, texture, reduced material, and modifications were decided largely as a result of the analysis.

Two significant modifications have been made to establish an idiomatic saxophone part: first, to change registers in several passages that extend outside the normal range of the saxophone. The altissimo register has been applied in the saxophone part; however, several ossia sections have been written for saxophonists who prefer not to play in the altissimo range on the soprano saxophone. Secondly, double-stops in the original violin part have been changed to grace-notes or omitted.

More modifications have been made to the piano part. These include changes to accommodate a reduction of voices, writing for percussion, unconventional playing techniques, and other non-pianistic passages. The percussion parts are an essential 
timbral component in Chinese Folk Dance Suite. An attempt to keep the percussion writing was made but eventually withdrawn, especially in Lion Dance, due to the unplayable outcome on the piano. Unconventional techniques in YangKo include luo gu jing singing in both the saxophone and piano parts, as well as hand slapping inside the piano frame. Non-pianistic passages, such as quick parallel motion or repeated notes, are modified for a more idiomatic piano part, especially in Lion Dance. These modifications were advanced by pianists Qian Xu and Dr. Peter Amstutz throughout the process.

Minor modifications and suggestions have been made by the composer throughout the process of the project. Further details will be examined in the next sections. The final version has been approved by the composer.

\subsection{Lion Dance}

Significant modifications have been made in this movement. Although attempts were made to realize the percussion parts as tone clusters, prepared piano techniques, and other non-traditional techniques, the vast majority of the percussion parts were omitted in the reduction to avoid a highly complex and contrapuntal piano part.

In the saxophone part, several double-stops were adapted as grace notes: for example, in mm. 4-7 (Figure 25). In other cases they are omitted, especially in running passages, such as in mm. 42-43 (Figure 26). 


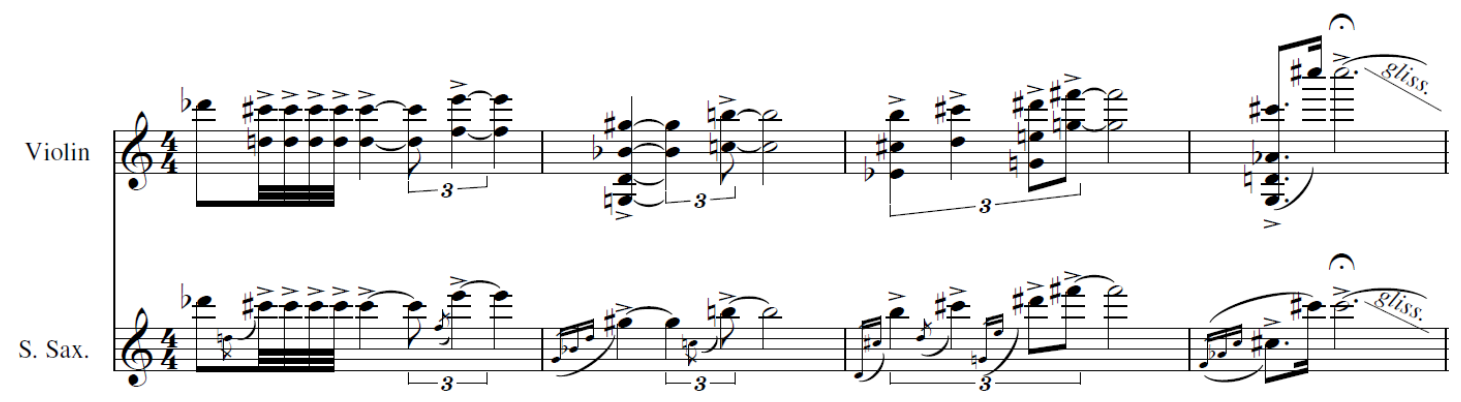

Figure 25. Lion Dance, mm.4-7

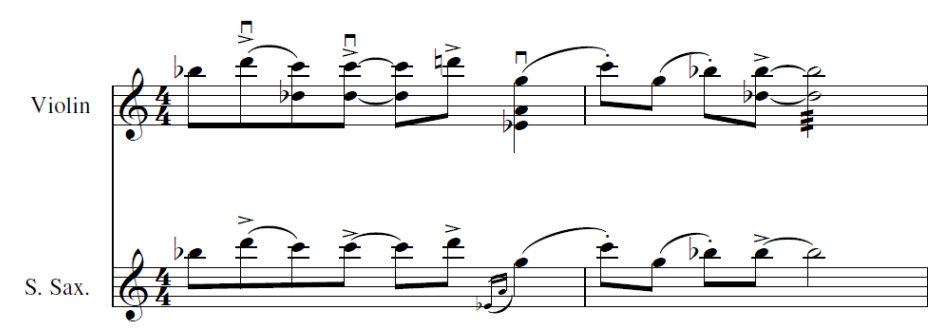

Figure 26. Lion Dance, mm.42-43

Thirty-two out of ninety-nine measures in Lion Dance have ossia saxophone parts.

They were applied to passages which involve the altissimo register, such as in $\mathrm{mm}$. 65-76 (Figure 27). 

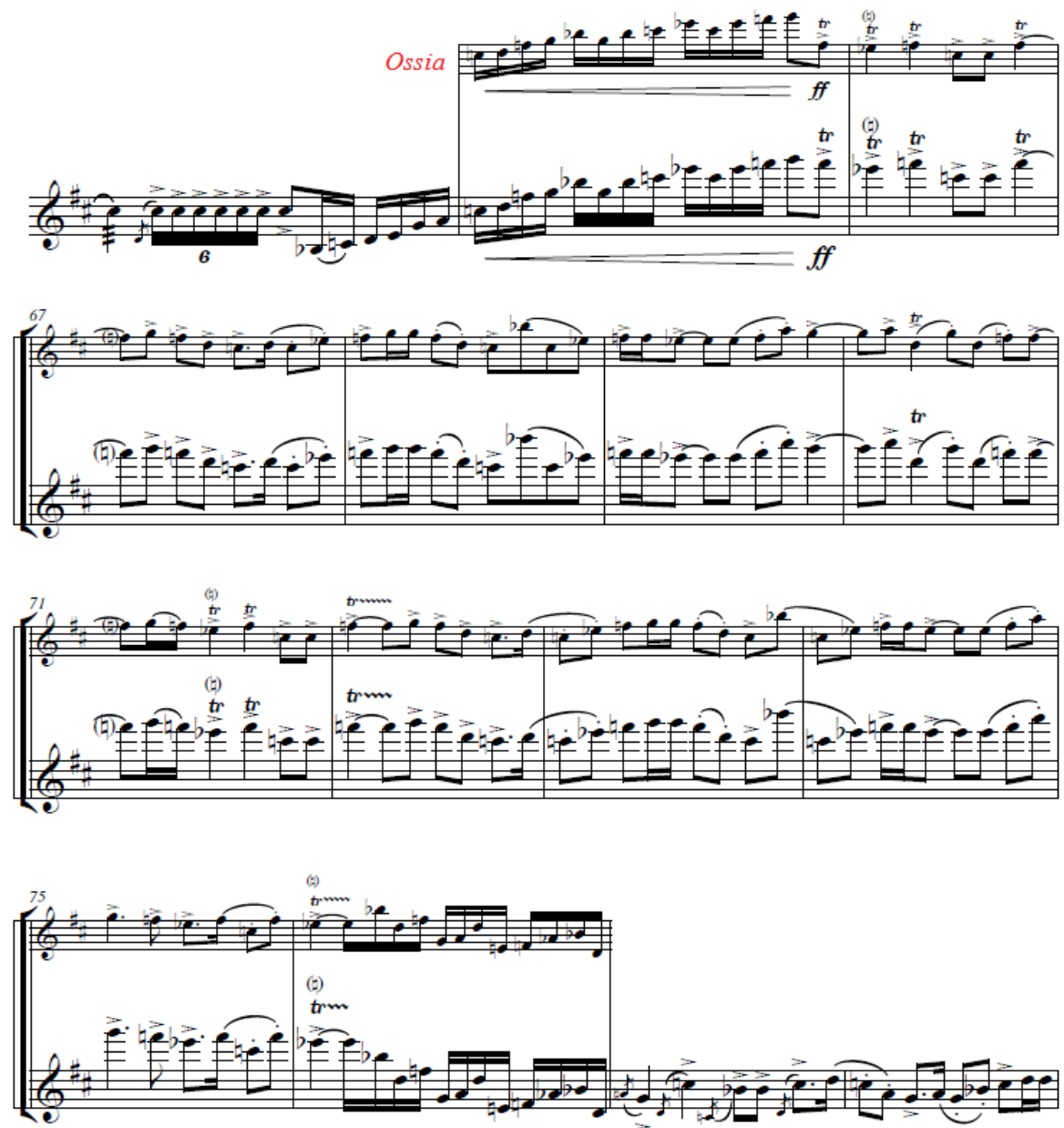

Figure 27. Soprano saxophone (in B-flat), Lion Dance, mm.64-78

Slight changes in articulation were applied to a fast passage in the saxophone part; for instance, a slur is applied to the first two notes in $\mathrm{m} .20$, and the tremolo became a flutter tongued note (Figure 28). 


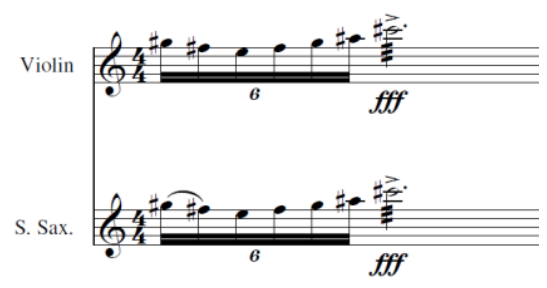

Figure 28. Lion Dance, m.20

Polyphonic orchestral writing that contained a large number of notes was reduced to simpler chords. In mm. $41-43$, the brass and string harmonies were reduced to simple intervals and triads in the left hand of the piano part (Figure 29). A horizontal reduction was applied in sections with a highly contrapuntal texture where some of the orchestral parts were removed. An example can be found in mm. 49-52, where sections of upper brass and upper woodwinds were cut in order to maintain a playable piano part (Figure $30)$. 


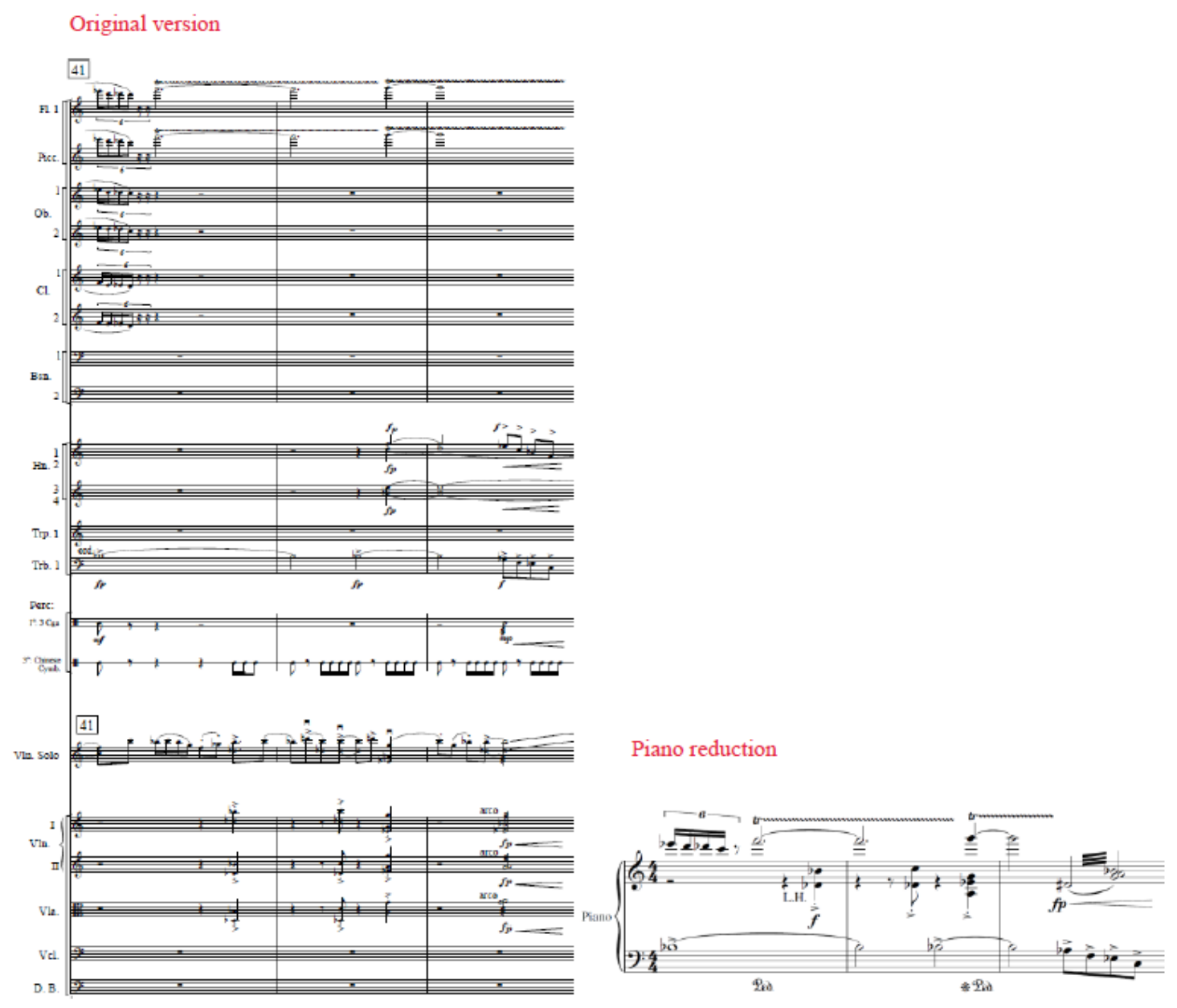

Figure 29. Lion Dance, mm.41-43 


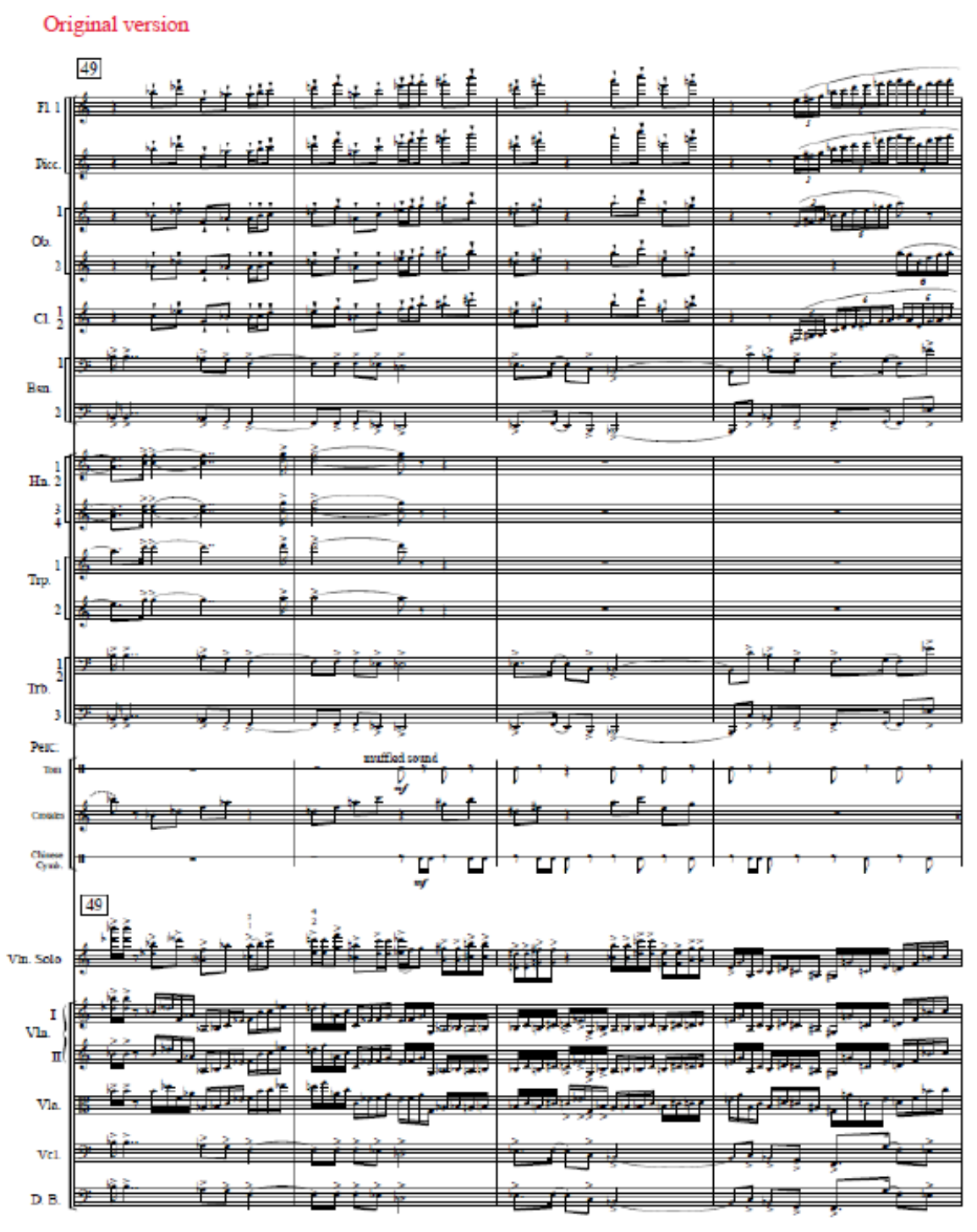

Piano reduction

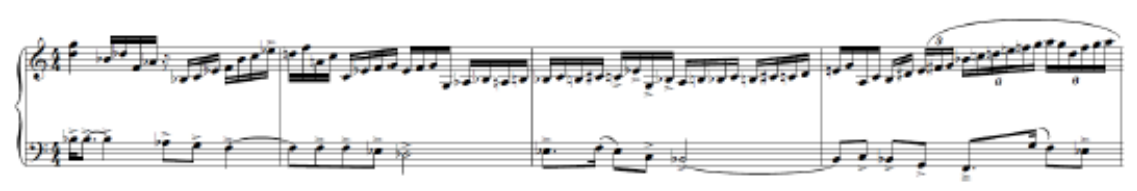

Figure 30. Lion Dance, mm.49-52

Tone clusters were treated in several ways. In mm. 3-4, a tremolo with ten pitch classes replaces the twelve-note chord clusters in the winds (錯誤! 找不到參照來源。).

At the suggestion of the composer, two specific chord clusters were modified: In mm. 86-93, in the reduction, a trichord (A-B-C) replaced the original cluster (A-[B-flat]-B-C) 
presented by the horns (Figure 32); in mm. 97-99, a tetrachord ([B-flat]-C-D-E) replaced the original cluster comprising all seven chromatic tones between B-flat and E (Figure $33)$.

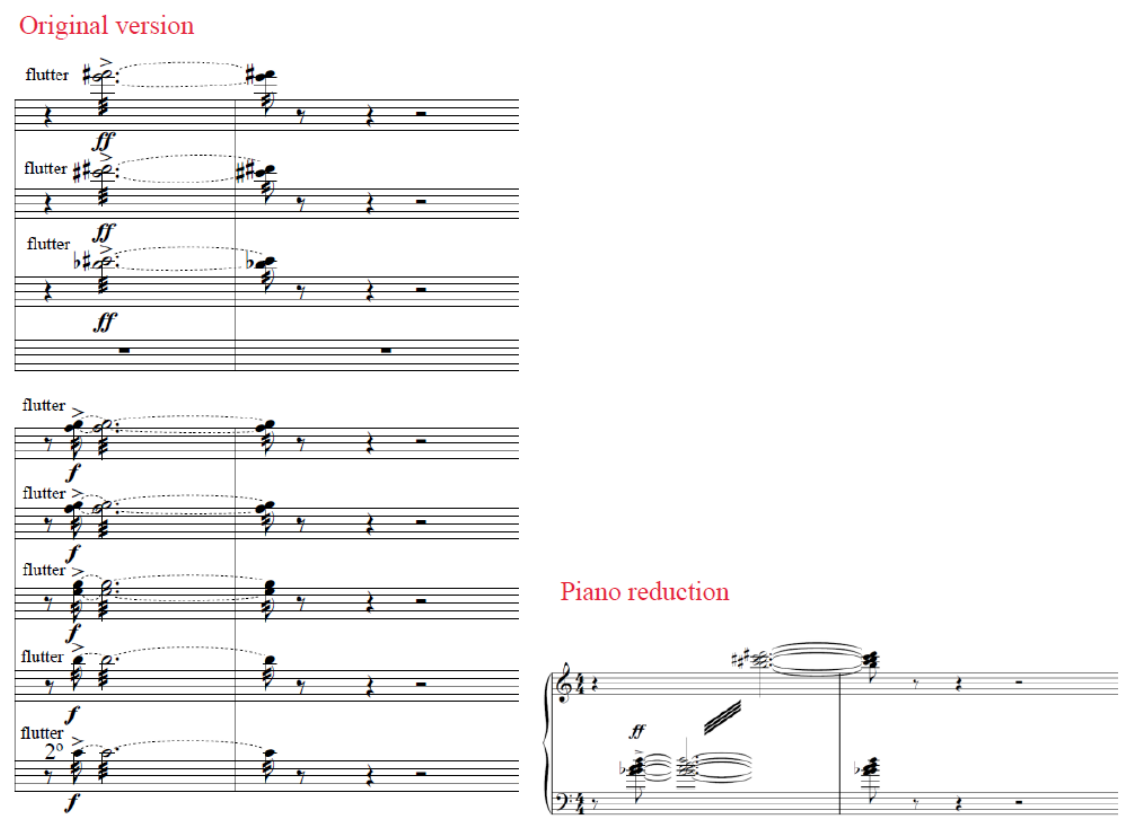

Figure 31. Lion Dance, mm.3-4

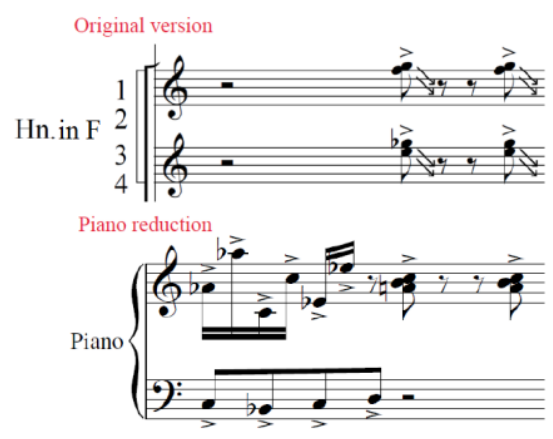

Figure 32. Lion Dance, m.89 


\section{Original version}

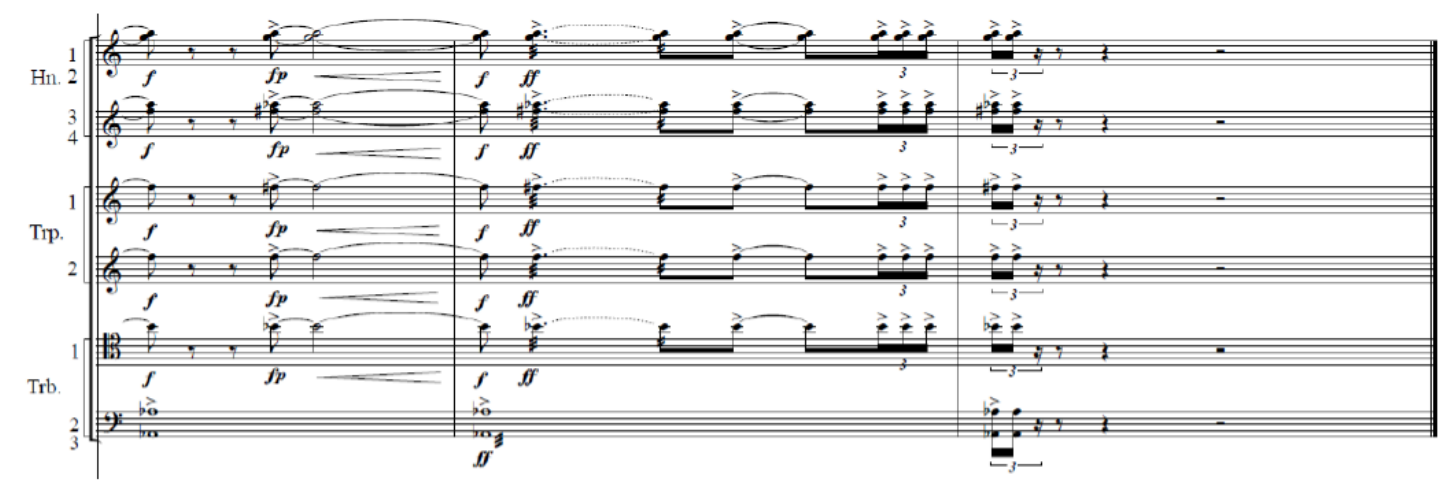

Piano reduction

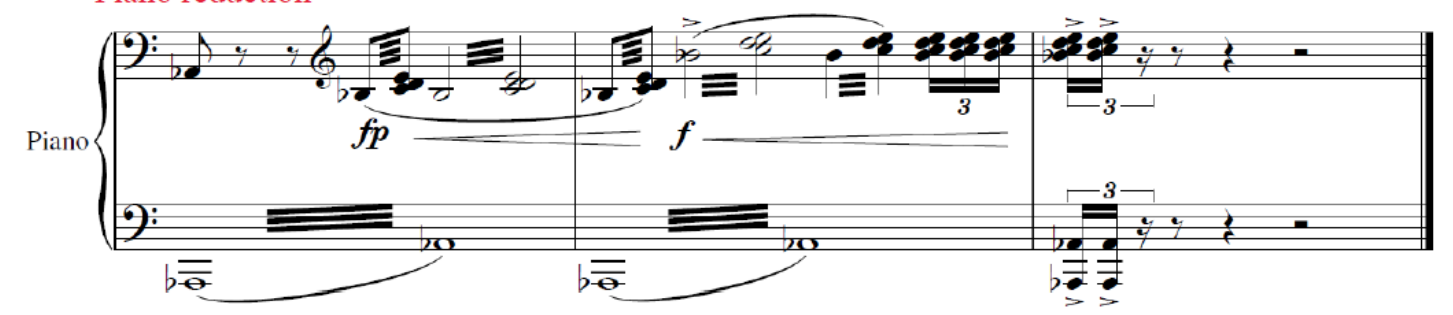

Figure 33. Lion Dance, mm.97-99

There are several passages of fast repeated notes, some which were harmonized in parallel intervals in Lion Dance. This material is essential to the movement, but is not particularly idiomatic for piano, and was adjusted to become alternating intervals. For example, in $\mathrm{mm} .62-63$, the trumpets present a line in parallel fourths with repeated sixteenth-notes. This material was adjusted with a single-line melody given to the right hand in piano part, with alternating pitches a fourth apart (Figure 34). 


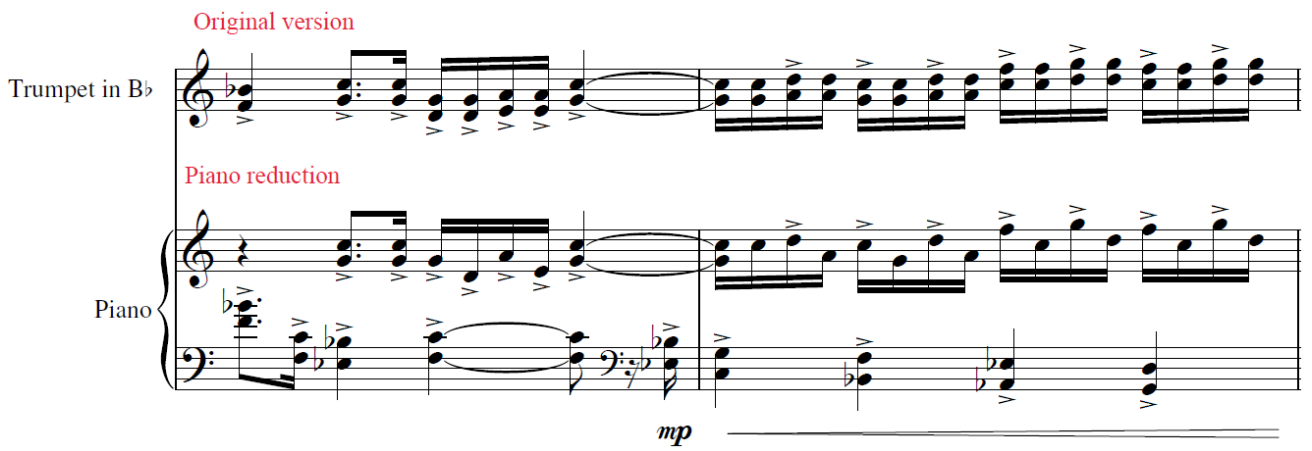

Figure 34. Lion Dance, mm.62-63

Chen claimed the final two-beat violin solo phrase is an imitation of playing of paigu (排鼓) (Figure 35), a set of Chinese drums, especially a musical situation where paigu players would demonstrate their virtuosity by playing rapid rhythmic patterns from high to low register. ${ }^{98}$ This melodic gesture is "more important than the actual pitches," and the original pitches were based on the ease of playability on the violin, instead of the harmonic structure in Lion Dance. At the suggestion of the composer, this phrase was transposed up a major second to best accommodate the fingerings on the saxophone. The articulations were also modified from alternating left-hand and right-hand pizzicatos to alternation of a two-slurred legato and two staccato pitches (Figure 36).

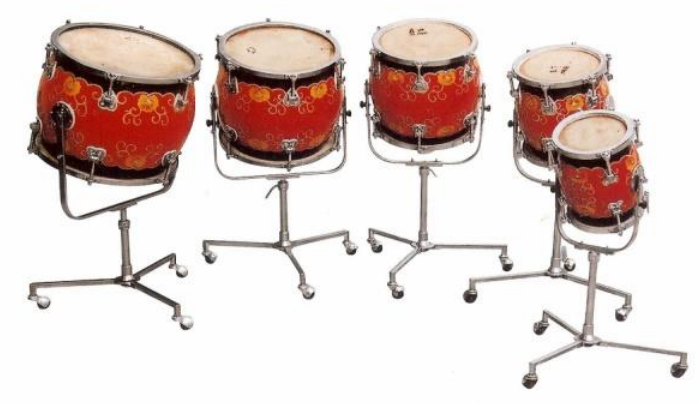

Figure 35. Paigu

\footnotetext{
${ }^{98}$ Chen, phone interview by author.

${ }^{99}$ Ibid.
} 


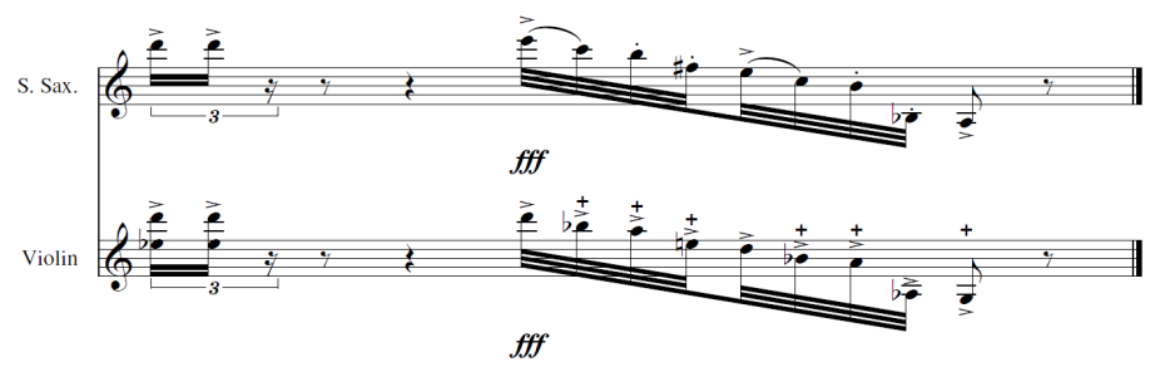

Figure 36. Lion Dance, m.99

\subsection{YangKo}

As mentioned in chapter four, Chen has transcribed this movement for solo violin and two percussionists. This existing edition had a significant influence on the current project in two ways. First, the choice of instrumentation inspired an attempt to achieve and maintain the percussive effect, and second, the writing for percussion inspired the use of luo gu jing singing in the solo part.

As in the Lion Dance, several attempts were made to maintain the rich layers of the orchestral part. A prior version of the piano part was produced, which involved both conventional and unconventional playing and luo gu jing singing. The composer encouraged this approach and expressed that this movement required no conventional piano playing. ${ }^{100}$ Under the recommendation of Chen, a simplified final edition was produced. ${ }^{101}$

The preparation of YangKo in its version for soprano saxophone and piano began with assigning luo gu jing singing in both parts. Significant modifications of register were applied to the original violin part to create a saxophone part that maintains a lyrical line without a large degree of altissimo range in the movement. Double-stops were simplified with alternated register to form a single-line melody; an example can be found in $\mathrm{mm}$.

100 Ibid.

101 Ibid. 
59-69 (Figure 37). An ossia section was made between mm. 87-122, while altissimo range was applied to imitate the original top register on the violin part with overtones (Figure 38)
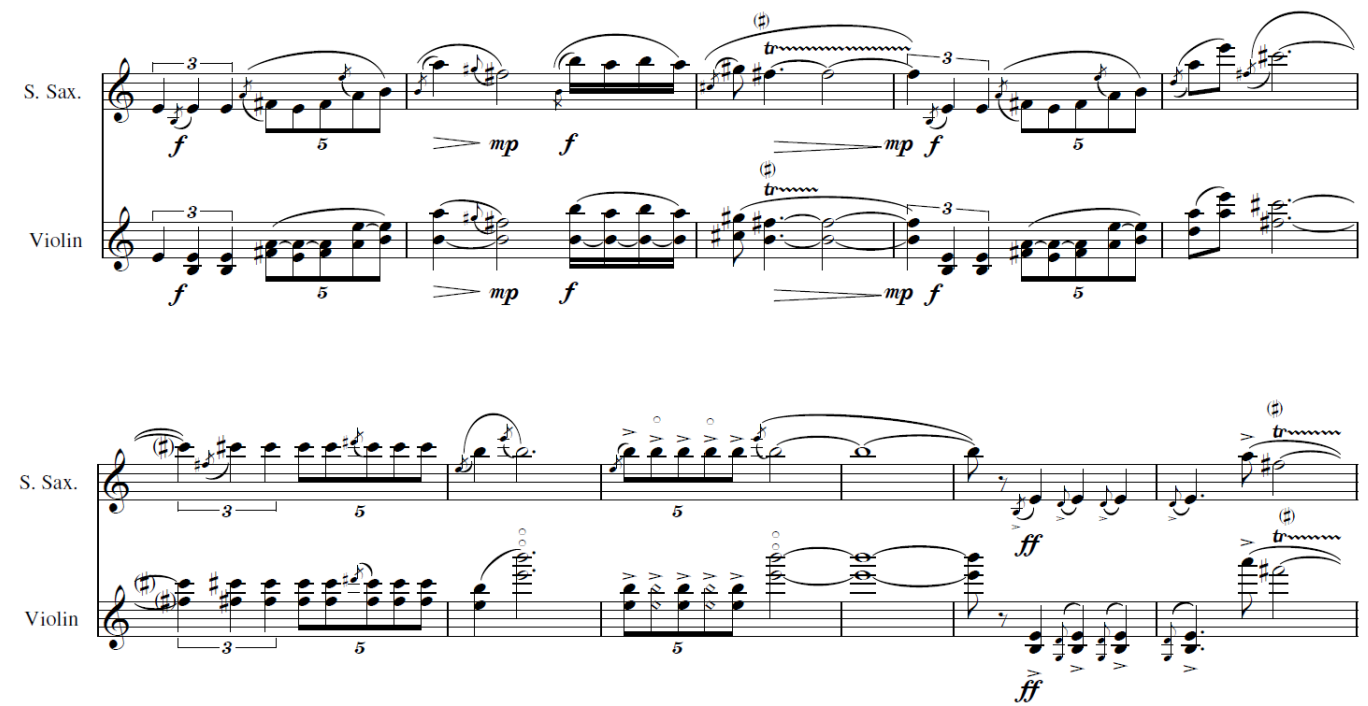

Figure 37. YangKo, mm.59-69
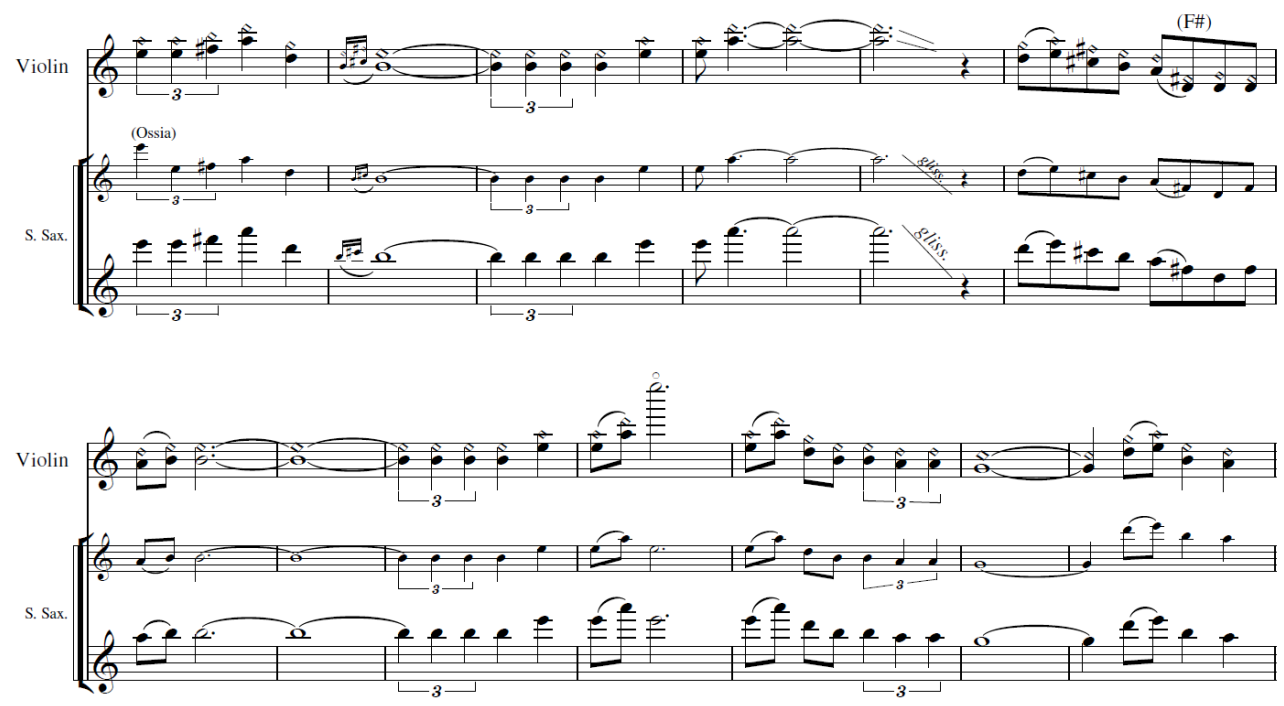

Figure 38. YangKo, mm.87-99

A minor pitch adjustment was made on the third grace-note before the first beat in m.73, from G to A, because it lies below the range of the saxophone (Figure 39). 


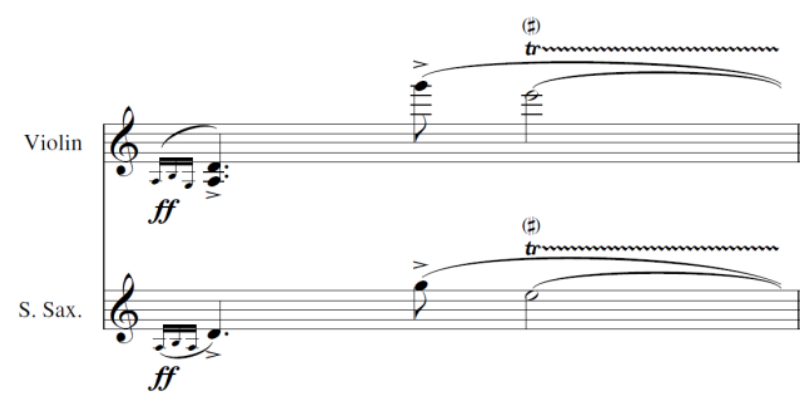

Figure 39. YangKo, m.73

The piano part was written in an unconventional manner. Luo gu jing singing was applied throughout the movement. Conventional playing was only applied in mm. 91-110, using the high register of the piano to imitate the distant original background played by upper strings in harmonics (Figure 40). To achieve a percussive effect with different timbres, three approaches of unconventional playing were applied. First, foot tapping and body slapping were applied in mm. 9-58 to replace the orchestral luo gu jing singing, while maintaining the percussion effect (Figure 41). Second, in mm. 59-87, stress-bars inside the piano frame are to be slapped to create a metallic percussion effect, replacing the sounds of Chinese cymbal and paddle castanet from the original setting (Figure 42). Lastly, tapping with fingers and fingernails were applied from m.111 until the end to imitate the bass drum and temple block from the original version (Figure 43).

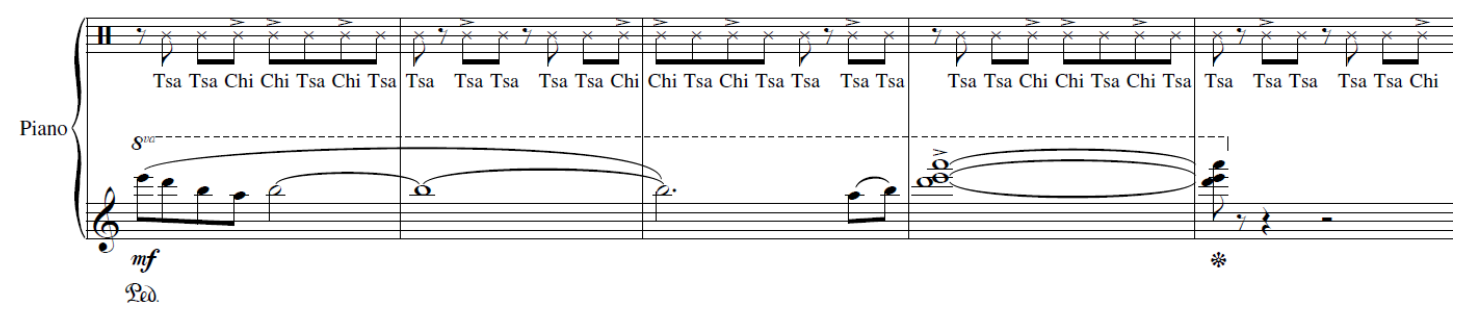

Figure 40. YangKo, mm.91-95 


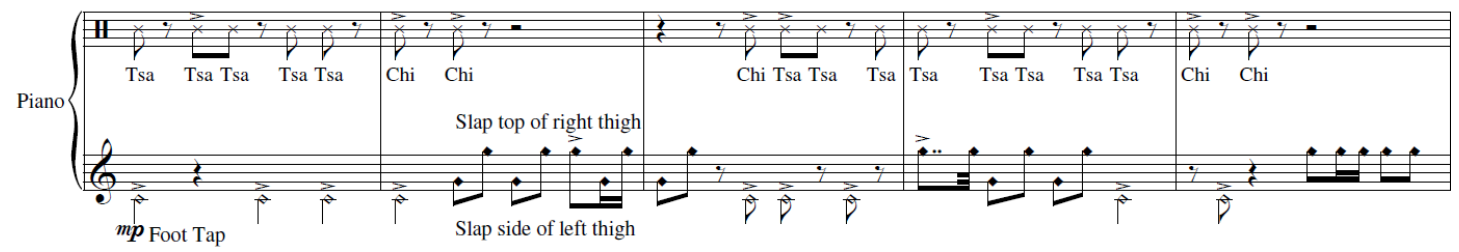

Figure 41. YangKo, mm.9-13

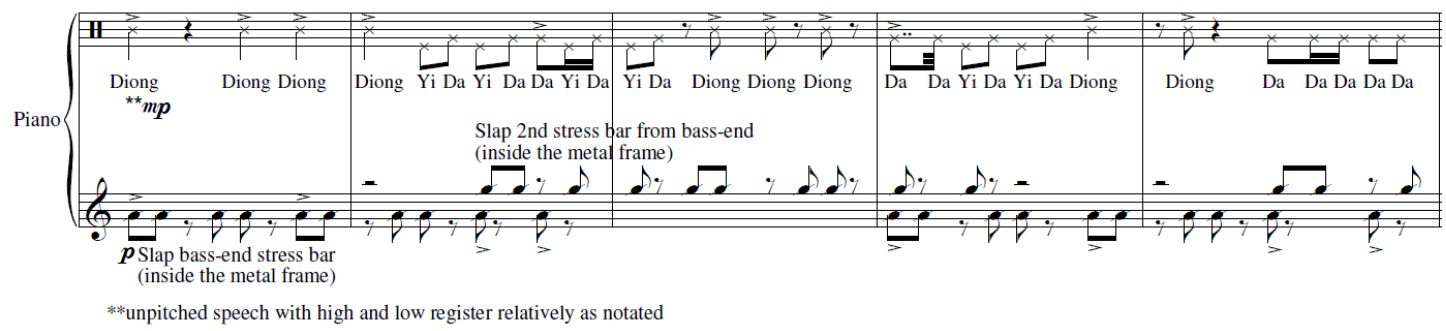

Figure 42. YangKo, mm.59-63

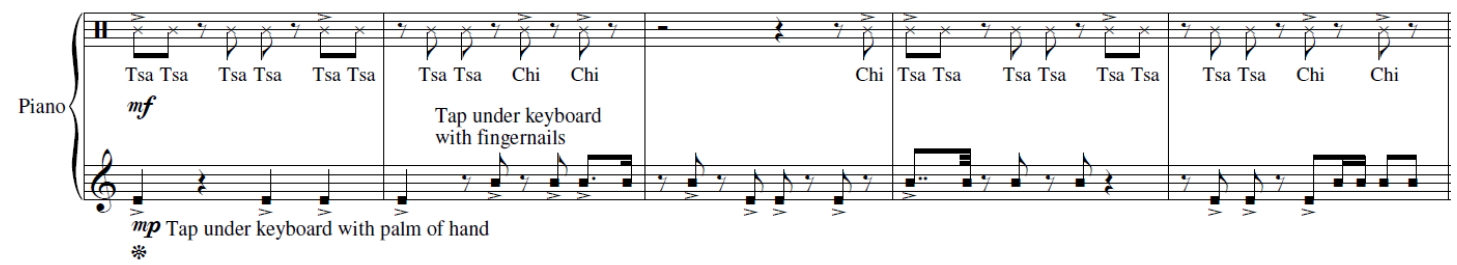

Figure 43. YangKo, mm.111-115

A chart comparing the instrumentation of the original version and texture of the transcription versions is supplied below (Figure 44). 


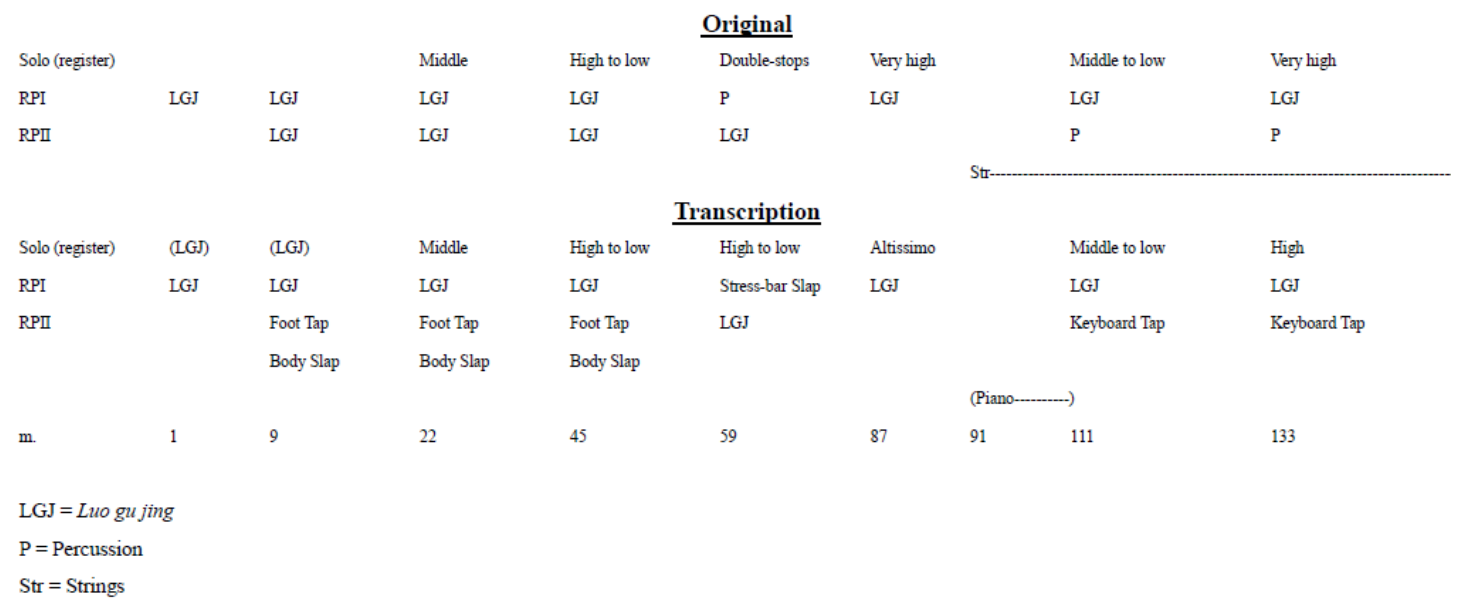

Figure 44. Texture Comparison, YangKo

\subsection{Muqam}

This movement was a straight-forward reduction from the orchestral setting, without significant modifications and requiring no unconventional playing. To maintain a common practice in muqam music, a heterophonic texture in tutti manner was kept in the first theme in all occurrences throughout the movement between the saxophone part and piano part, except for $\mathrm{mm}$. 77-91, where the material was not shared in the violin part (Figure 45). 

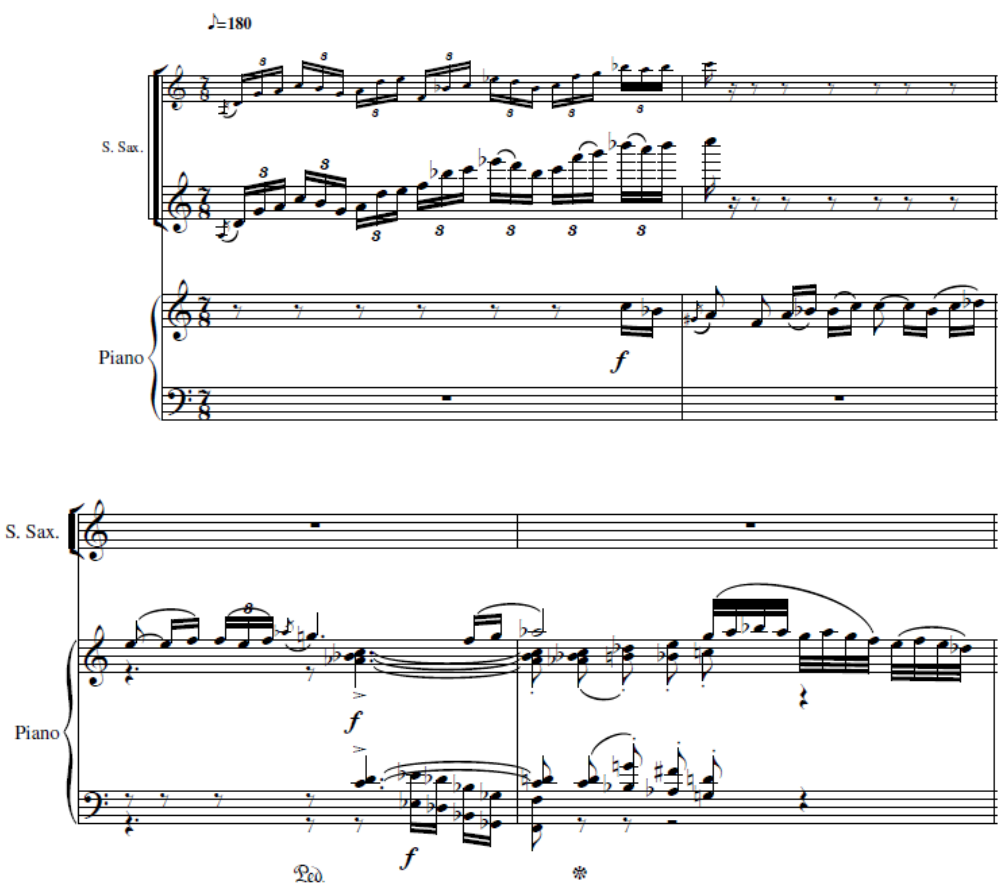

Figure 45. Muqam, mm.76-79

The most evident modification was applied in the saxophone cadenza in mm. 75-76. The original setting was highly contrapuntal with extensive use of double-stops (Figure 46). As was the case in Lion Dance, double-stops were changed to grace-notes or omitted. The omitted notes were not applied to notes below the top pitches, but were chosen after an analysis to form an idiomatic and virtuoso single-line melody for saxophone. A slight modification of articulation from fully articulated to varying degrees of legato was made (Figure 47). By the end of the cadenza, modification of articulations was only applied to the altissimo version (Figure 47). 


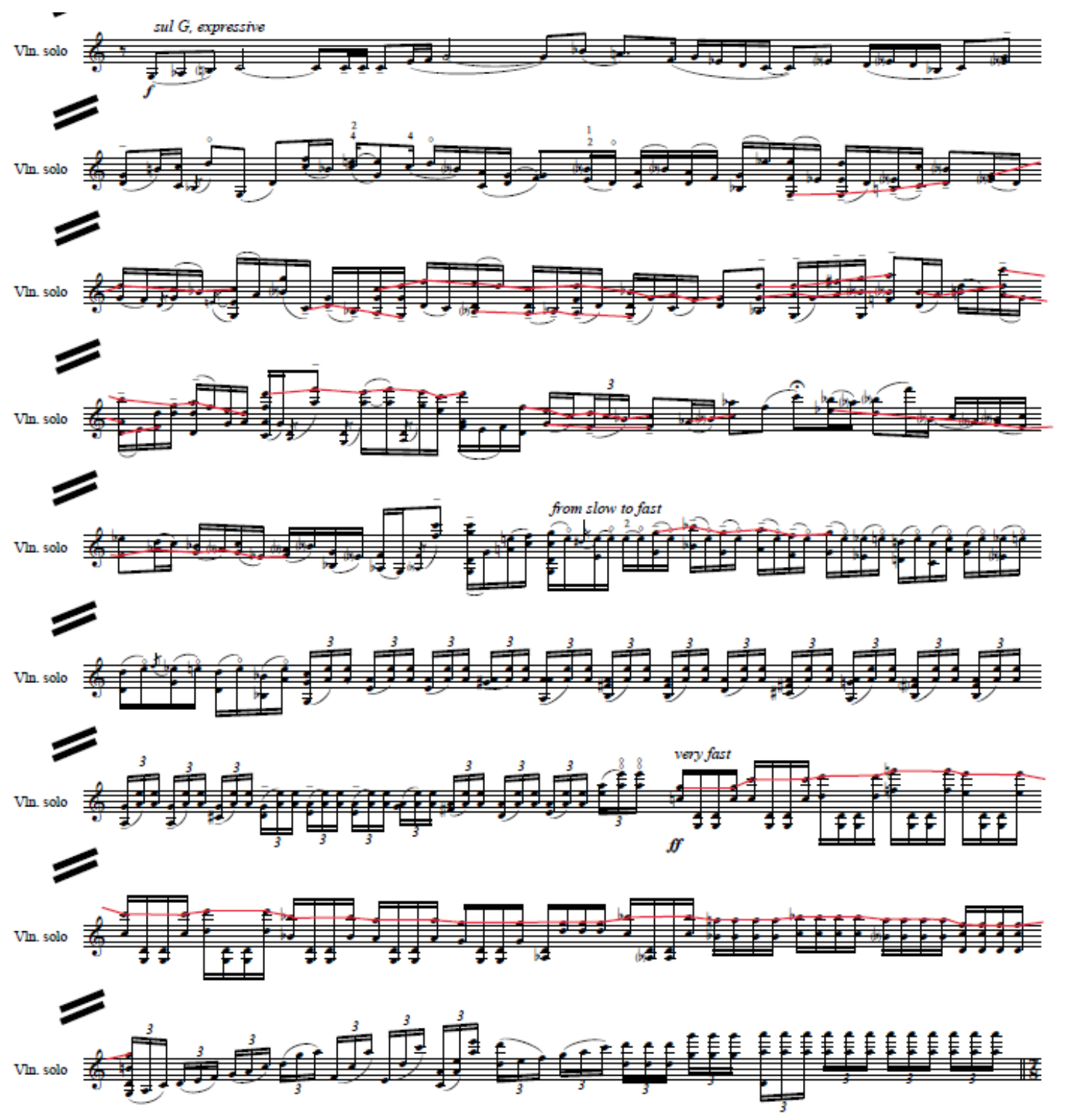

Figure 46. Violin cadenza, Muqam m.75 

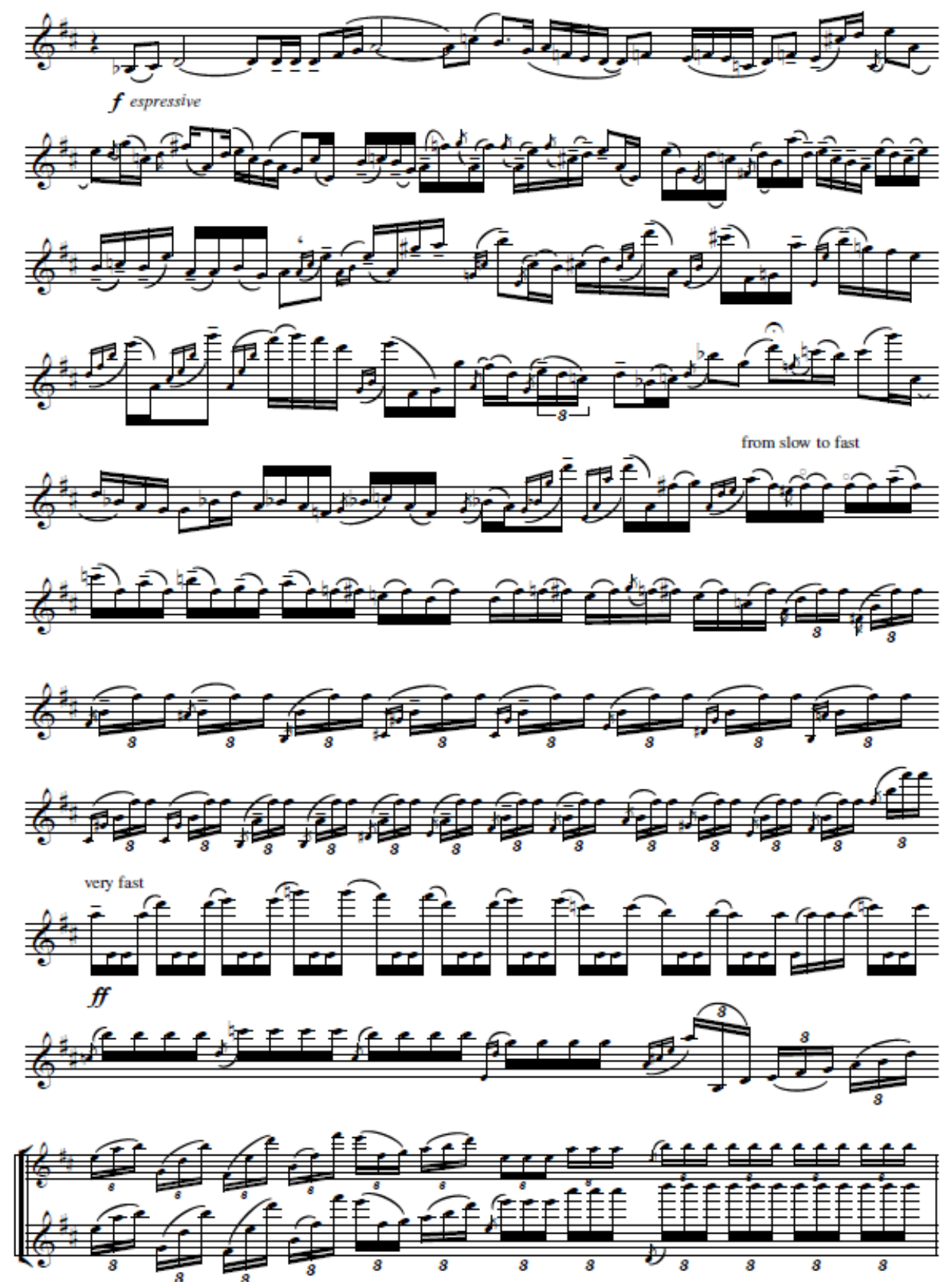

Figure 47. Saxophone cadenza (in B-flat), Muqam m.75

The only modification to the piano part was several trills to provide extra support for the balance between the saxophone part and piano part. An example can be found in $\mathrm{m} .20$ (Figure 48) 


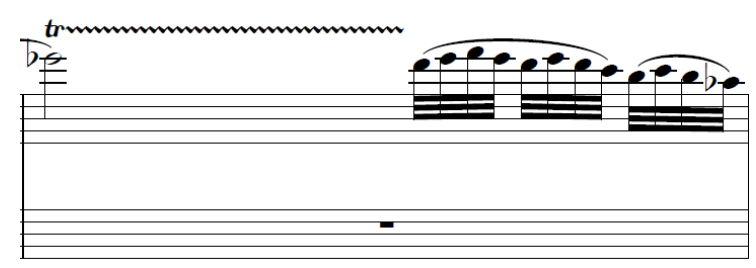

Figure 48. Muqam, m.20 


\section{CHAPTER 6}

Chinese Folk Dance Suite for Soprano Saxophone and Piano

\section{中國民族舞組曲 \\ Chinese Folk Dance Suite}
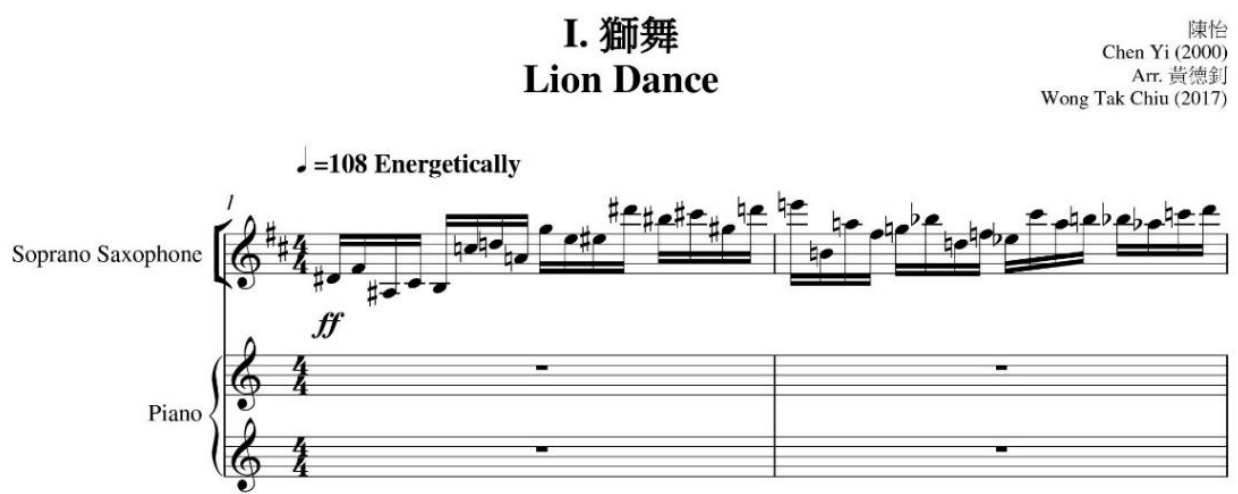

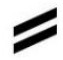
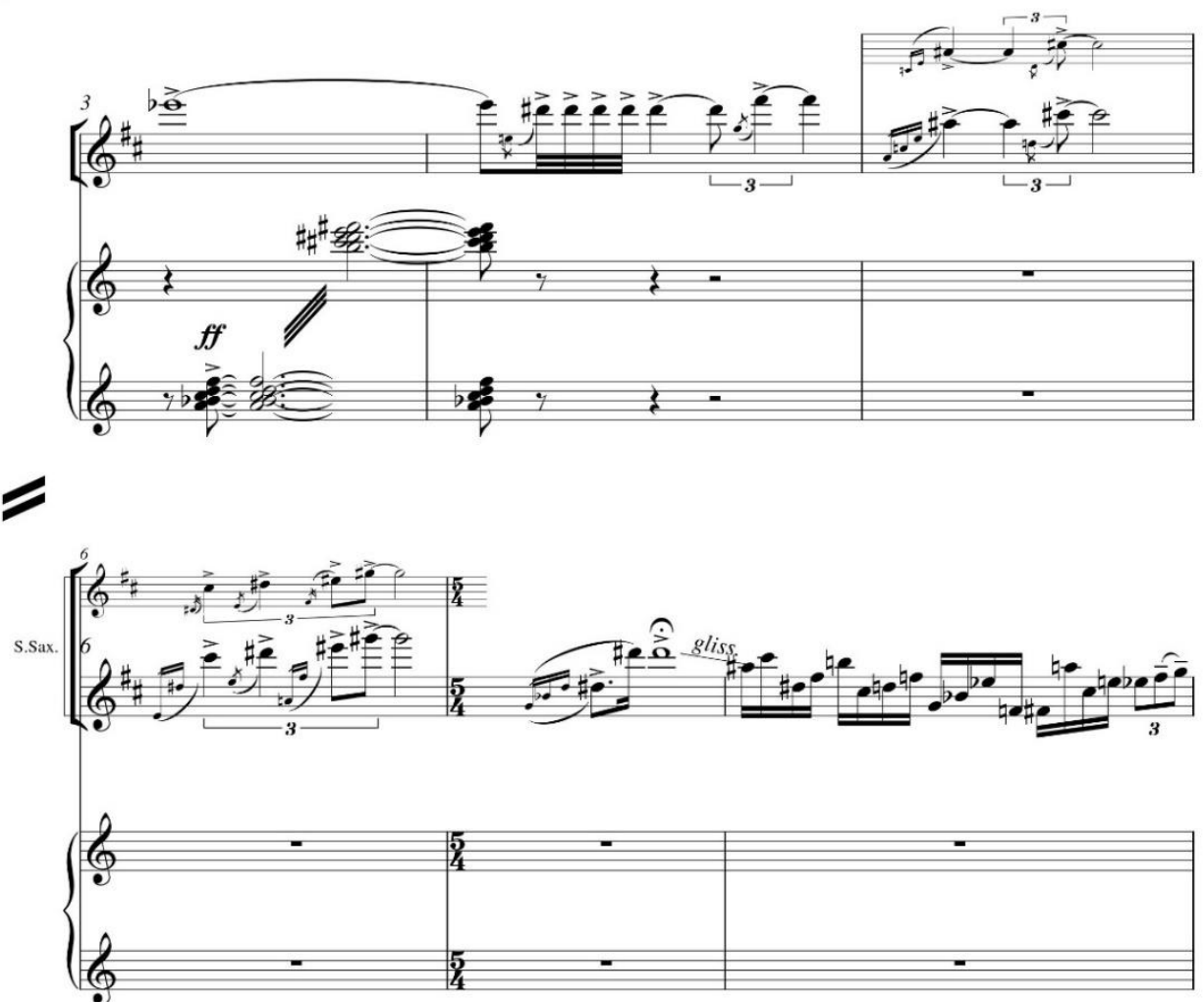

(c) 2000 by Chen $\mathrm{Yi}$ 
2
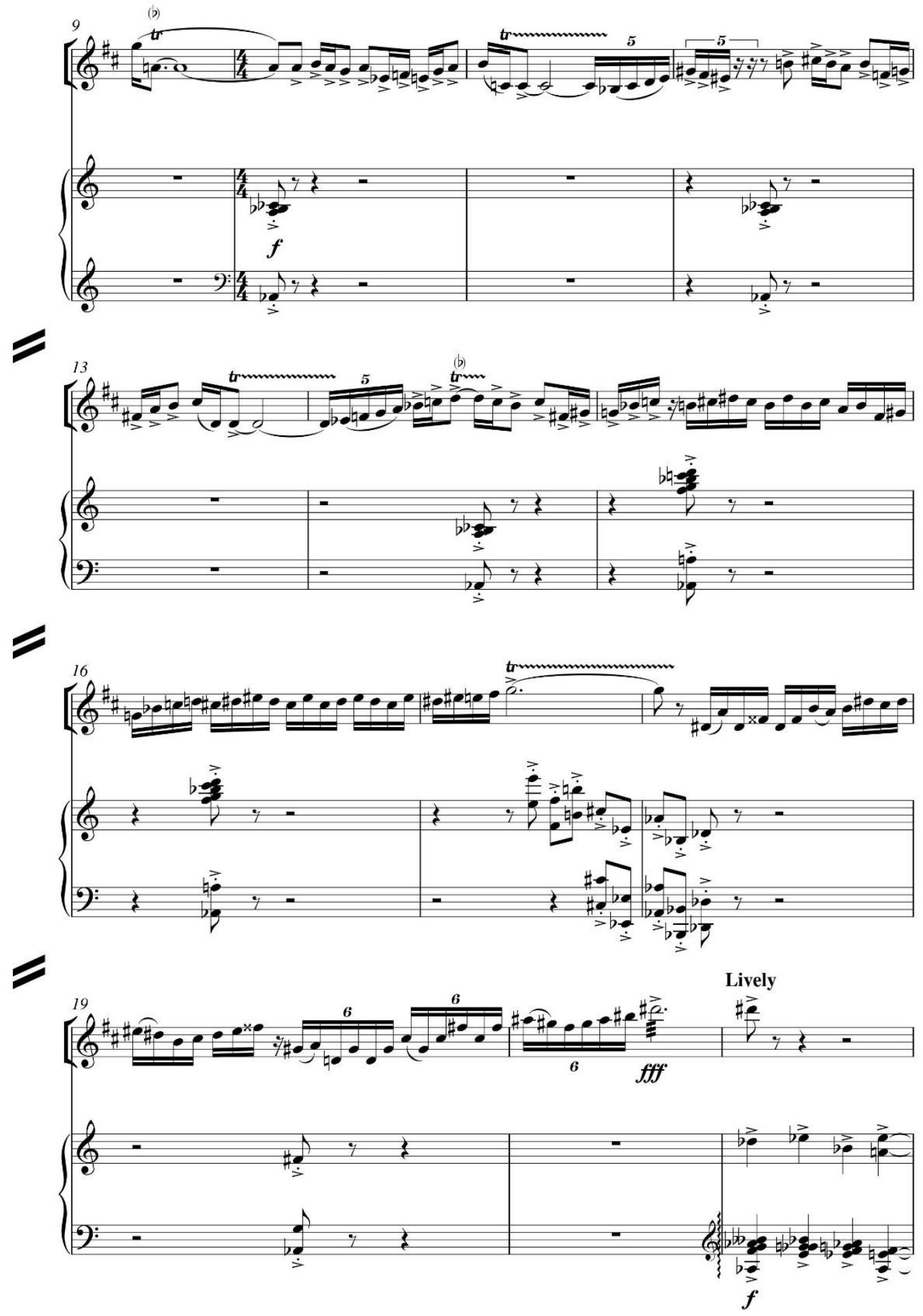


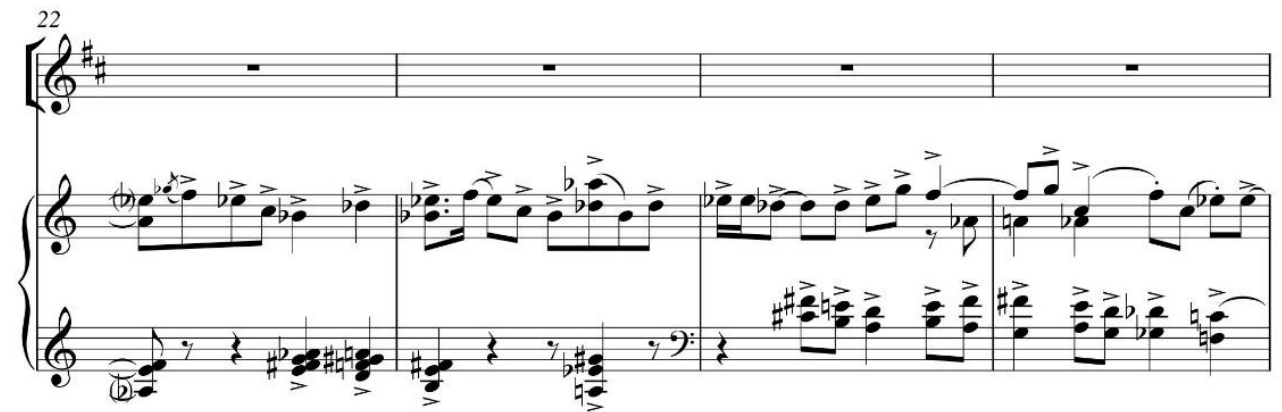

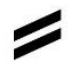
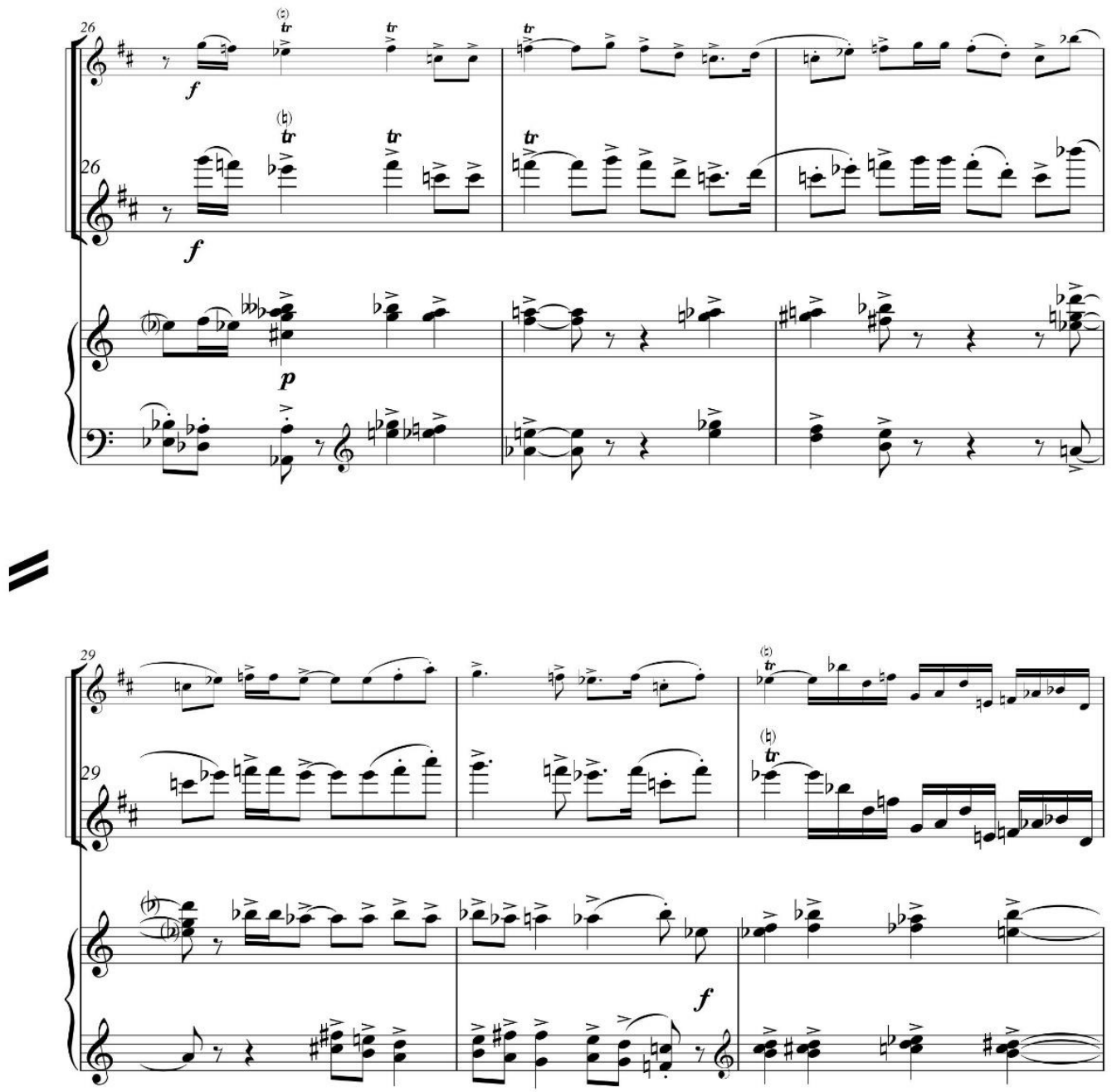

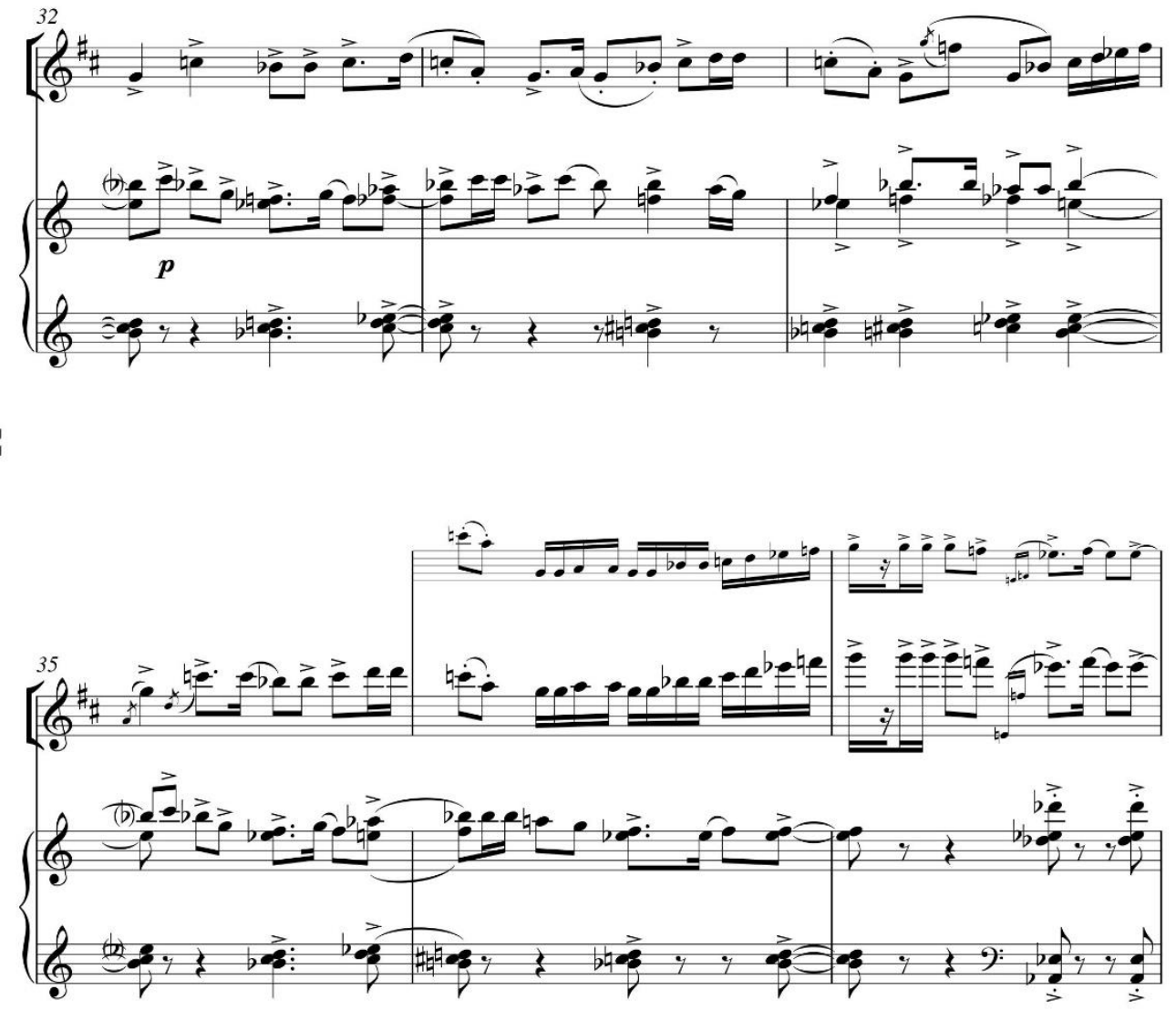

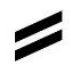

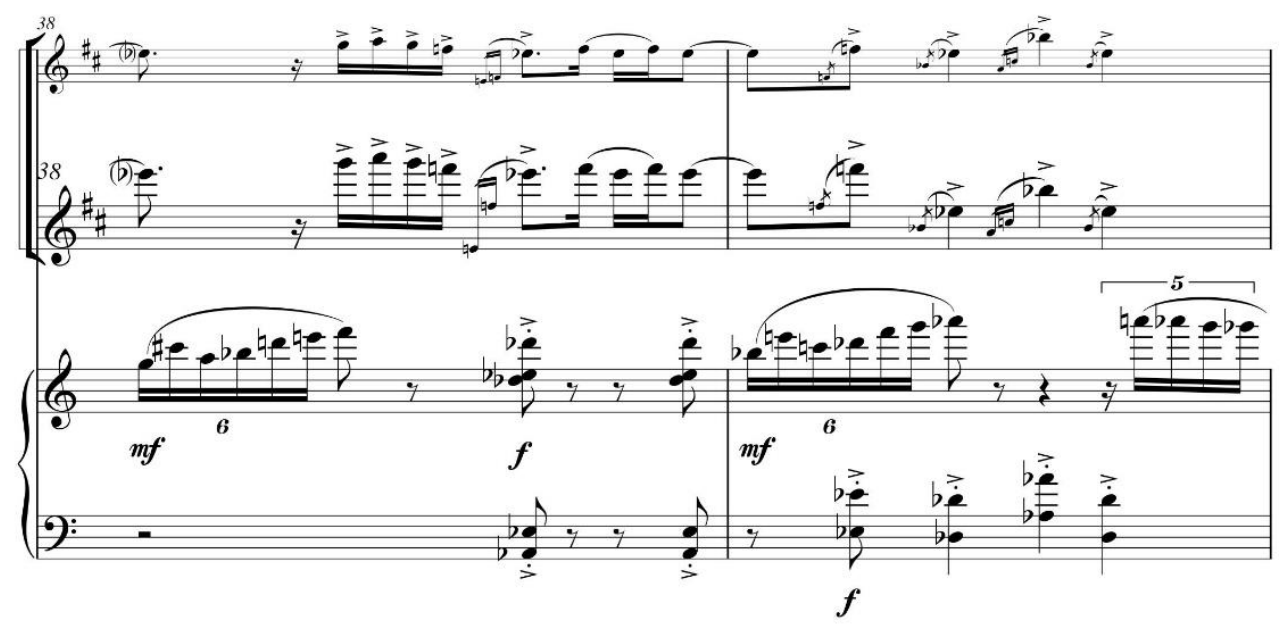



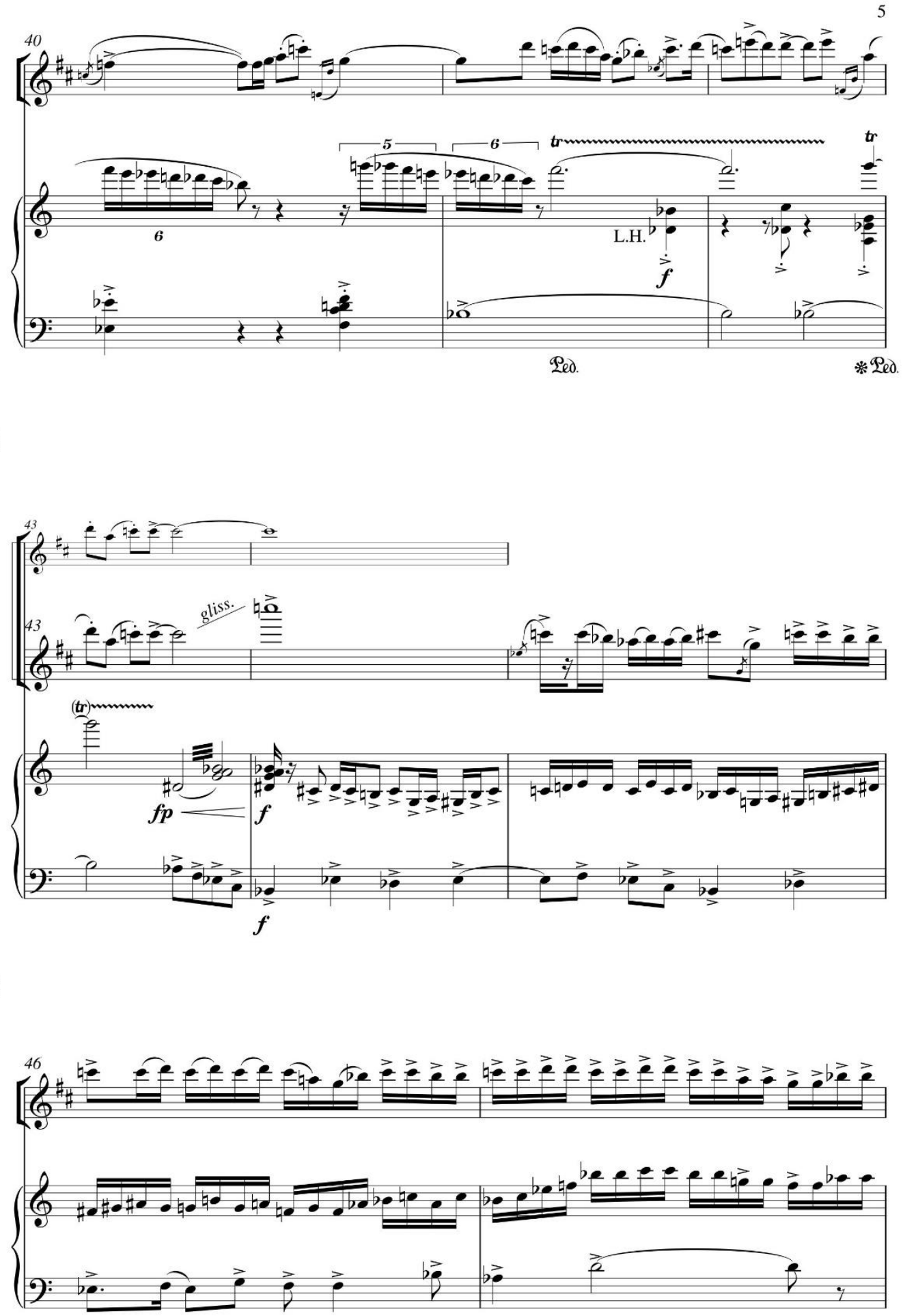
6
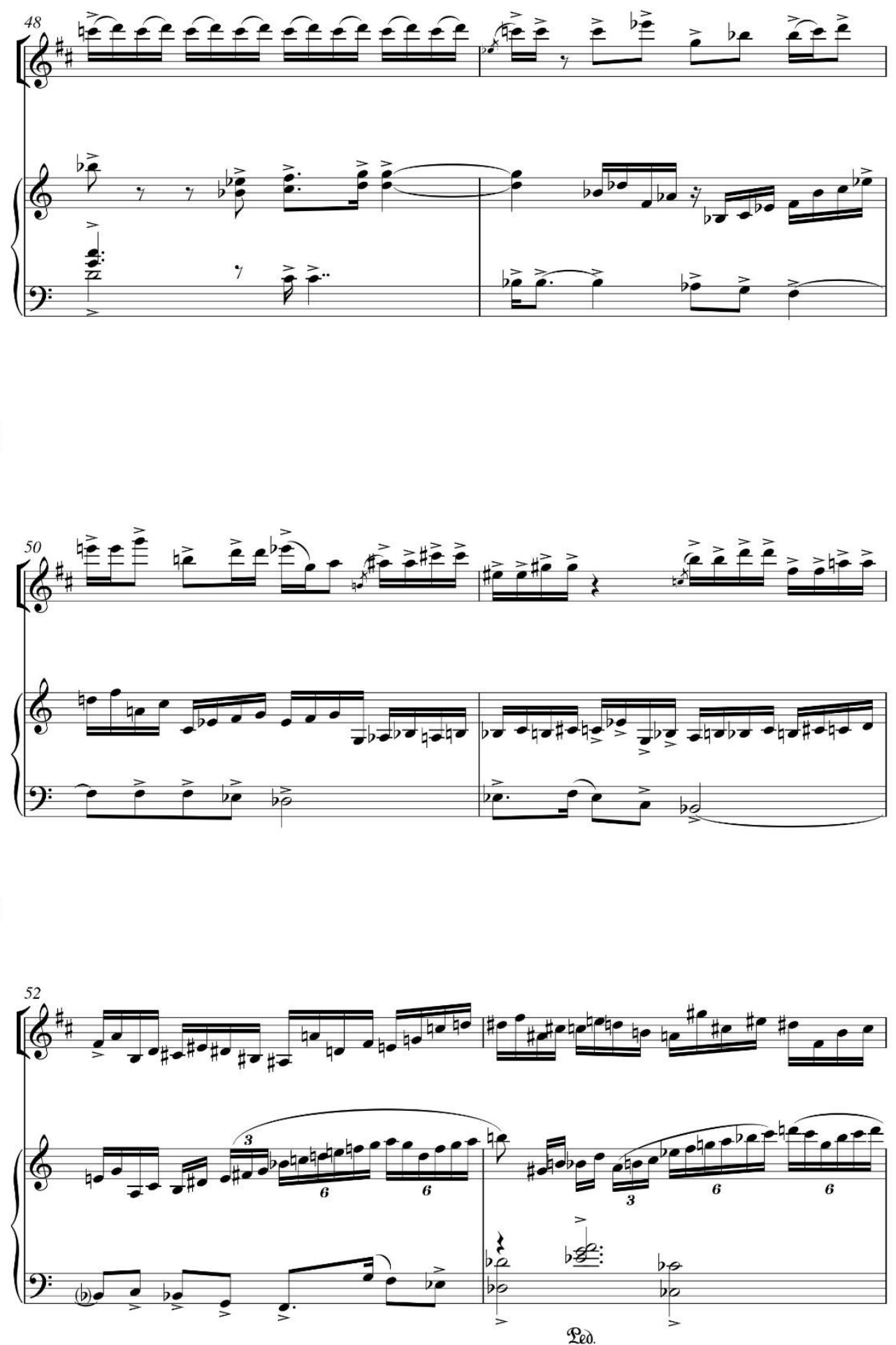

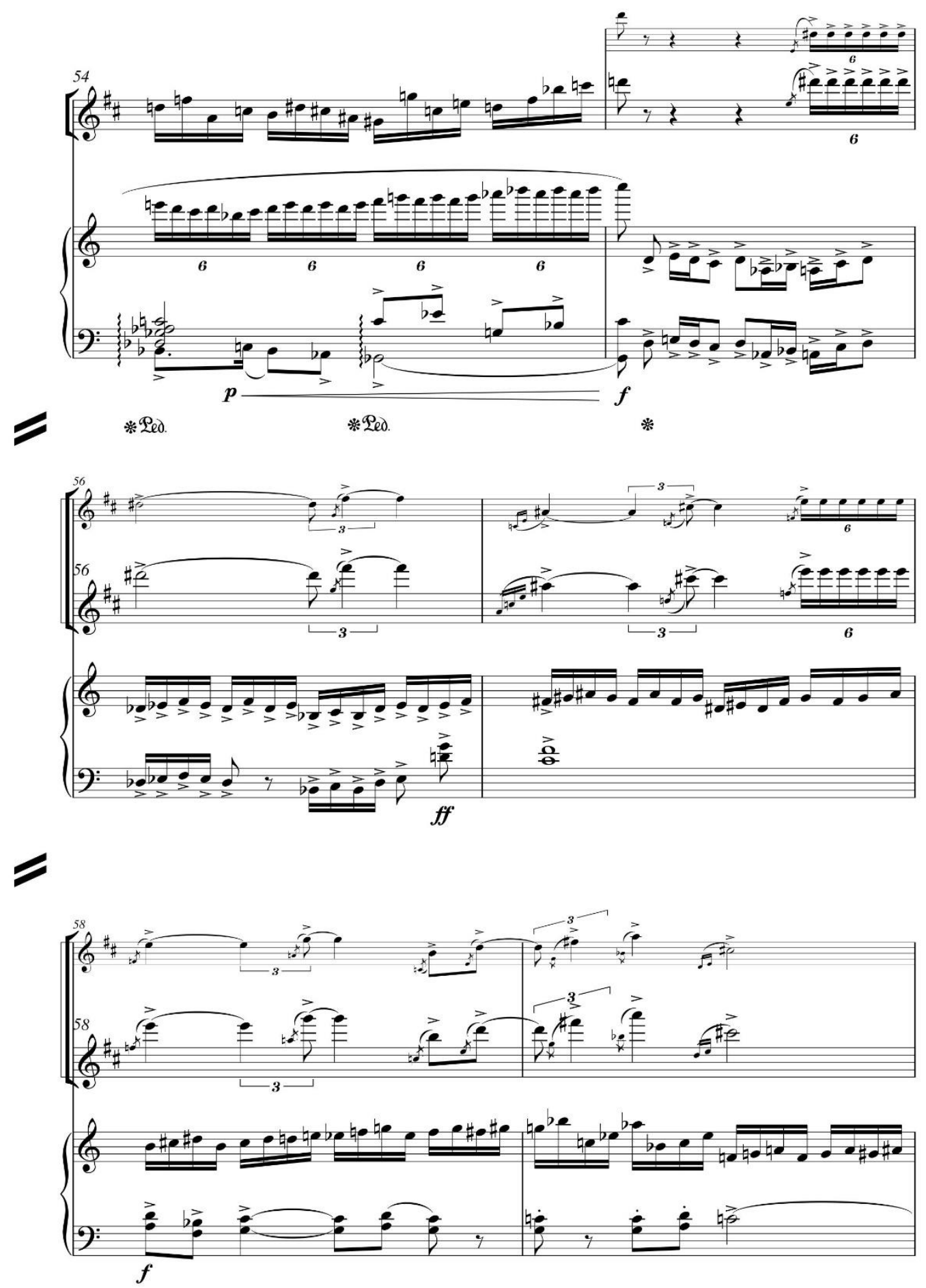

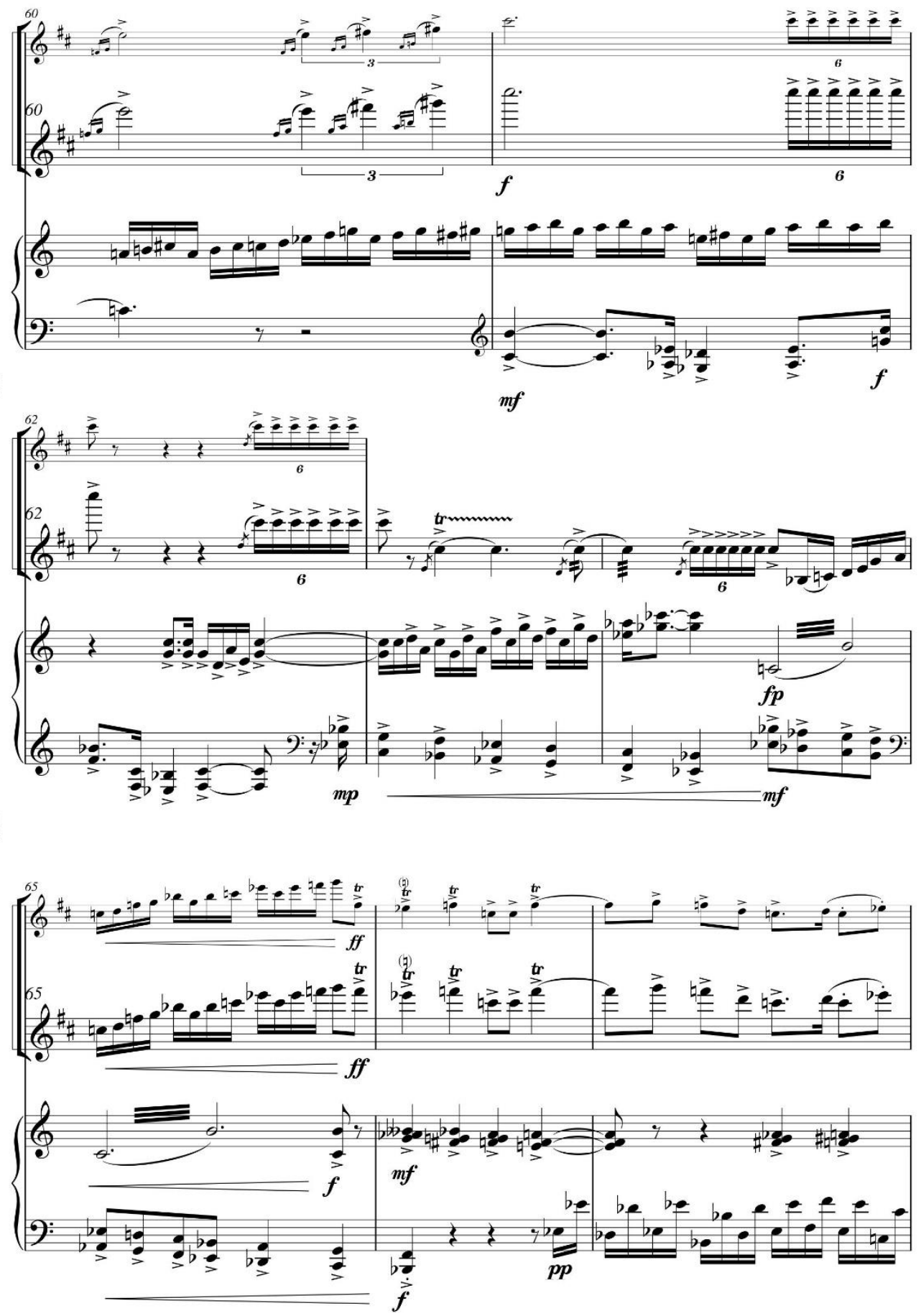

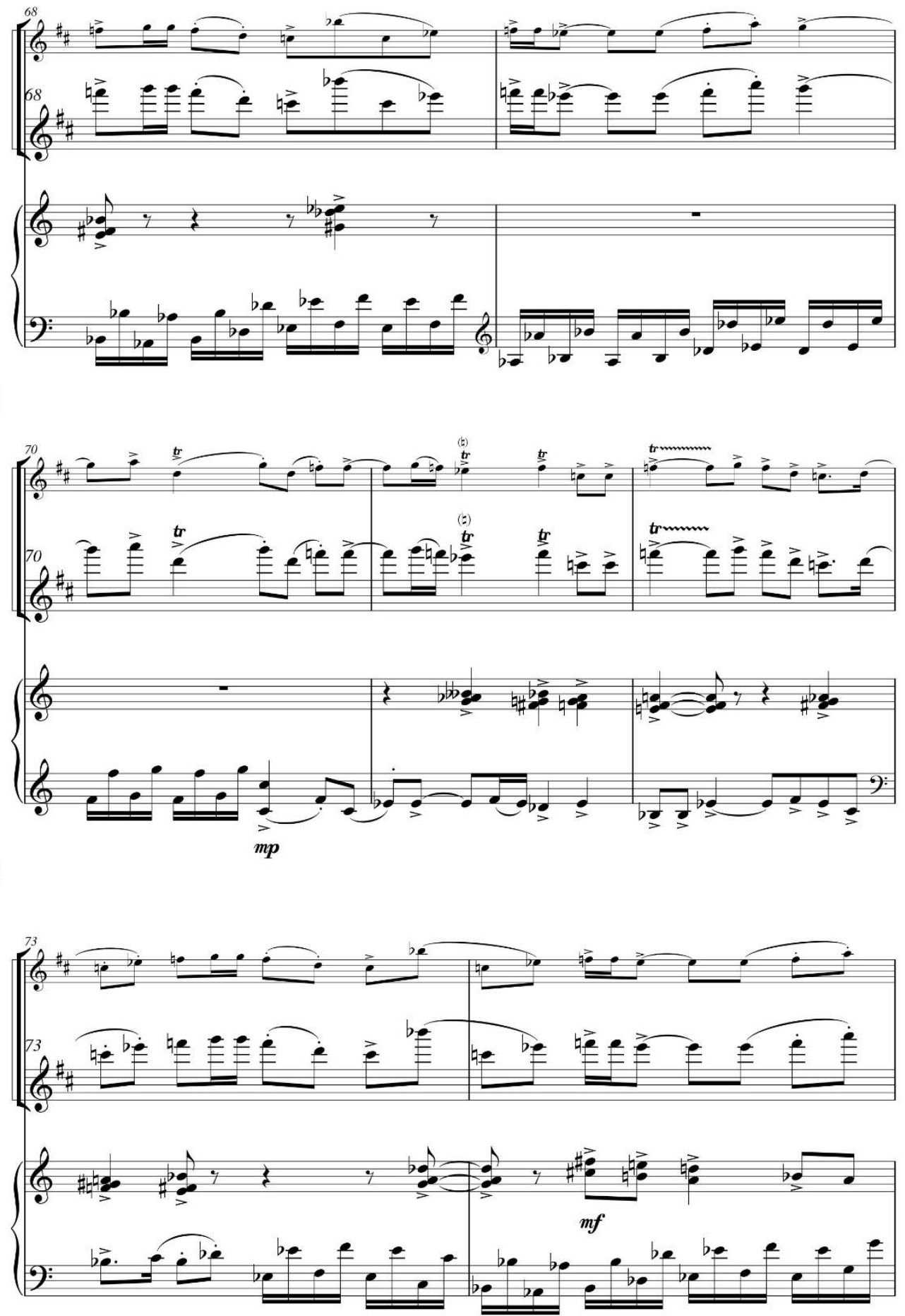

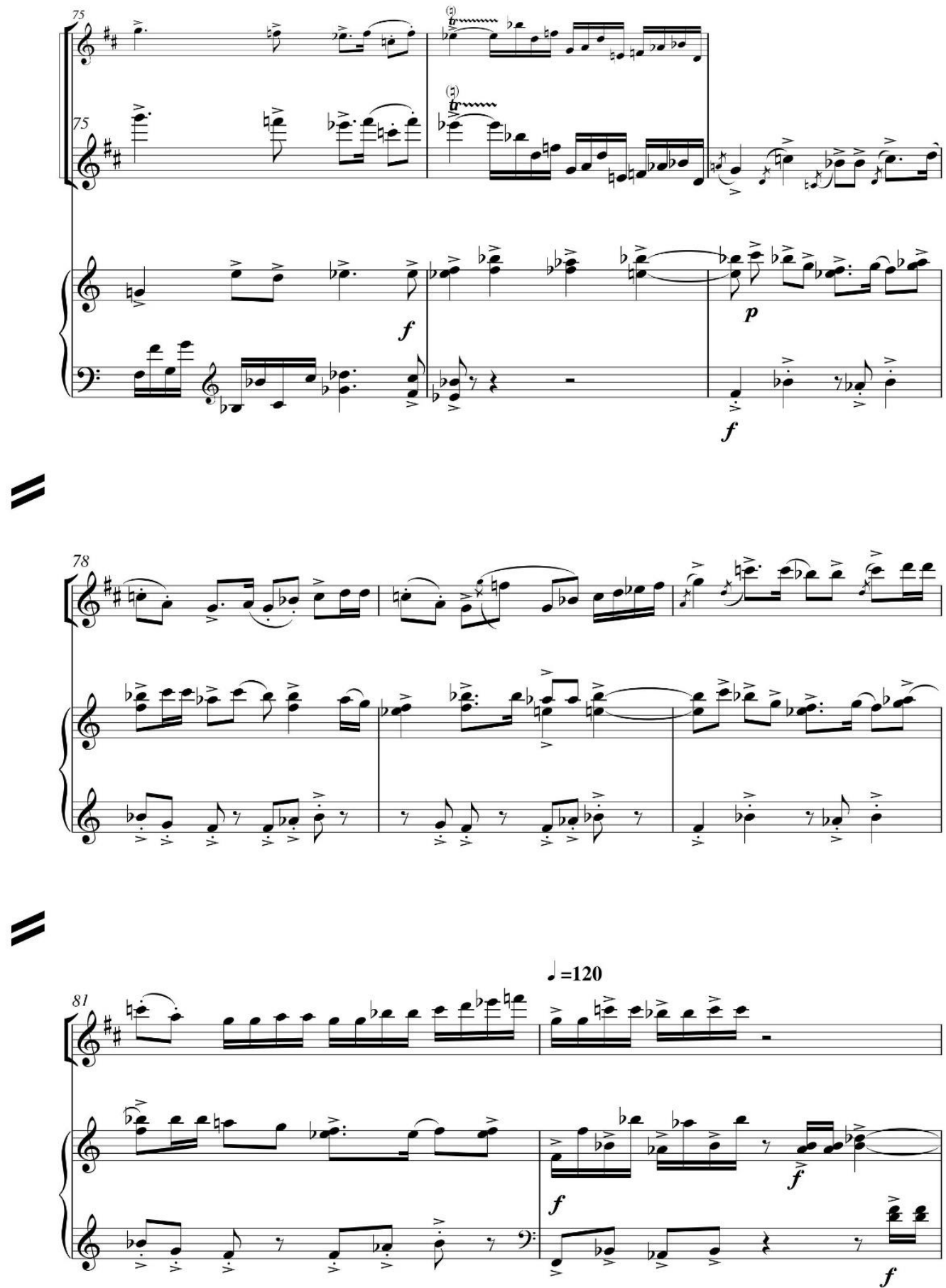

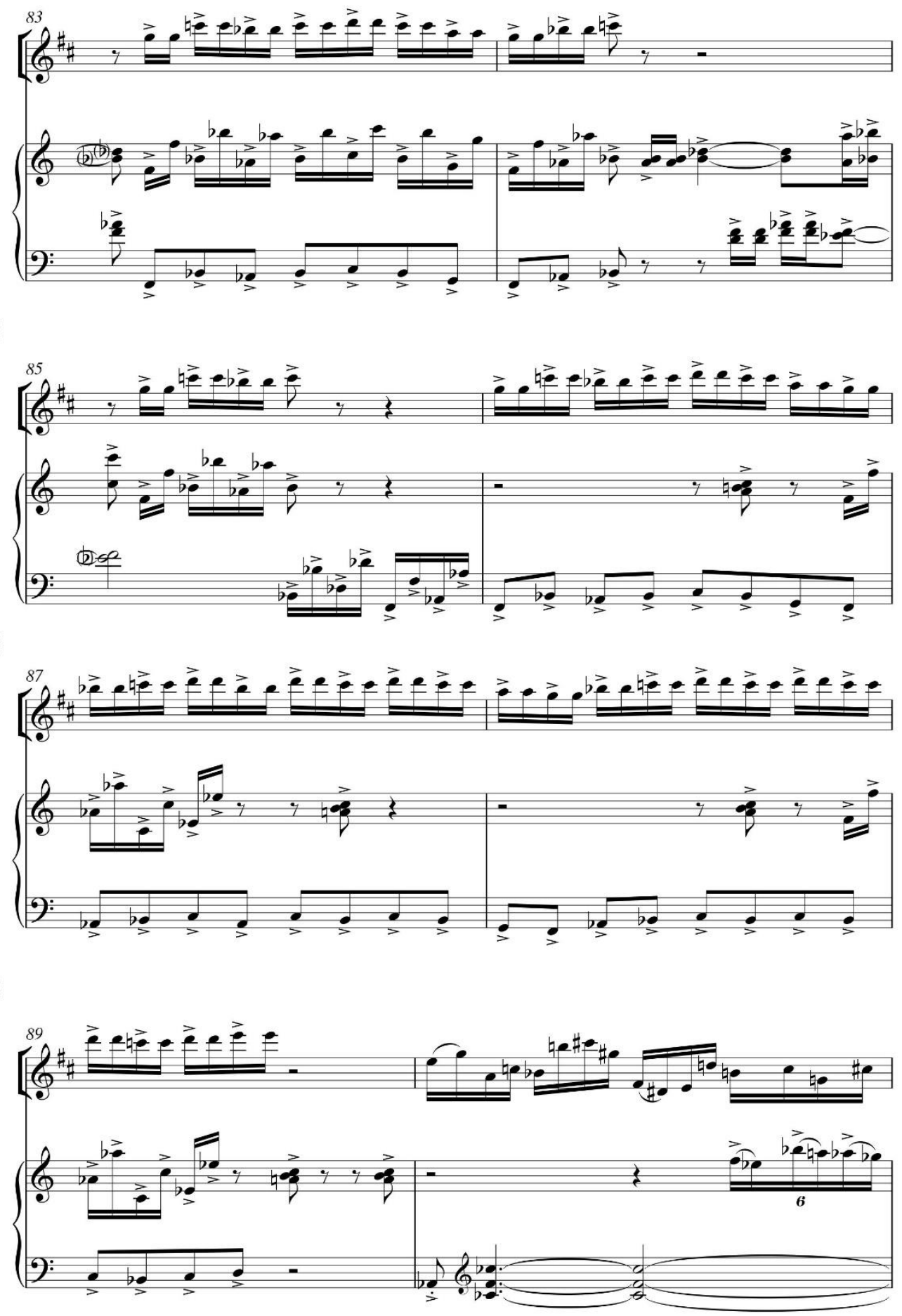
12
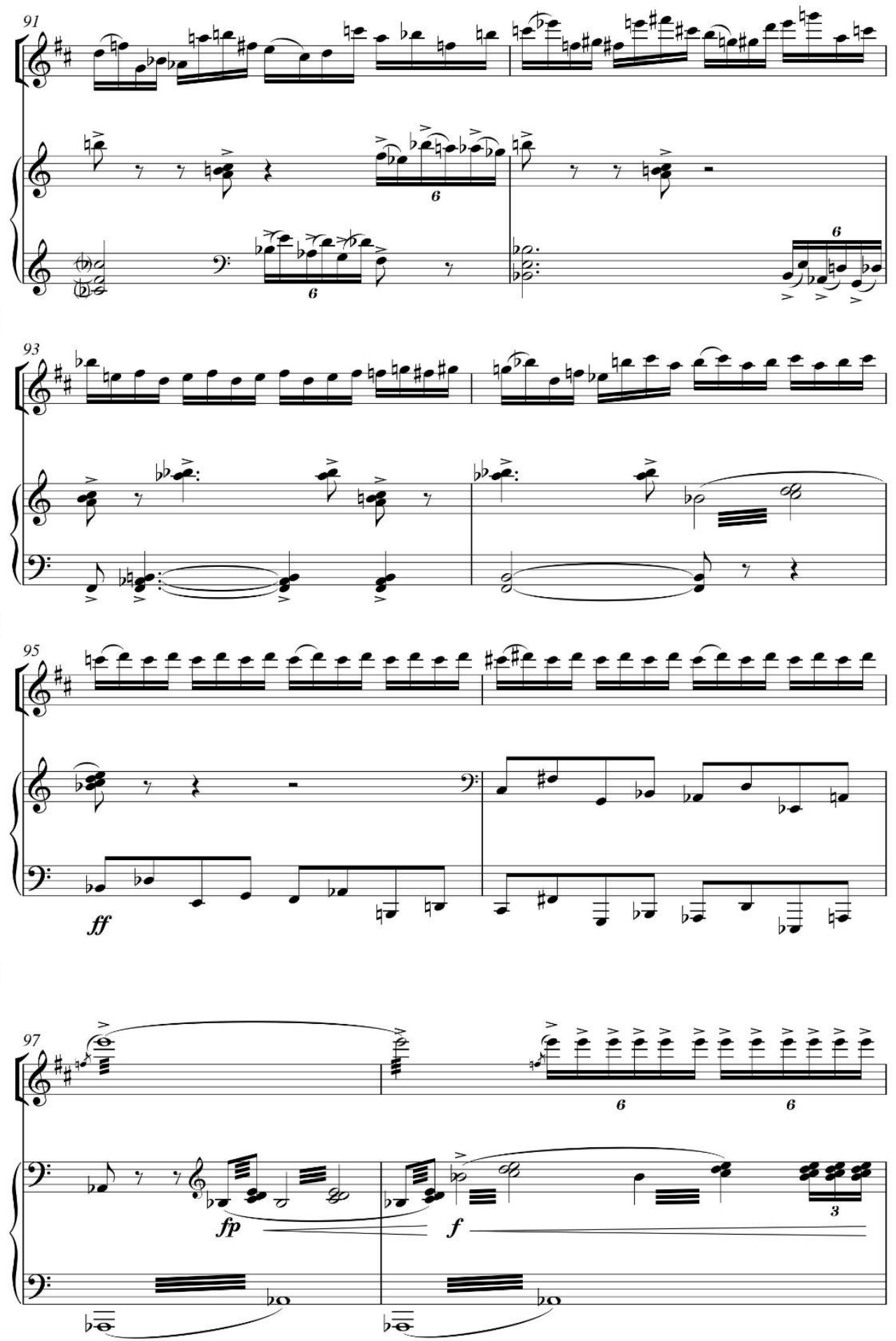


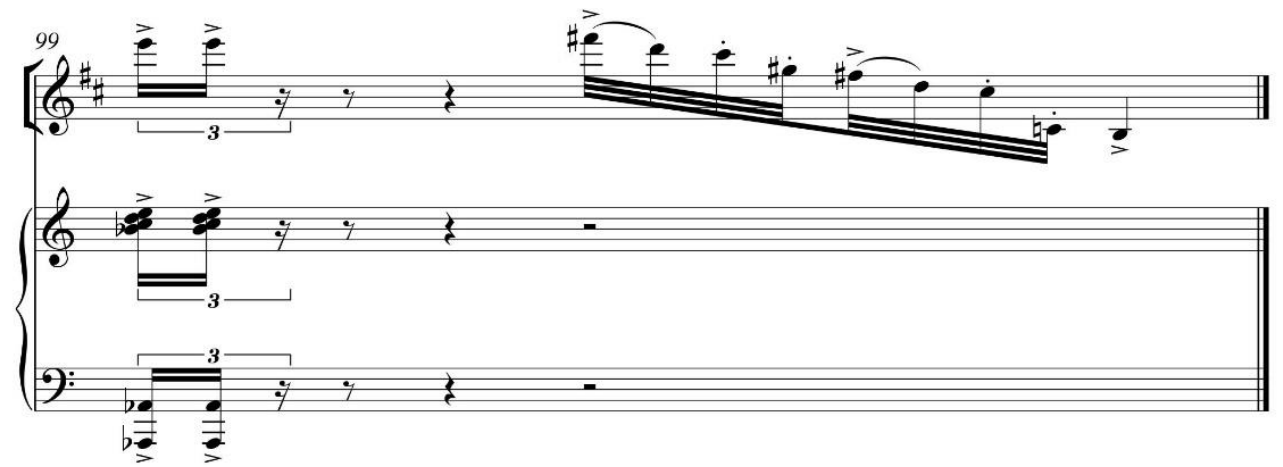




\section{II. 秧歌 \\ YangKo}

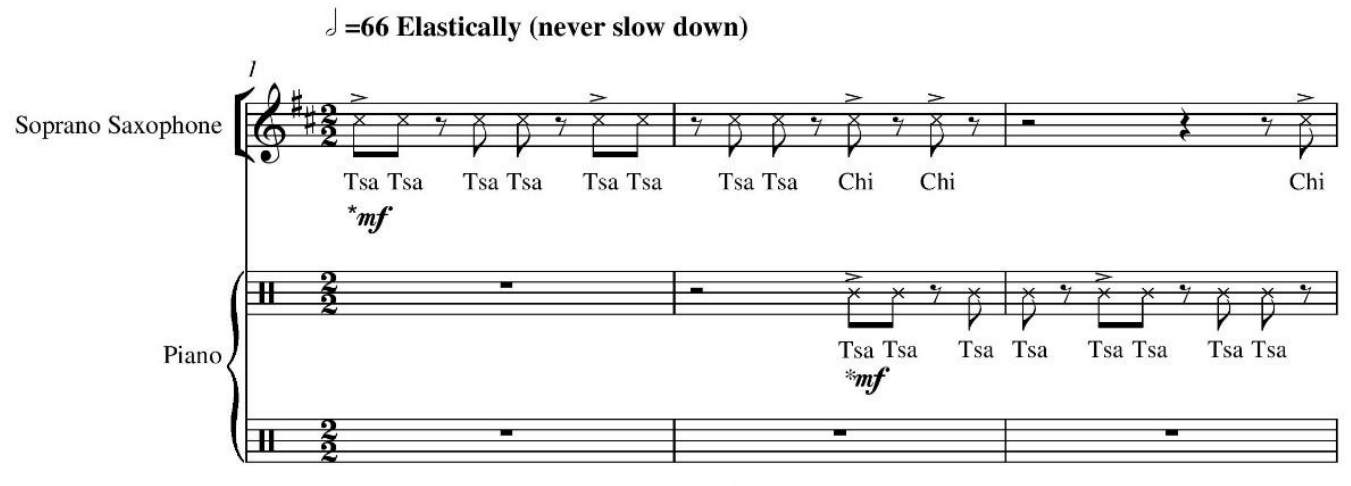

* half-breath and half-unpitched speech
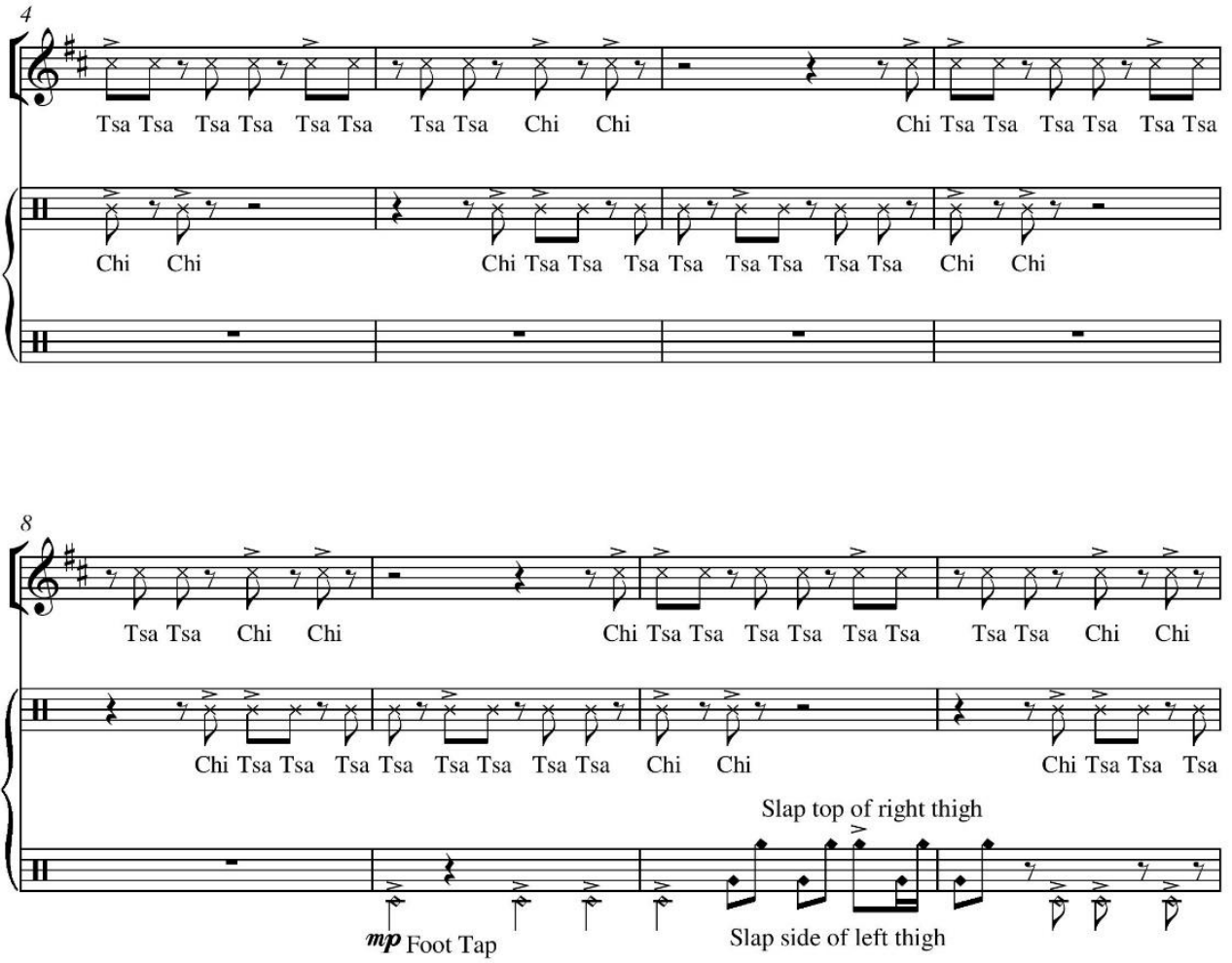

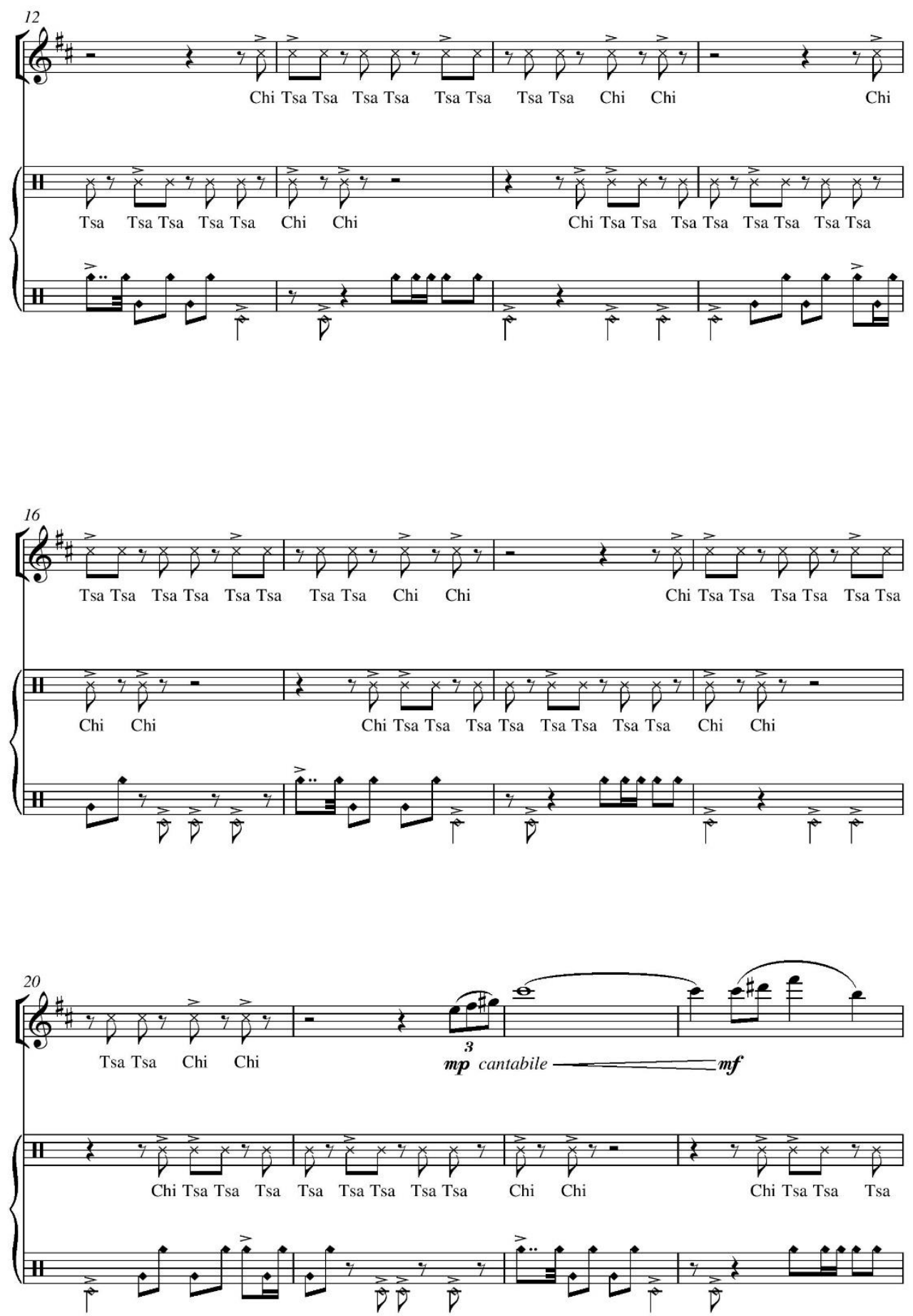

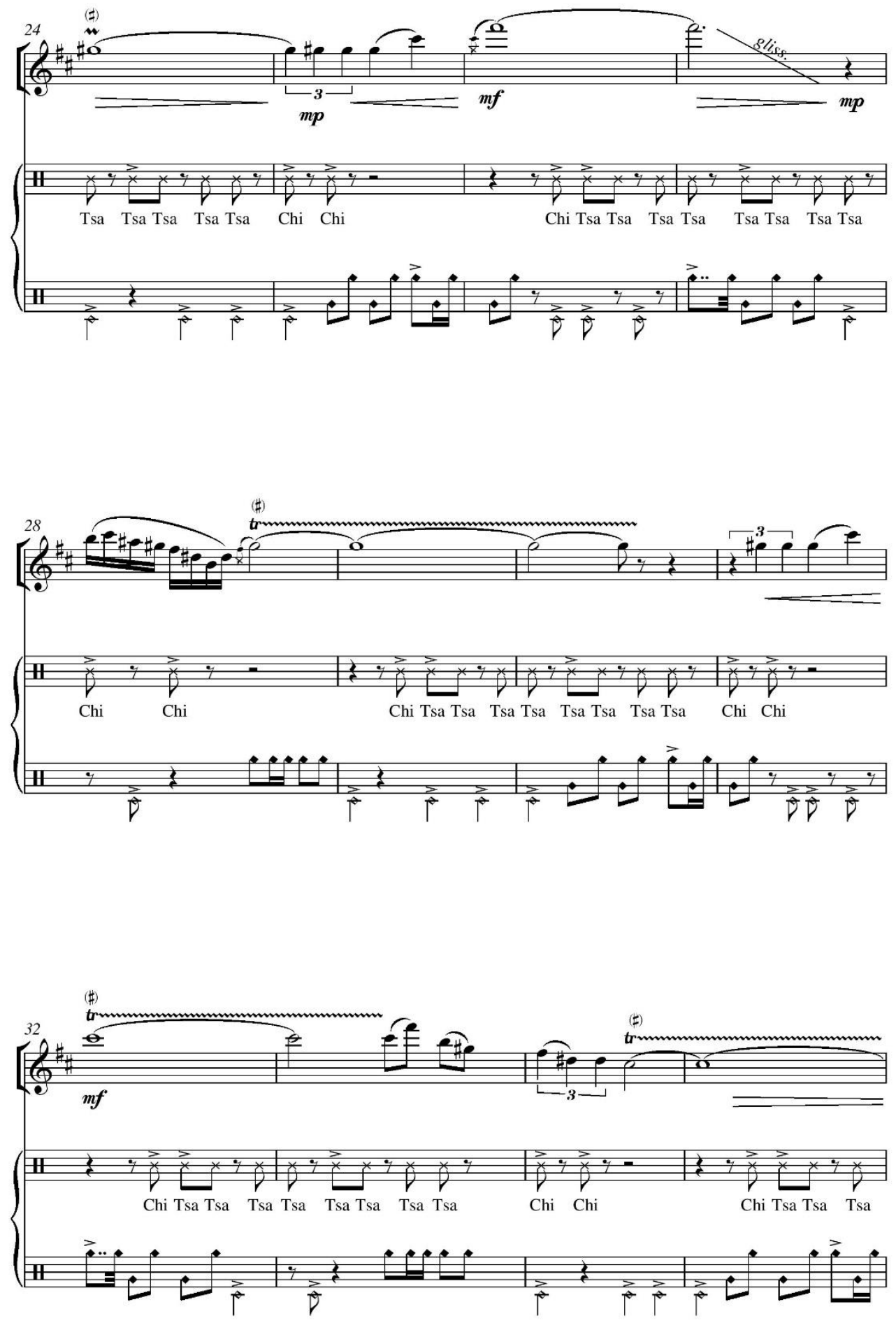

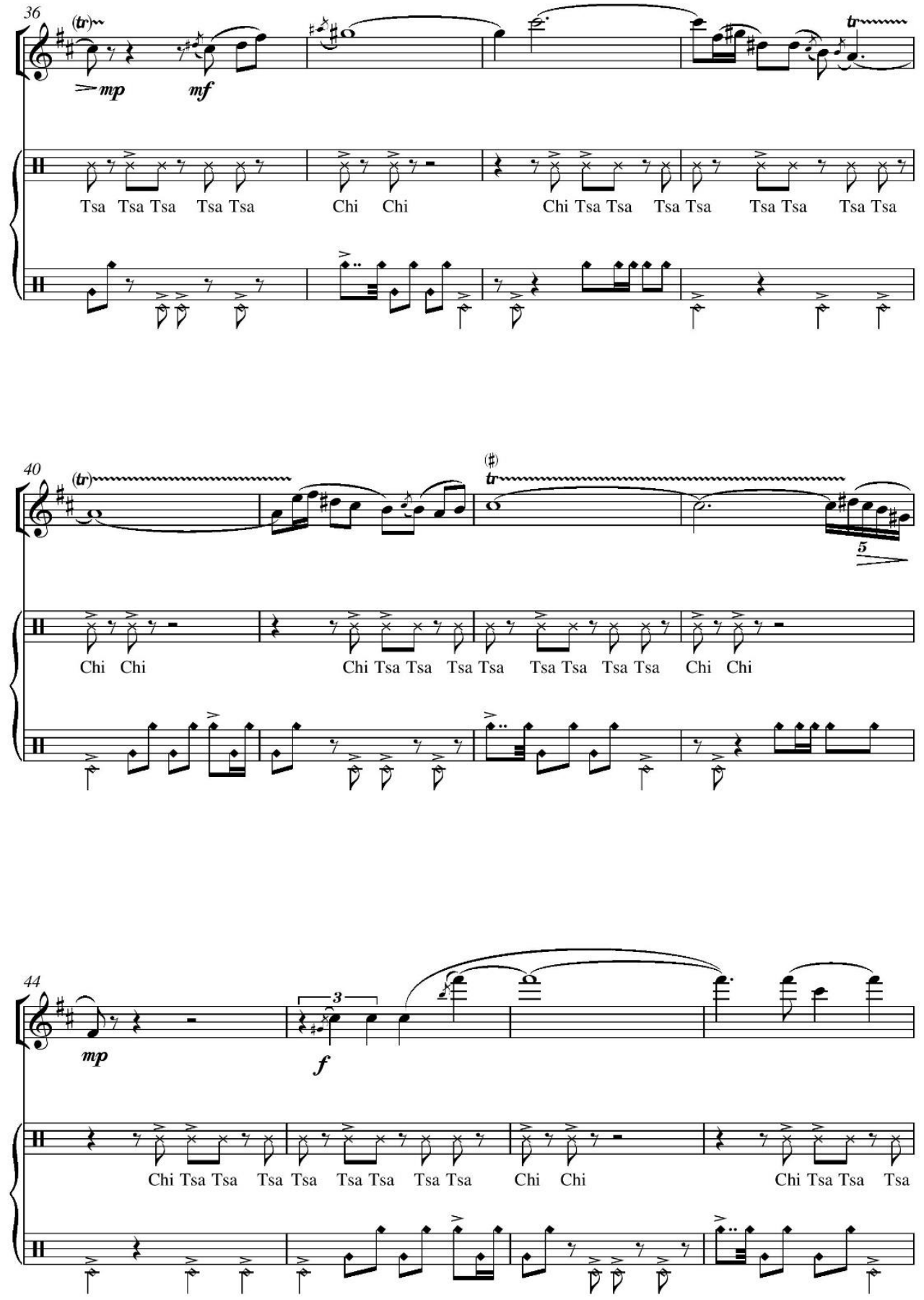

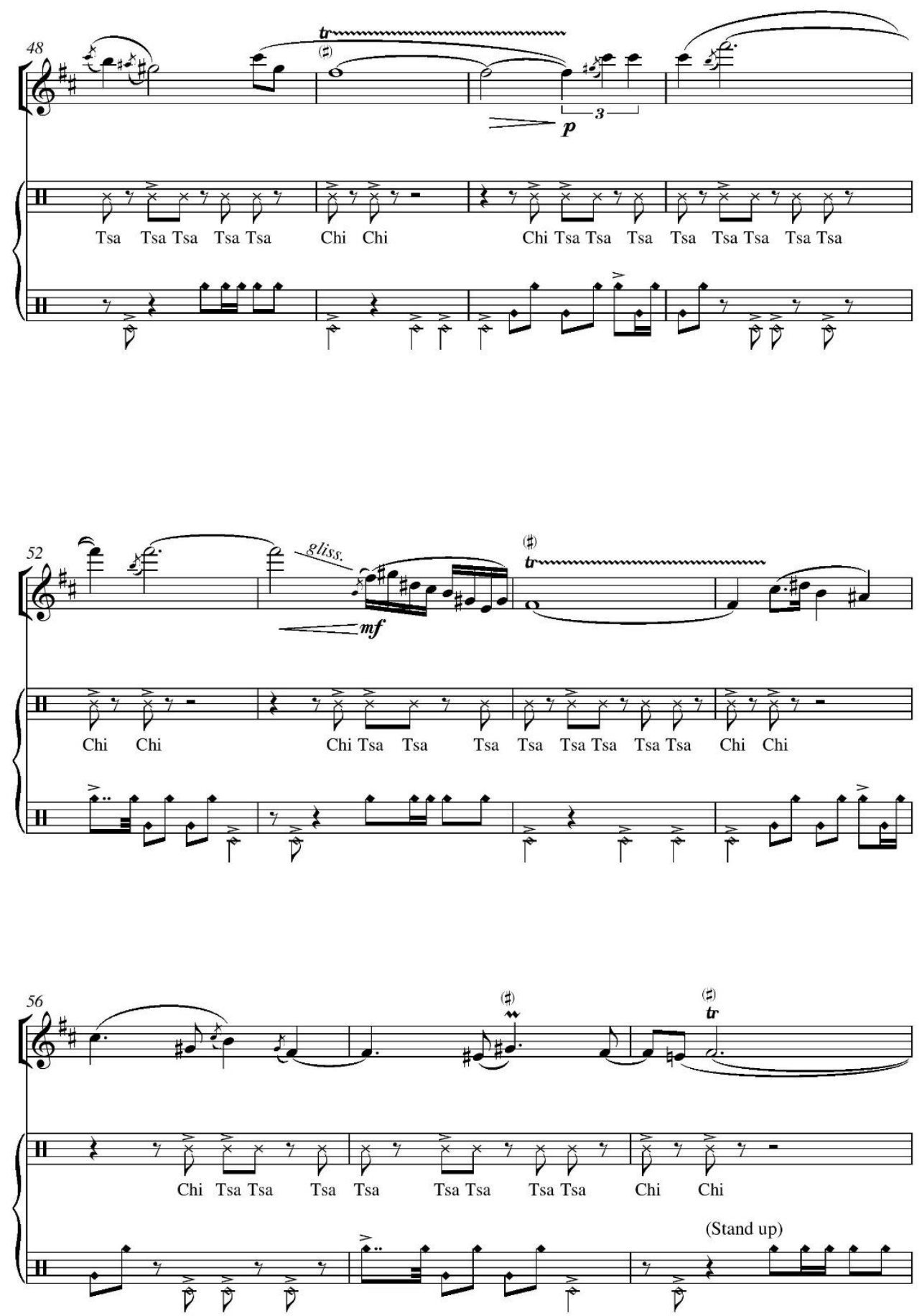
6

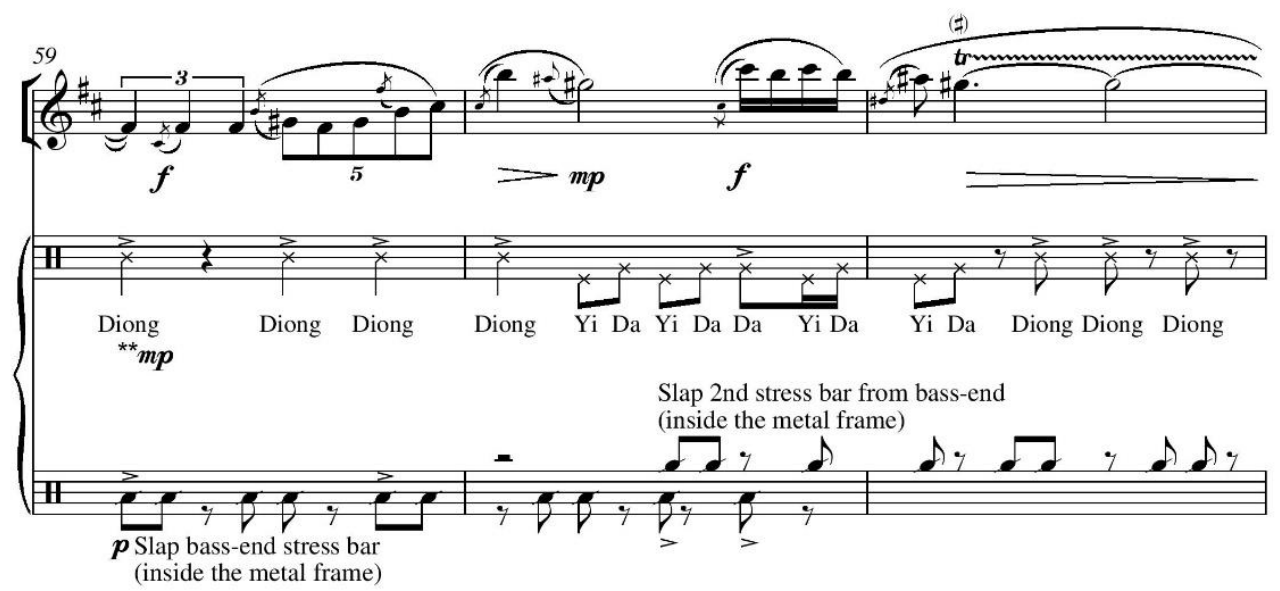

**unpitched speech with high and low register relatively as notated
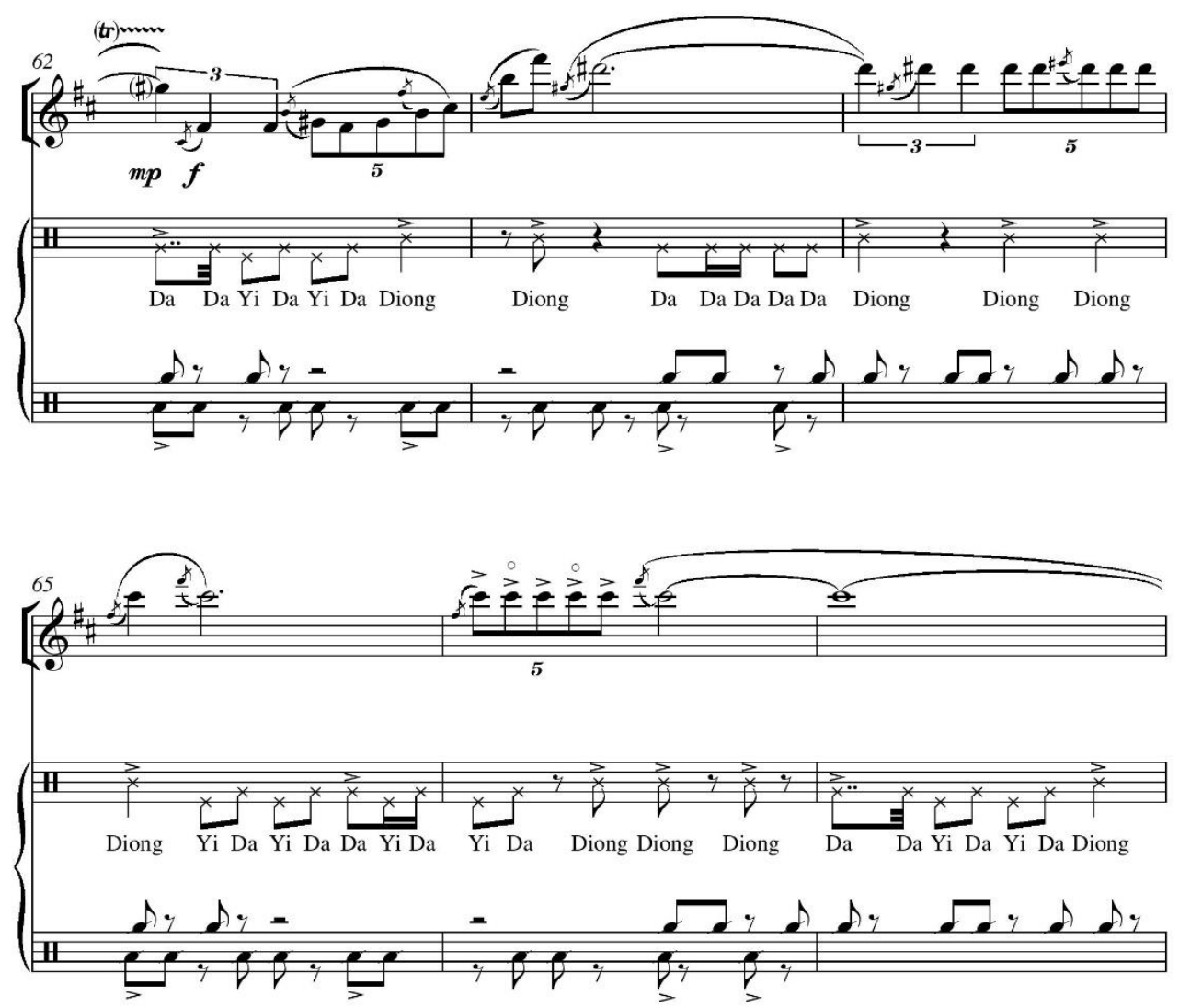

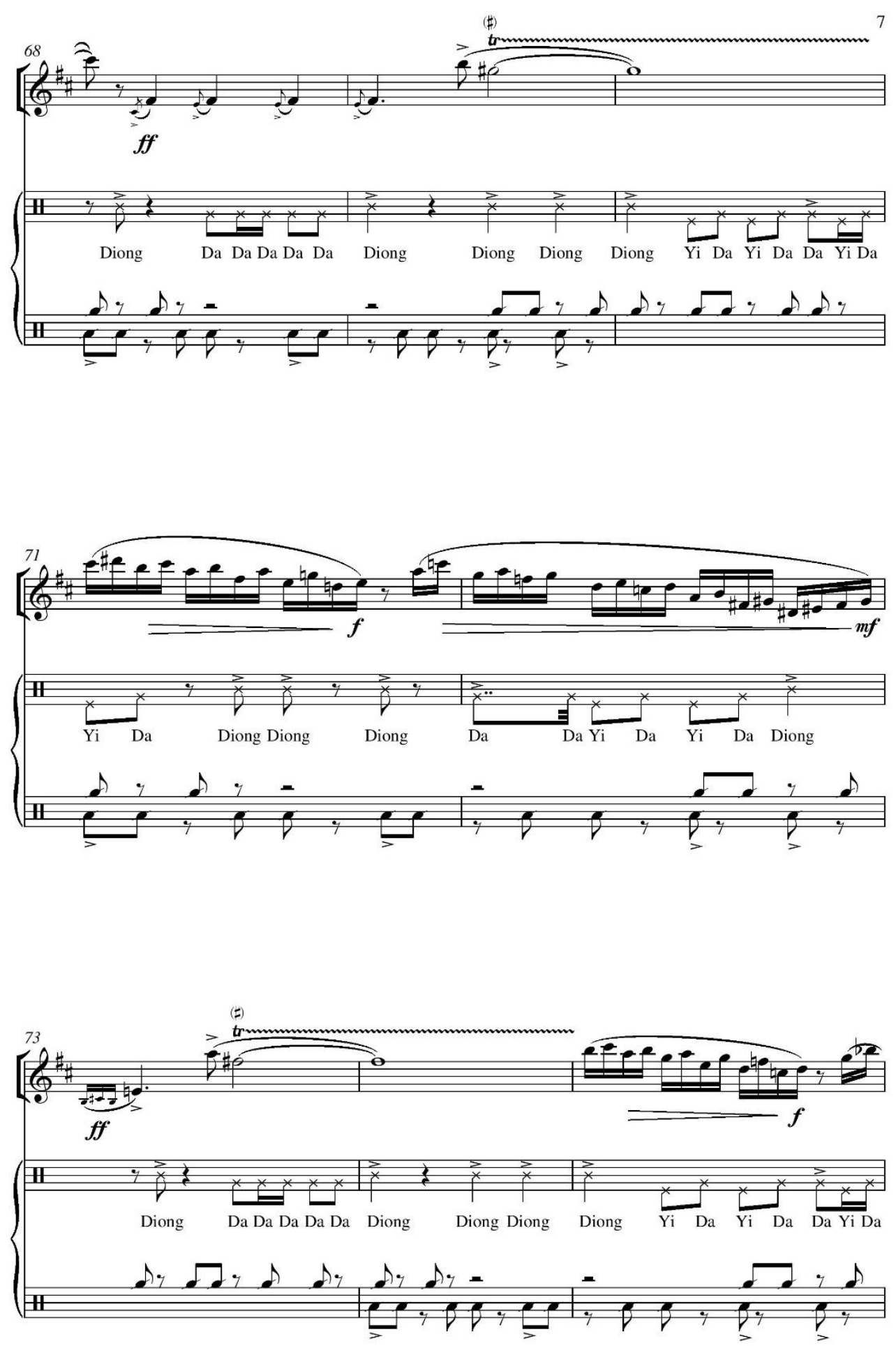
8
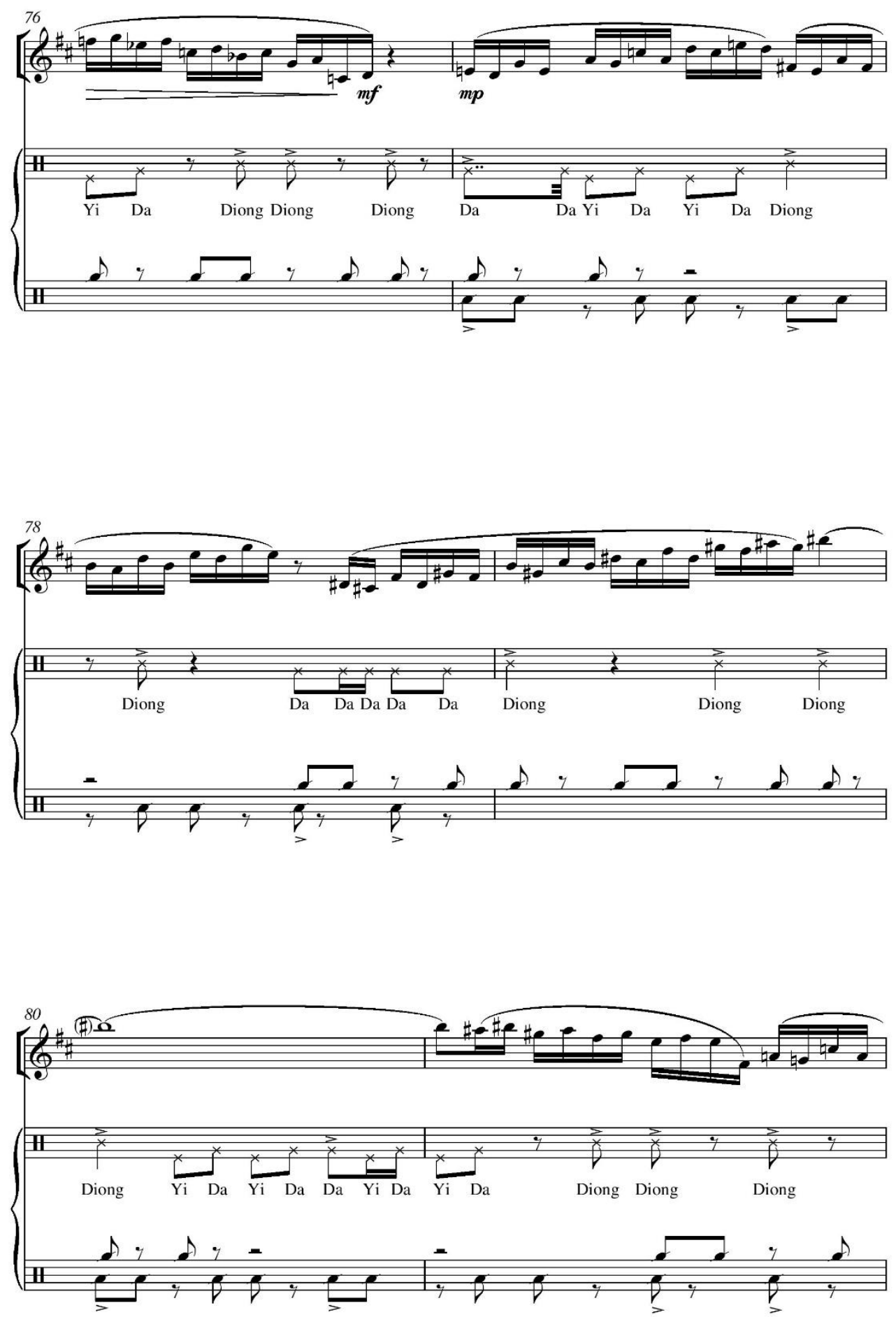

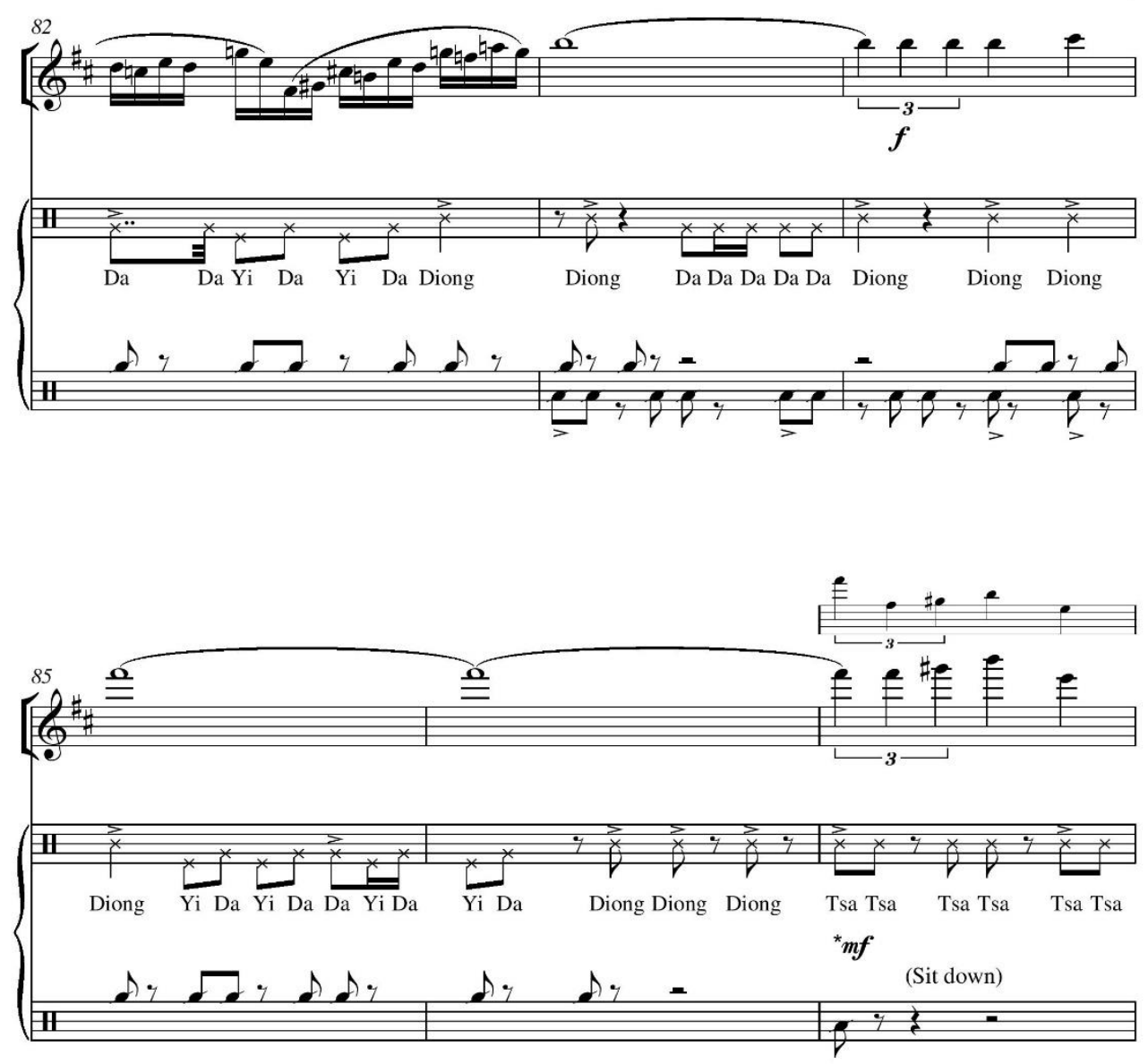

* half-breath and half-unpitched speech

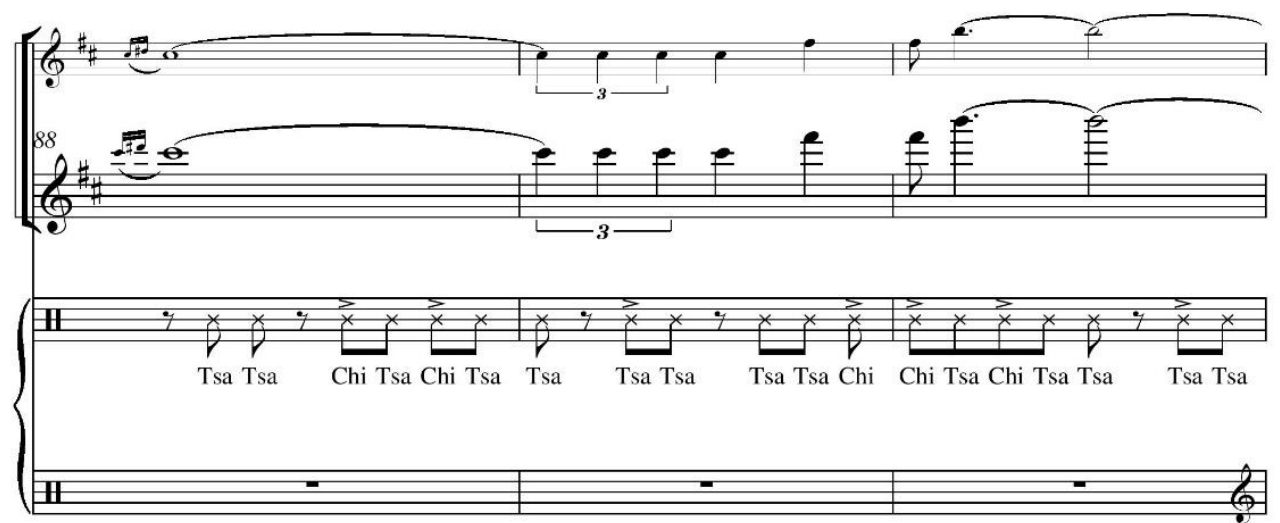


10

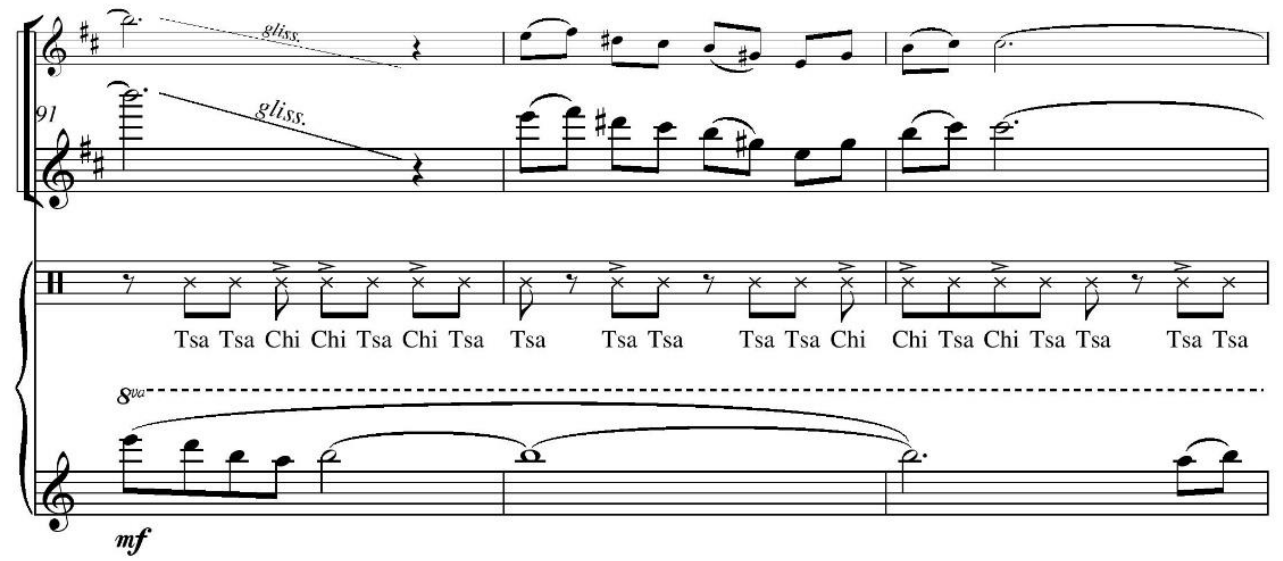

Ted.
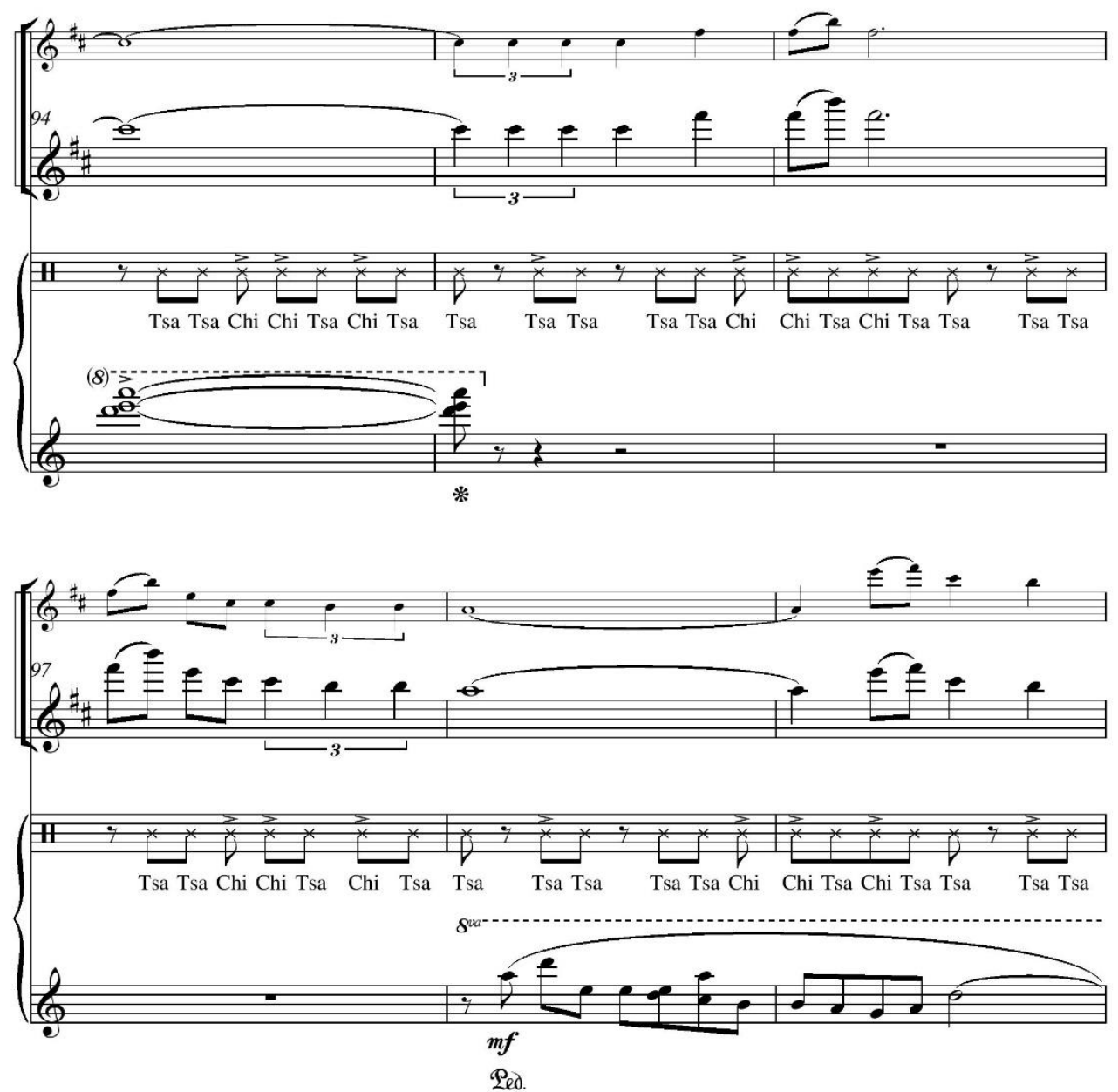

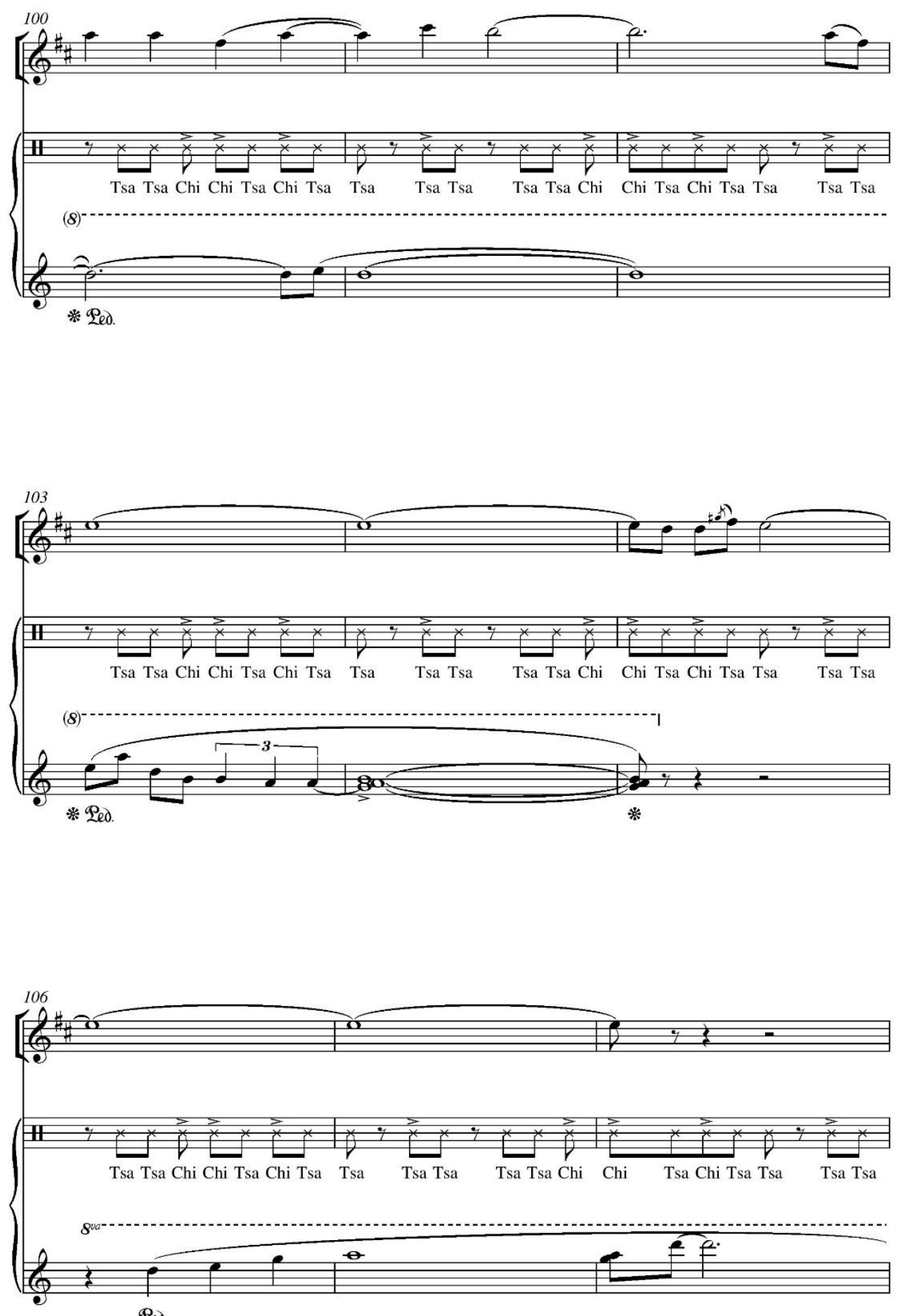

Tер. 

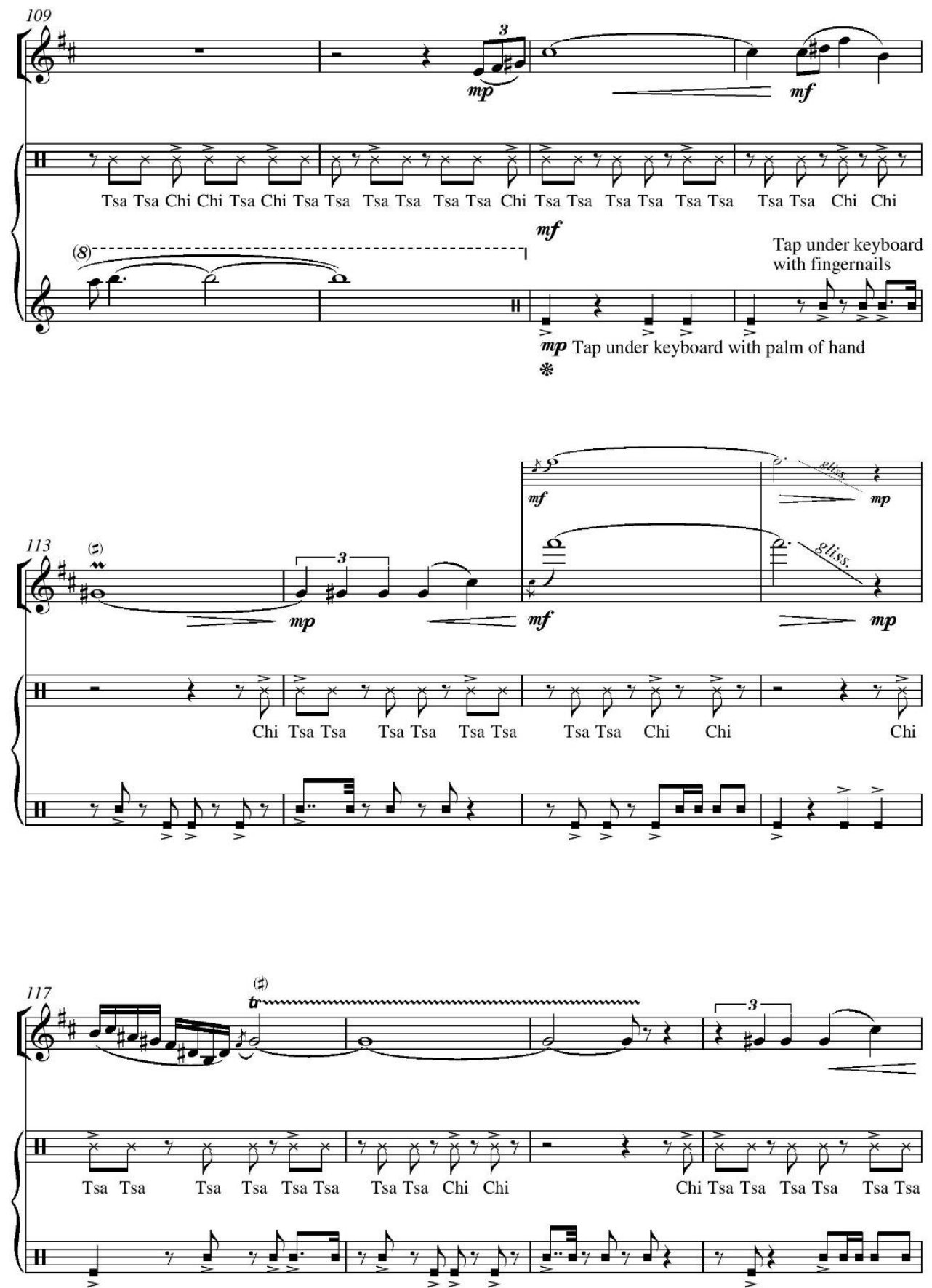

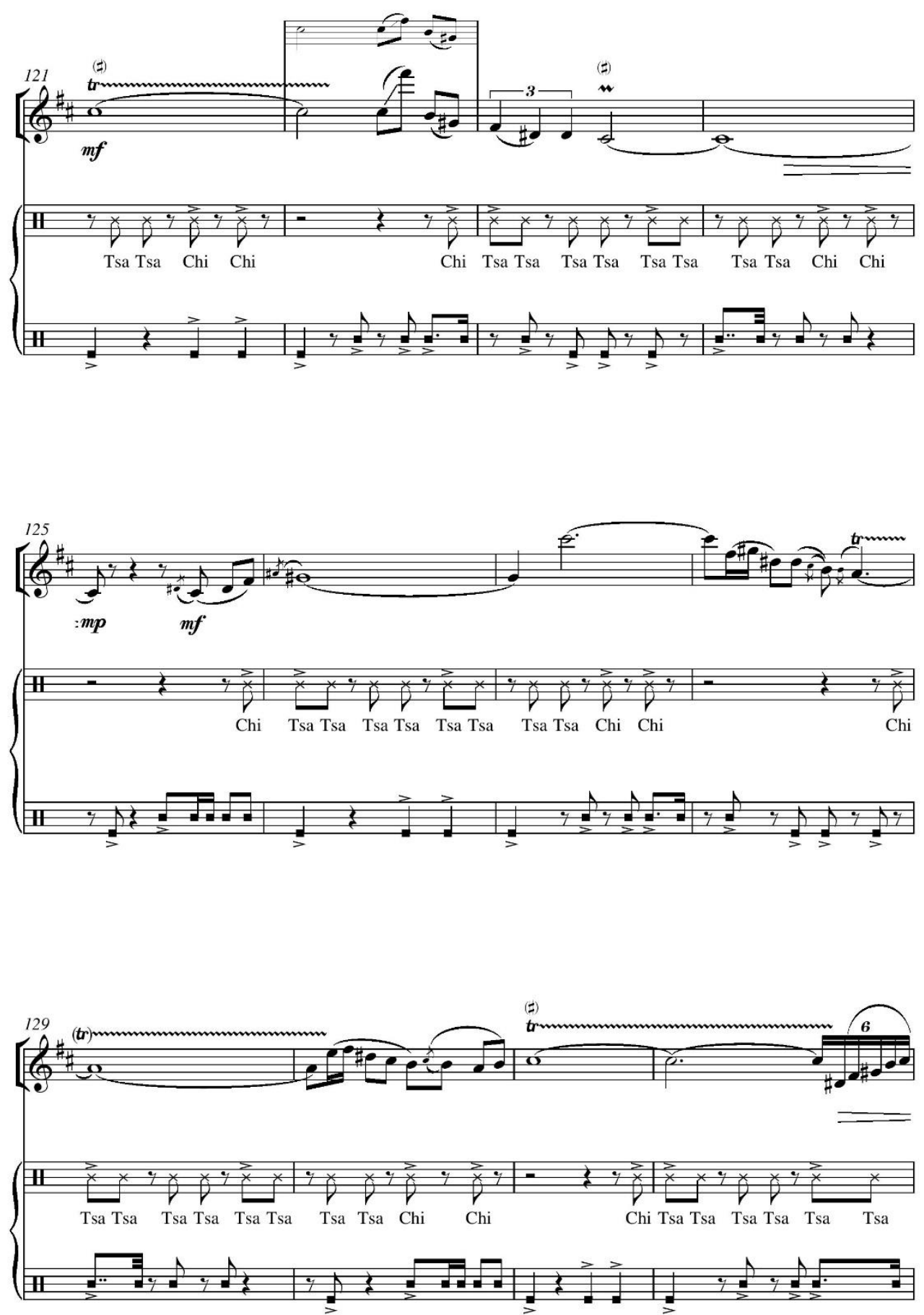
14
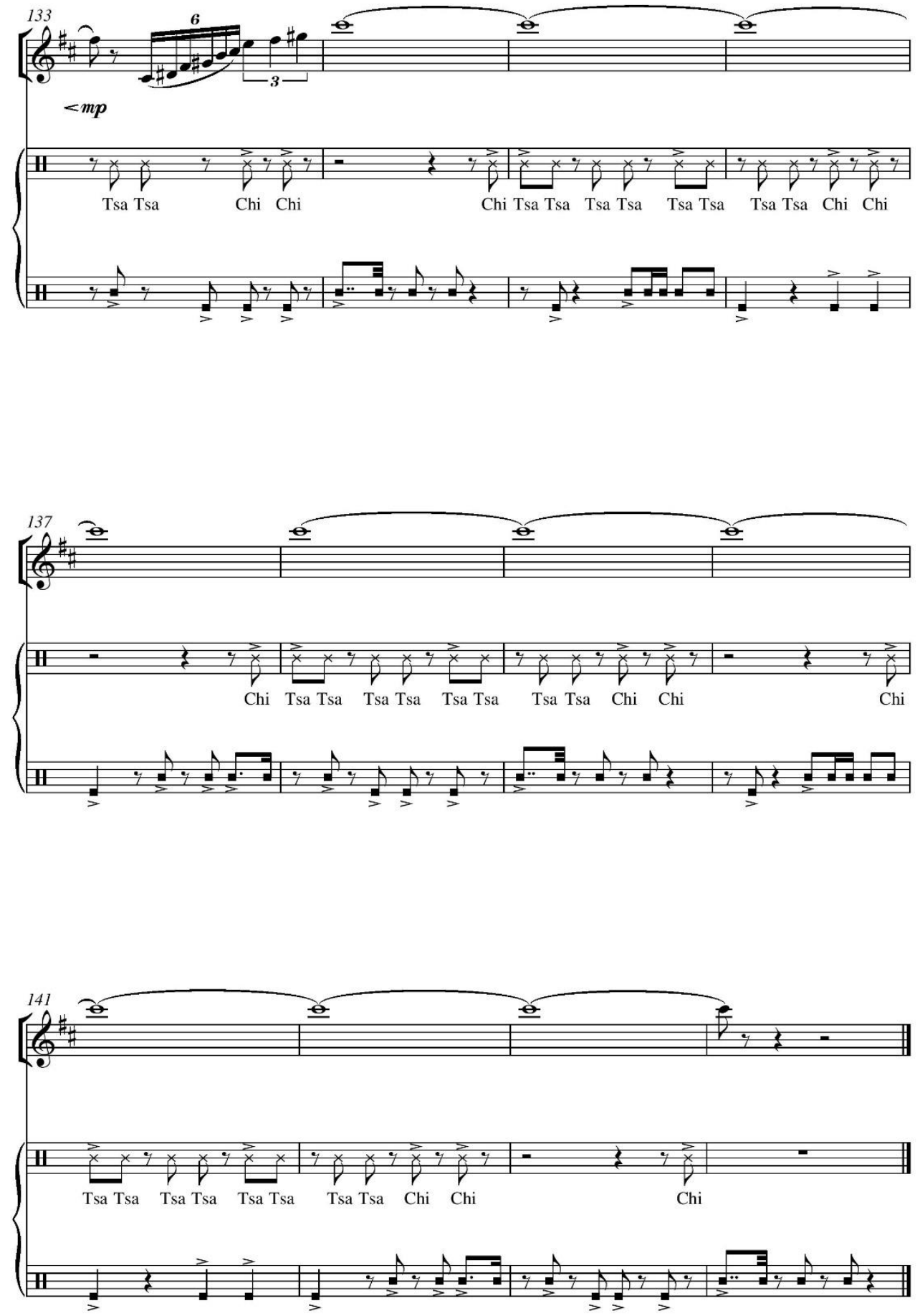


\section{III. 木卡姆}

\section{Mugam}

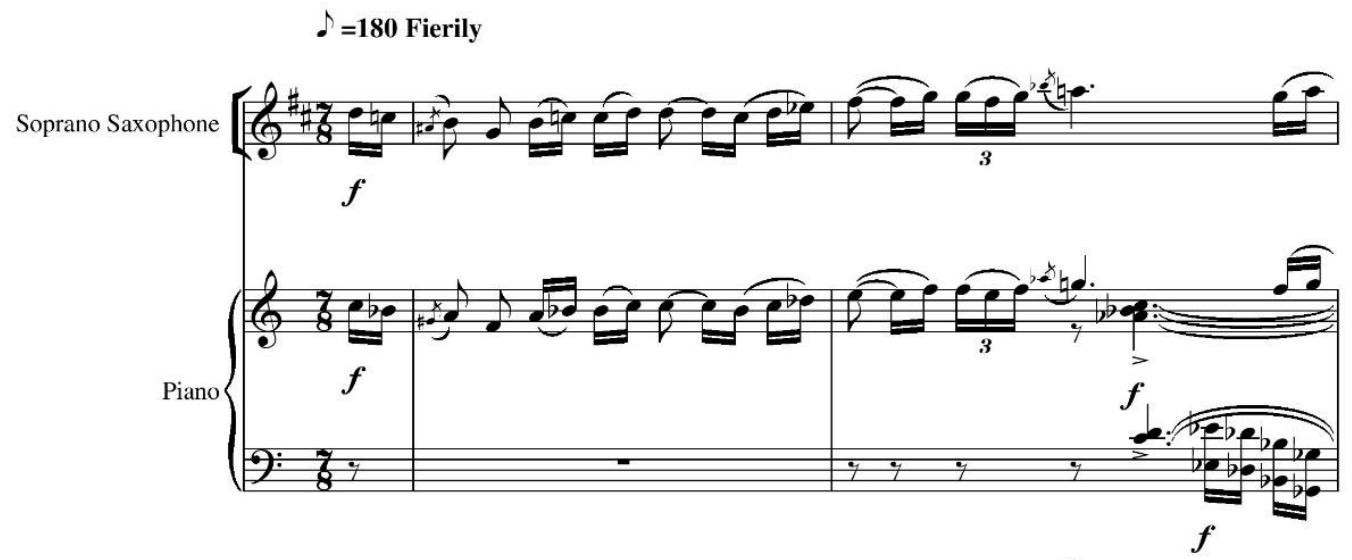

Ted
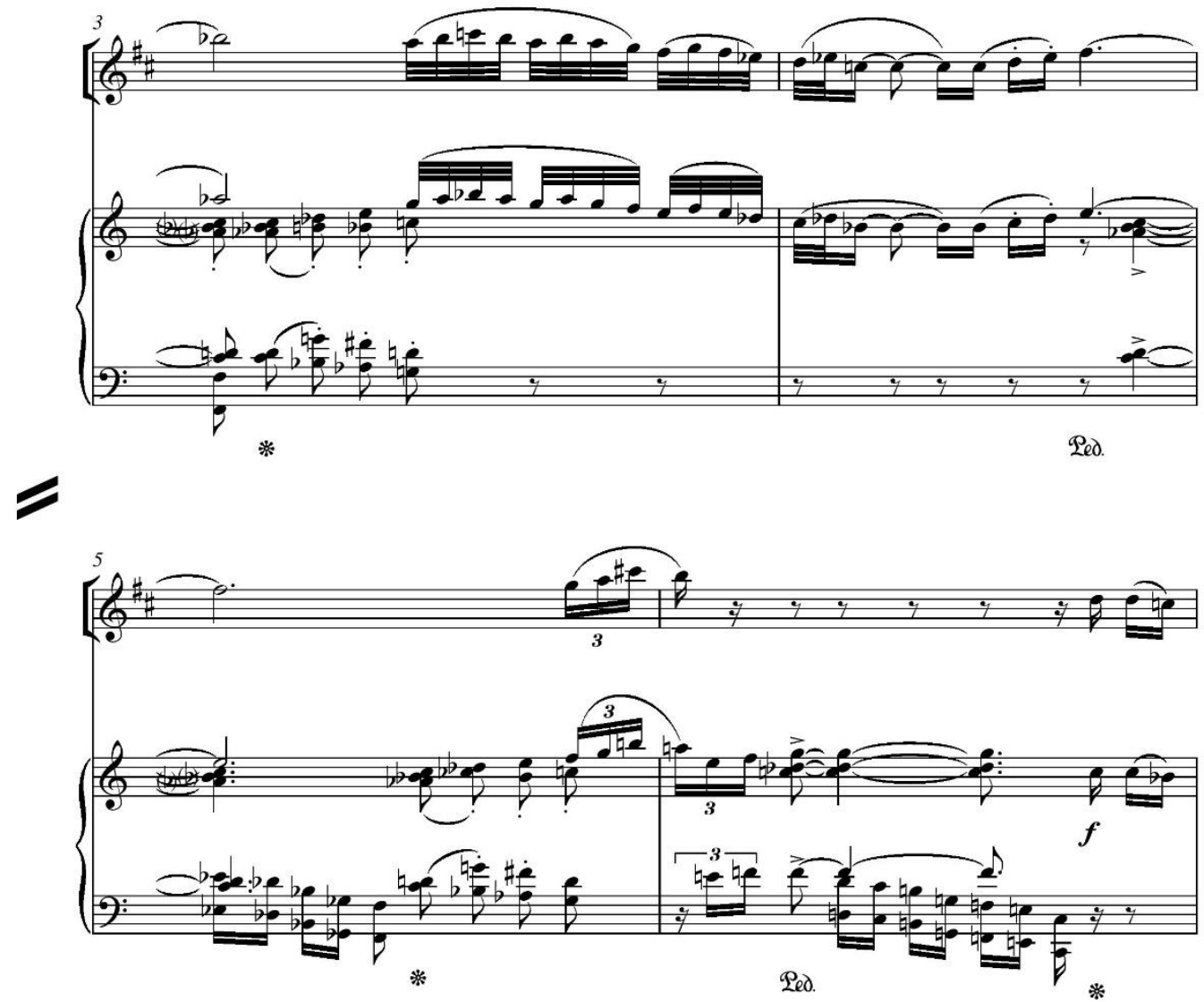
2
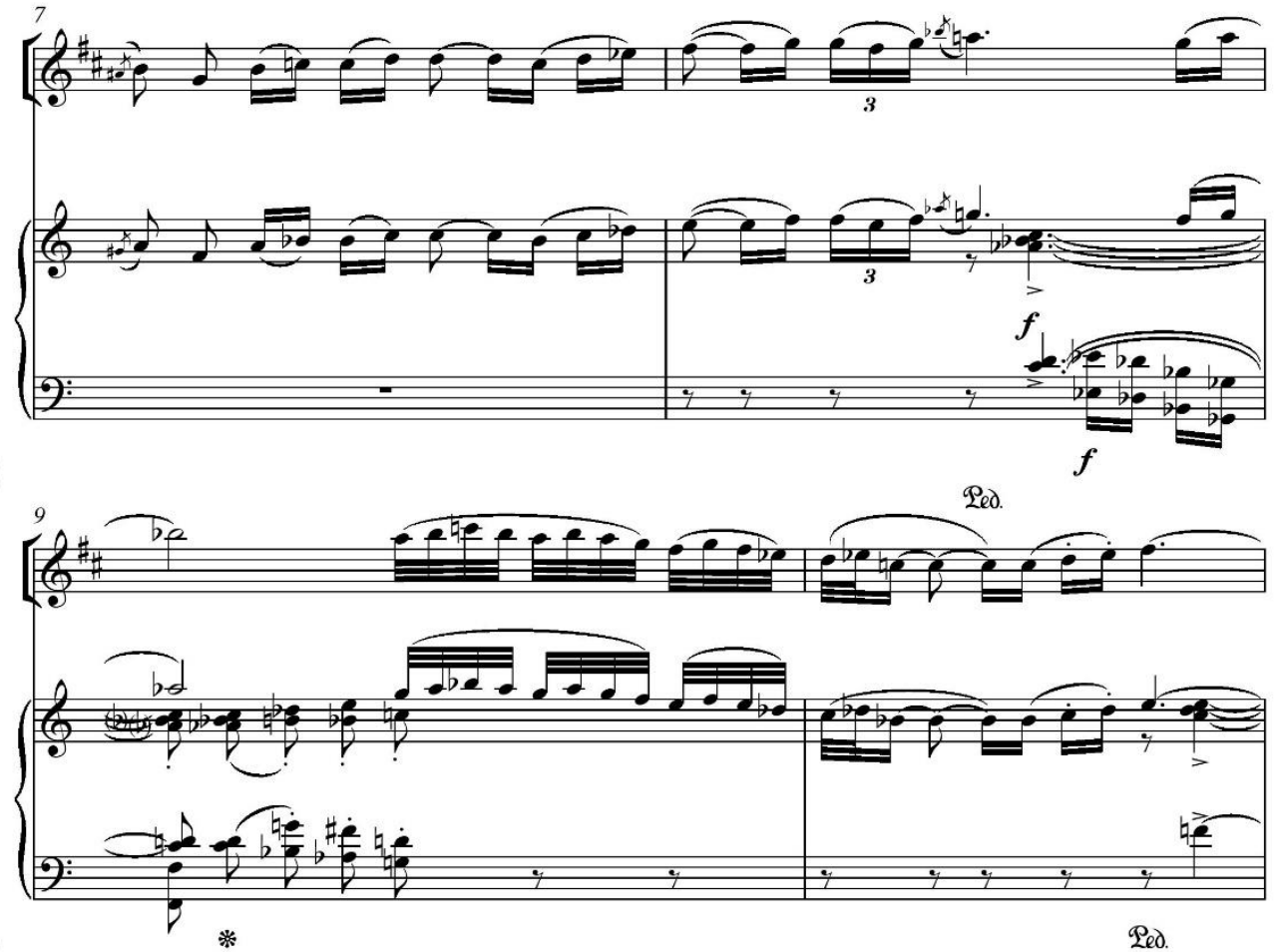

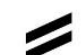
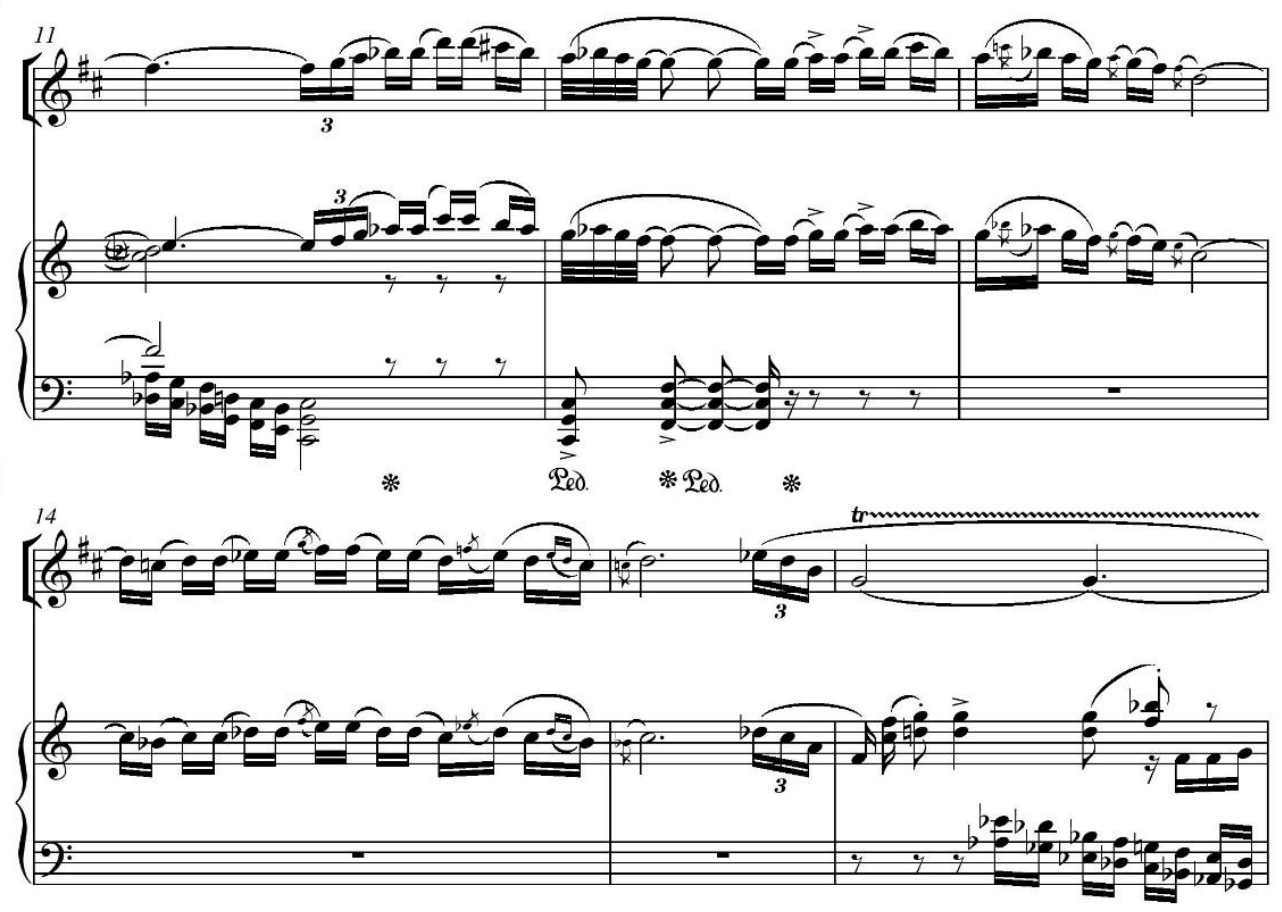


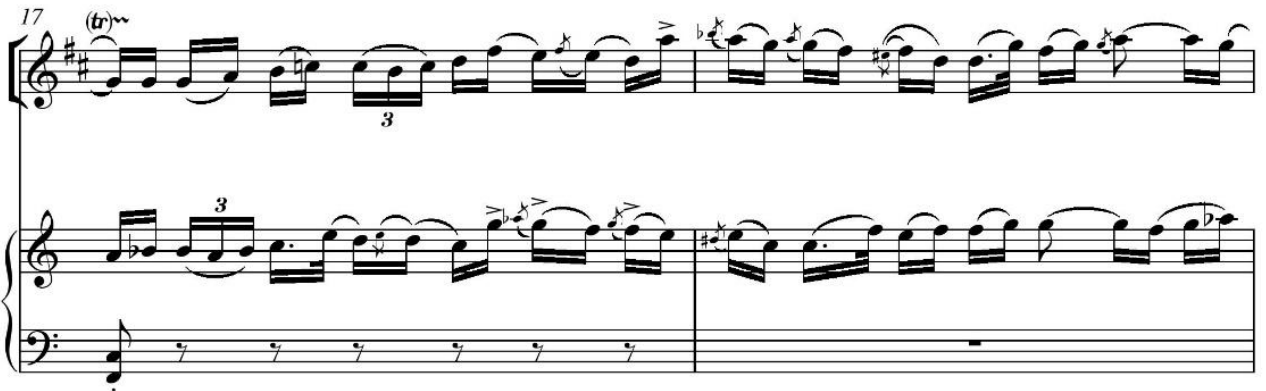

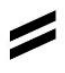
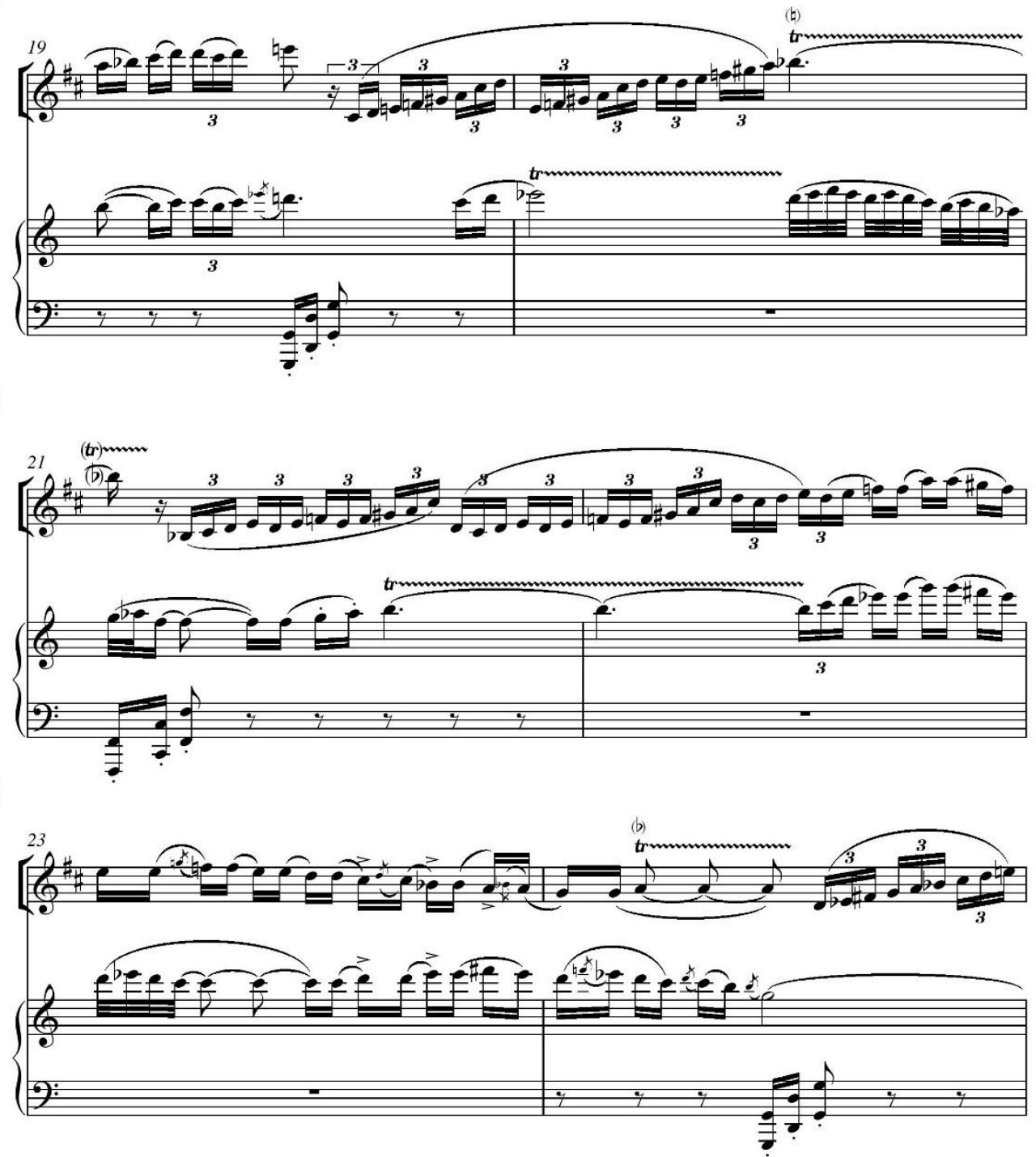
4
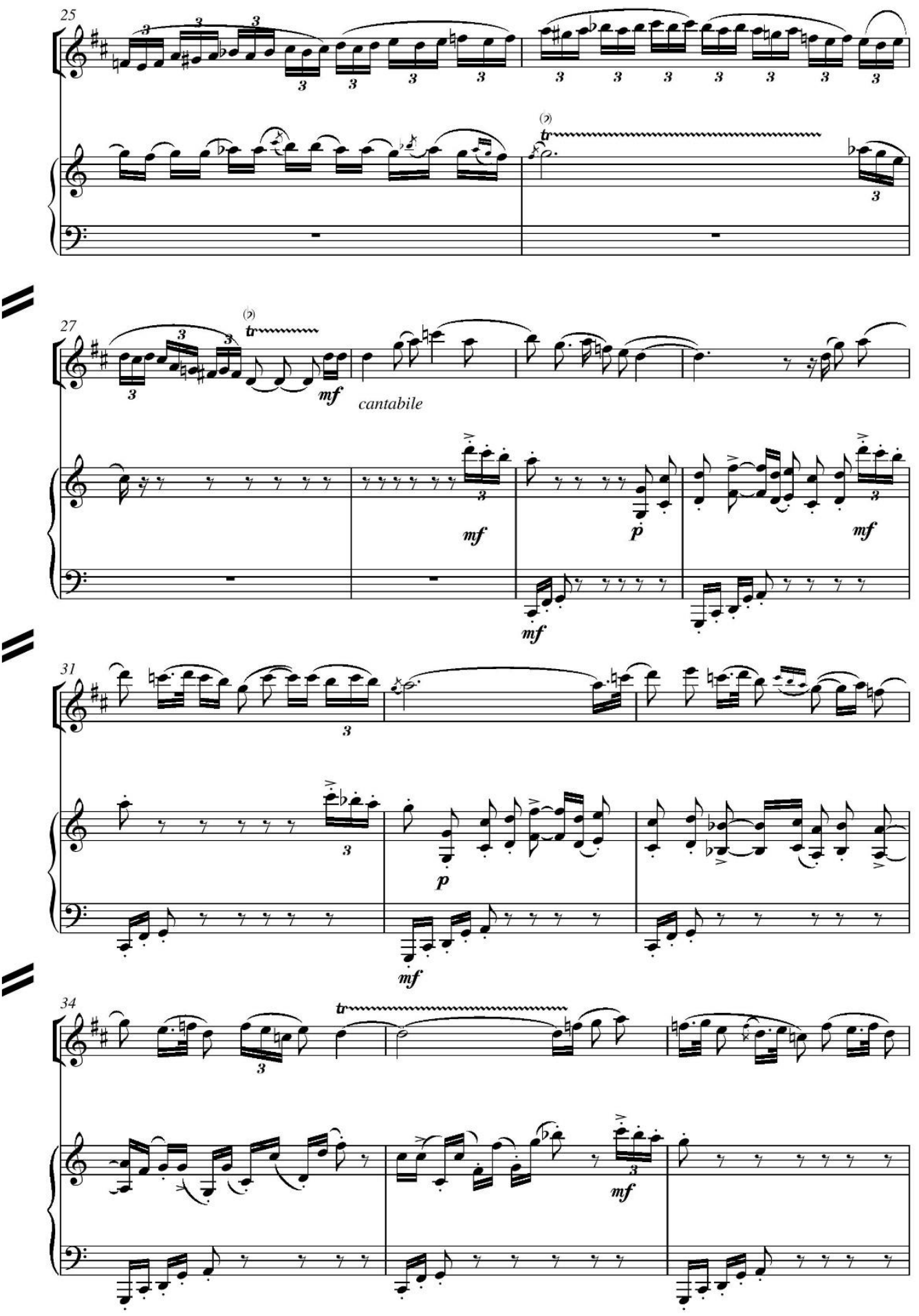


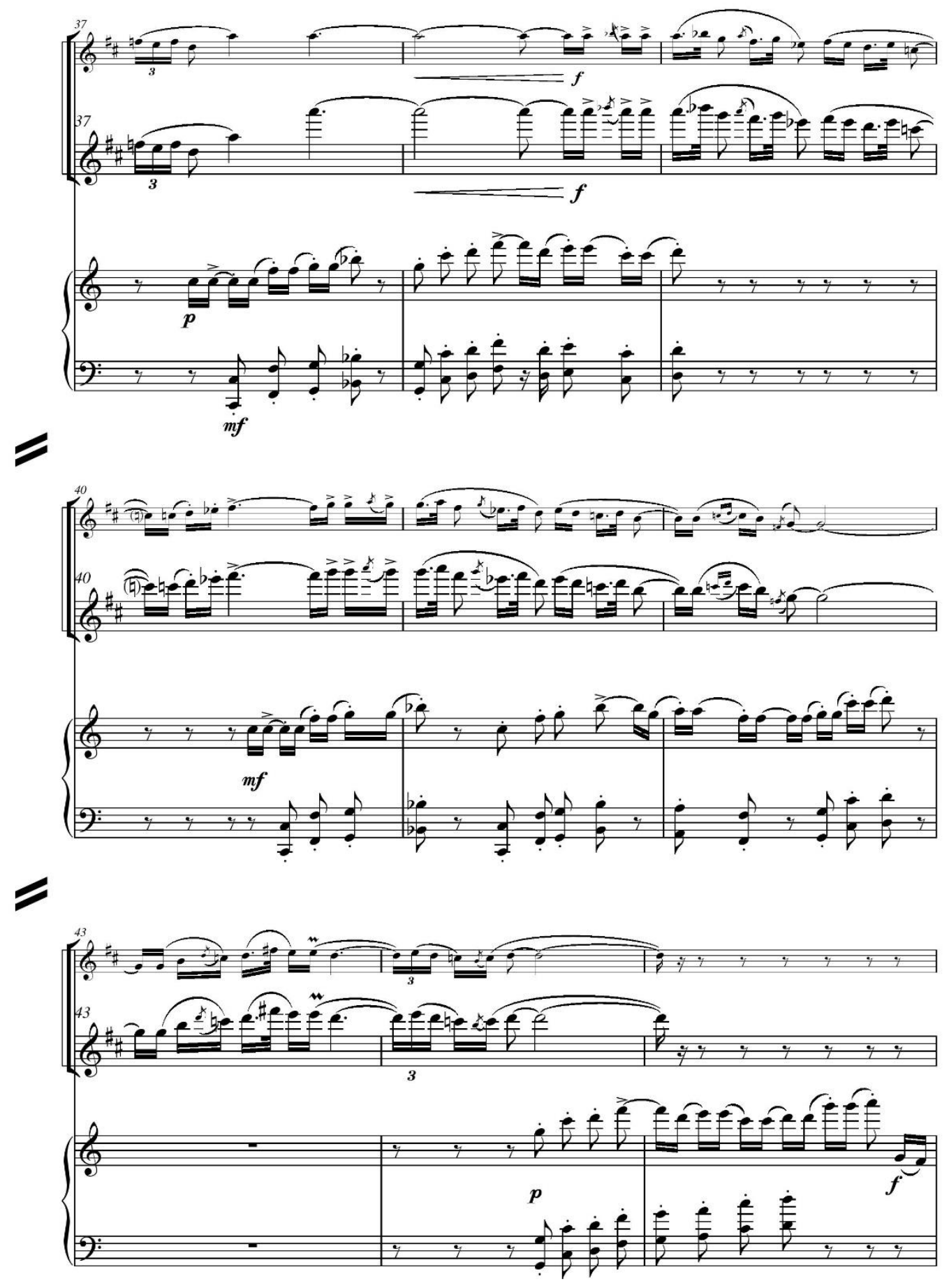


6
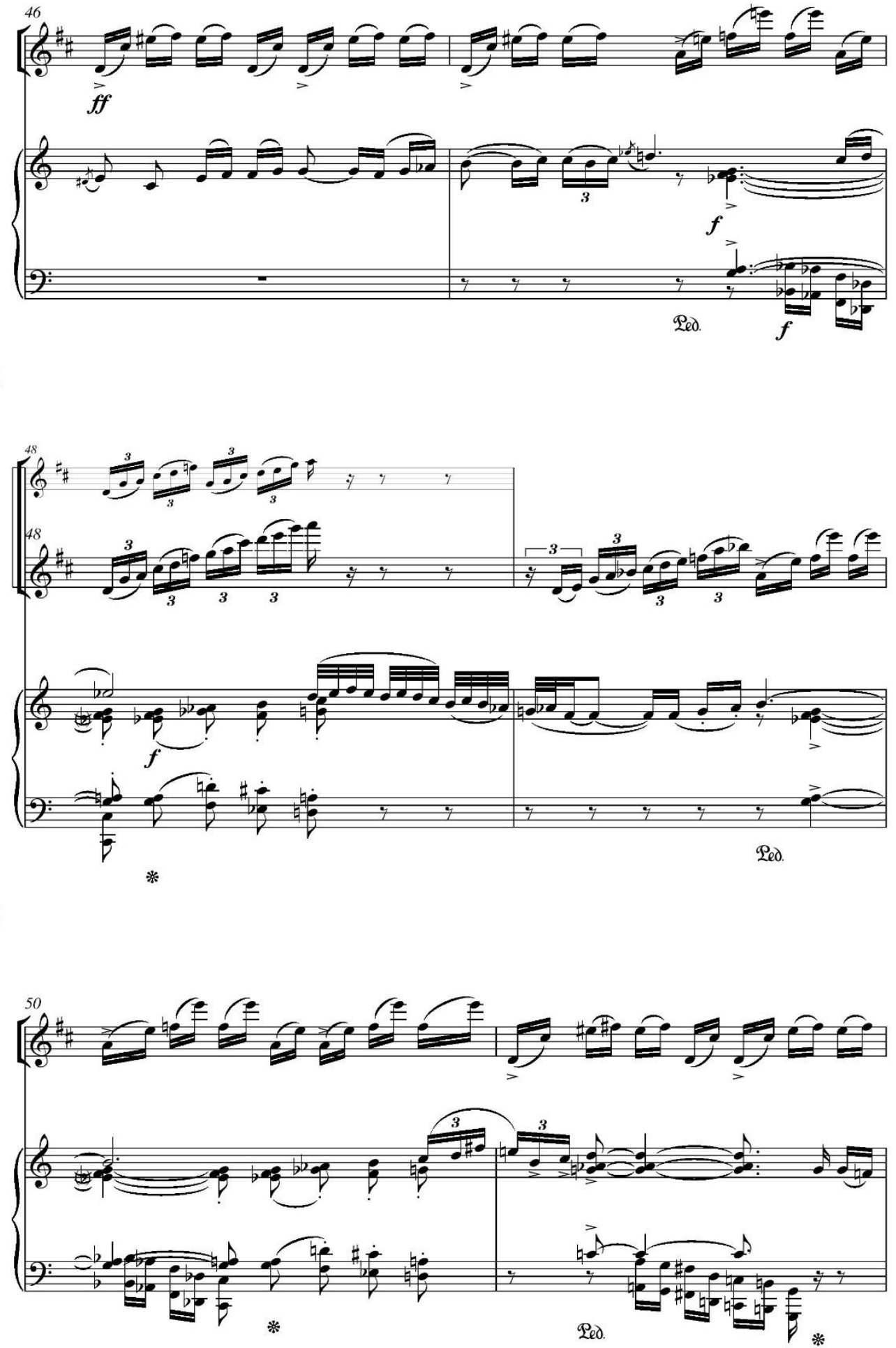


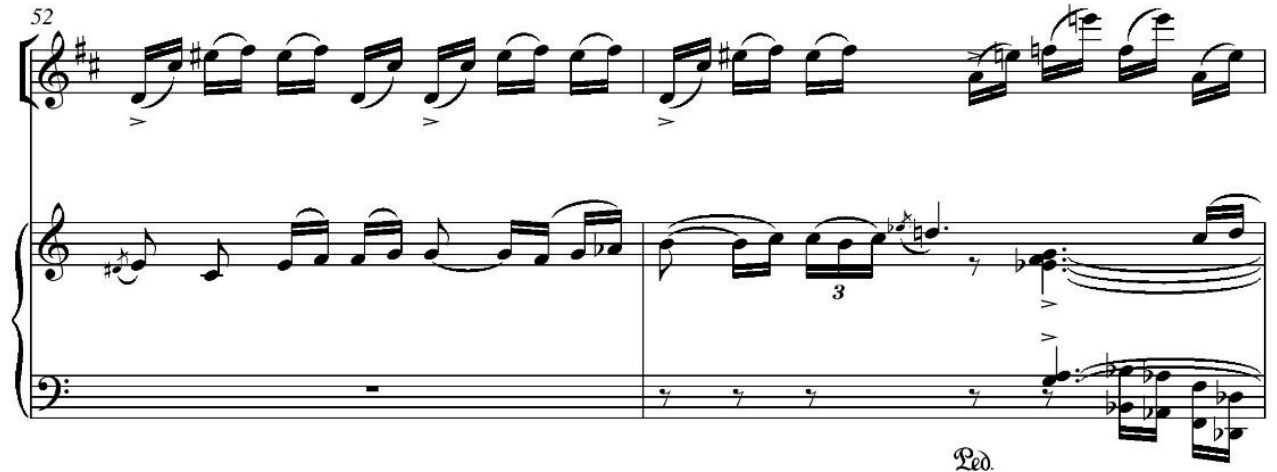

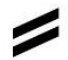
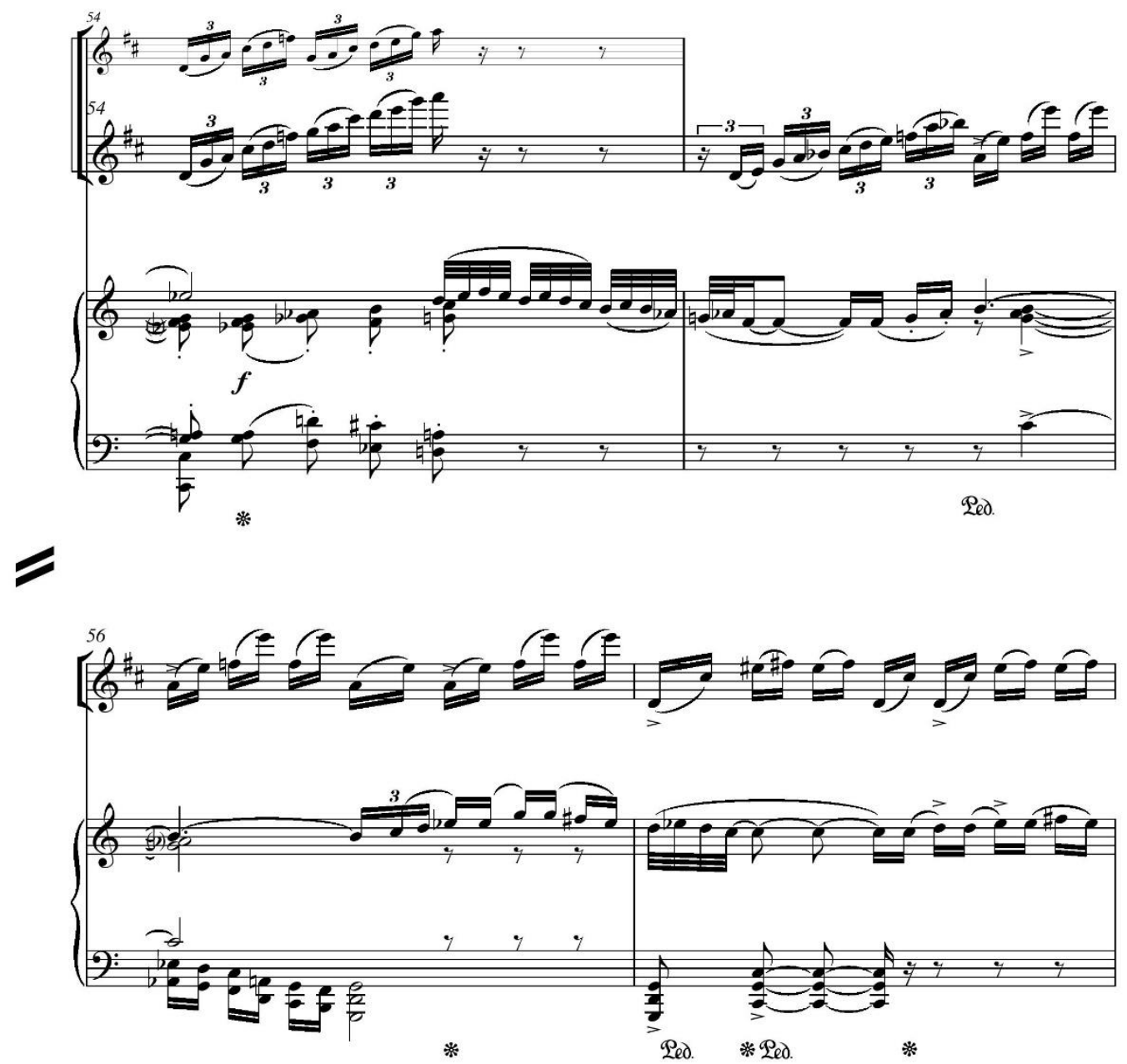

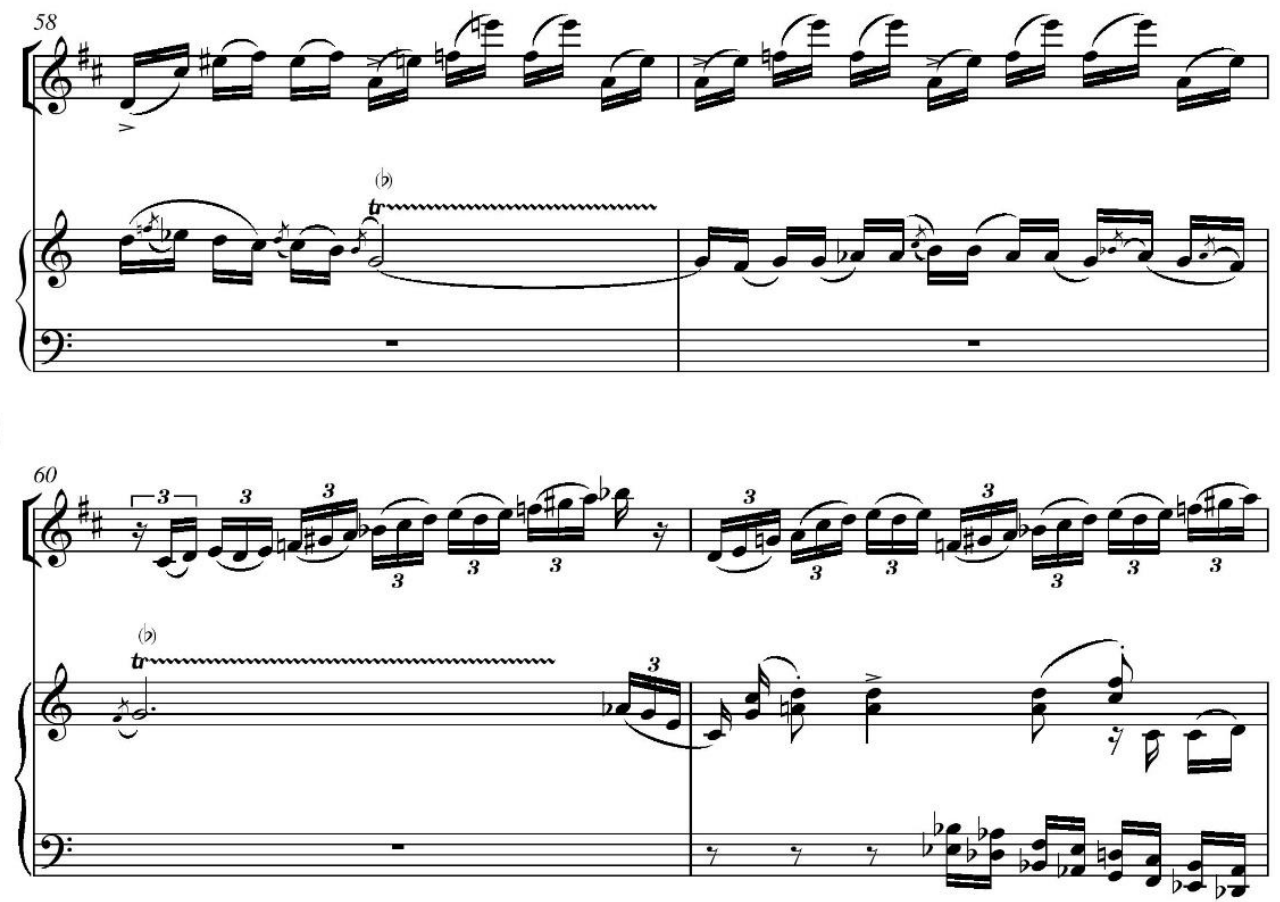

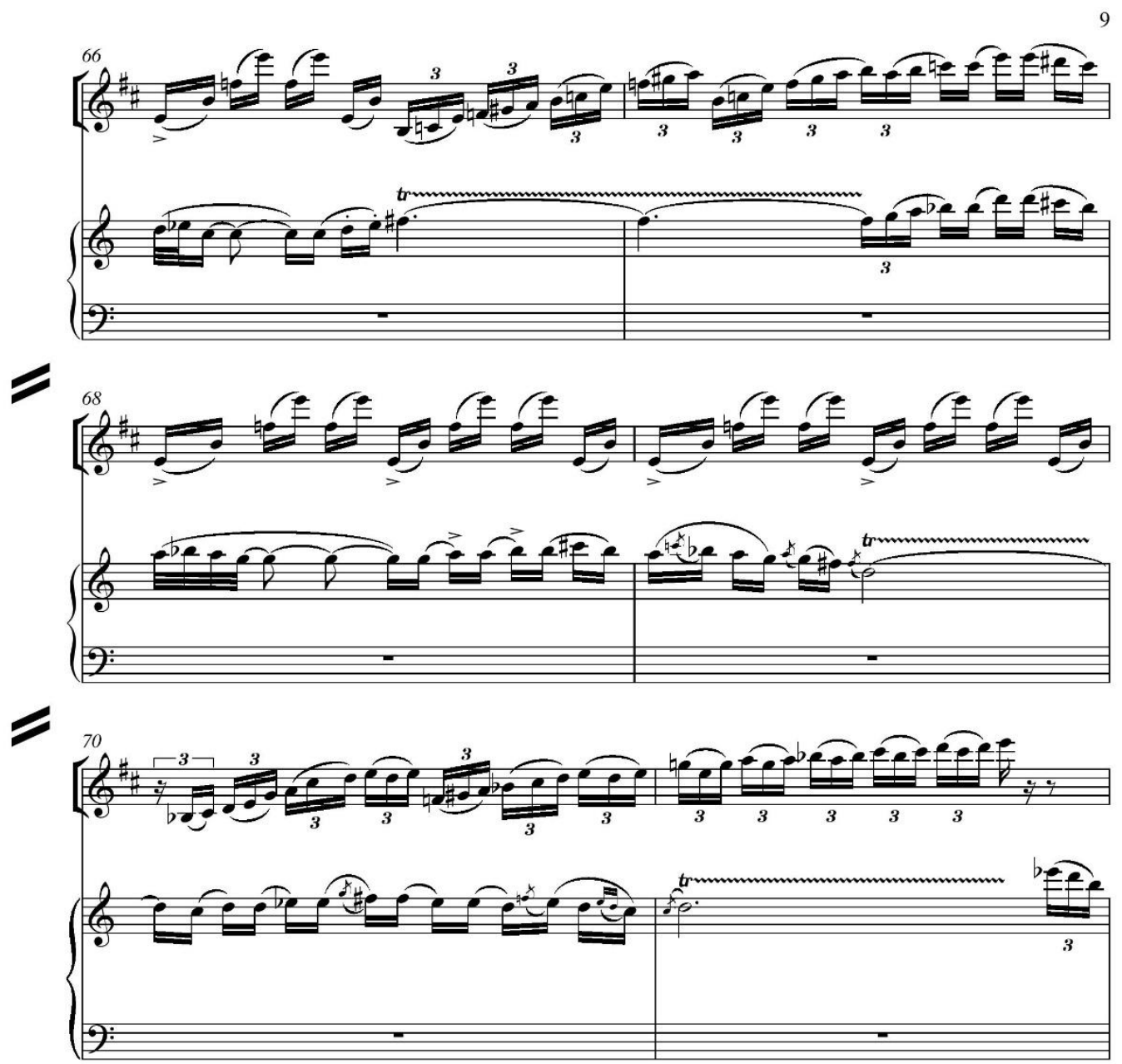

$=$

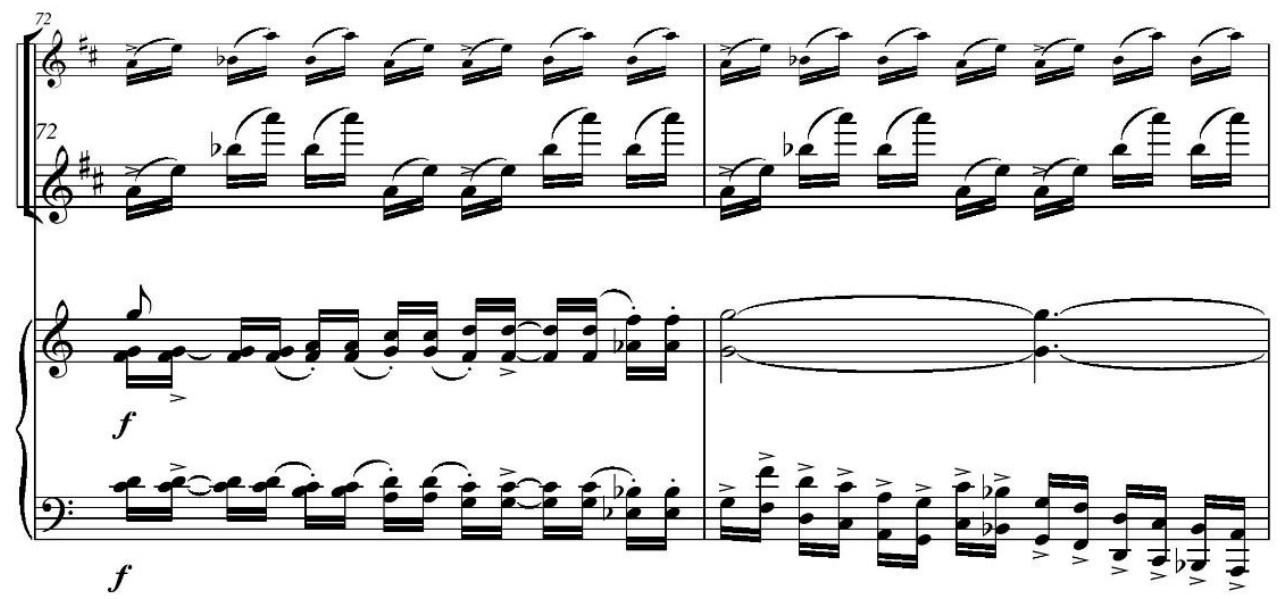




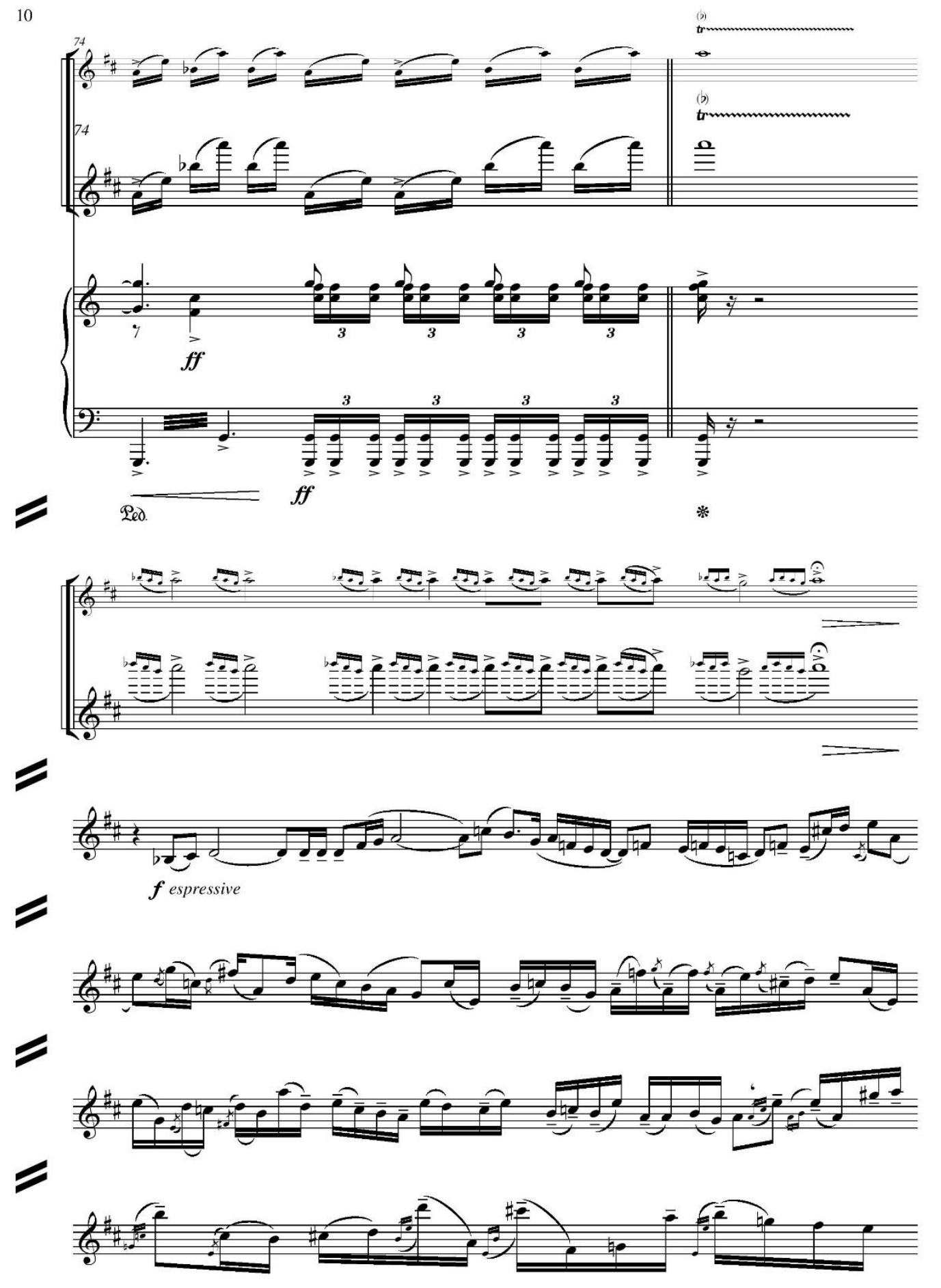




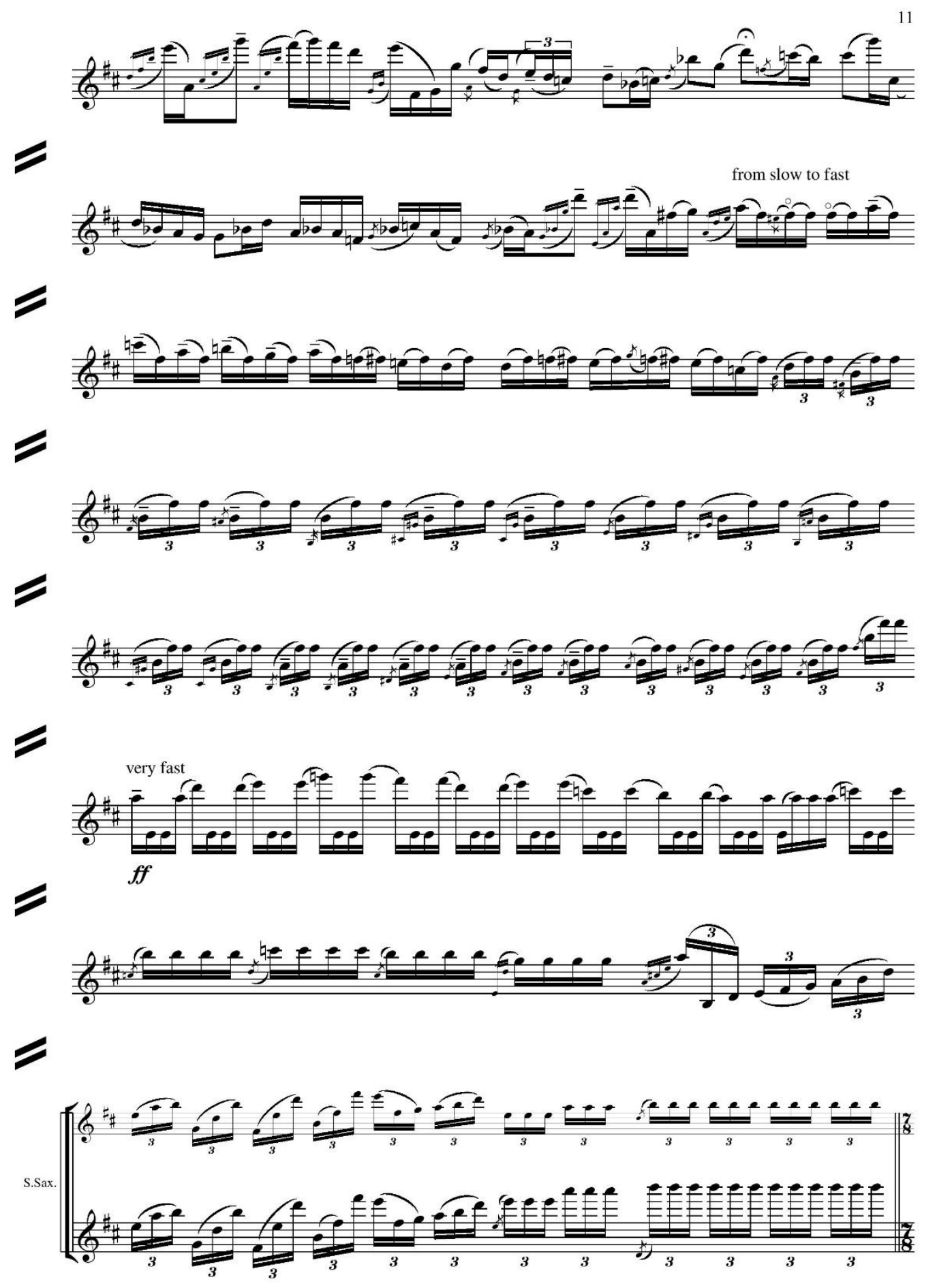


12
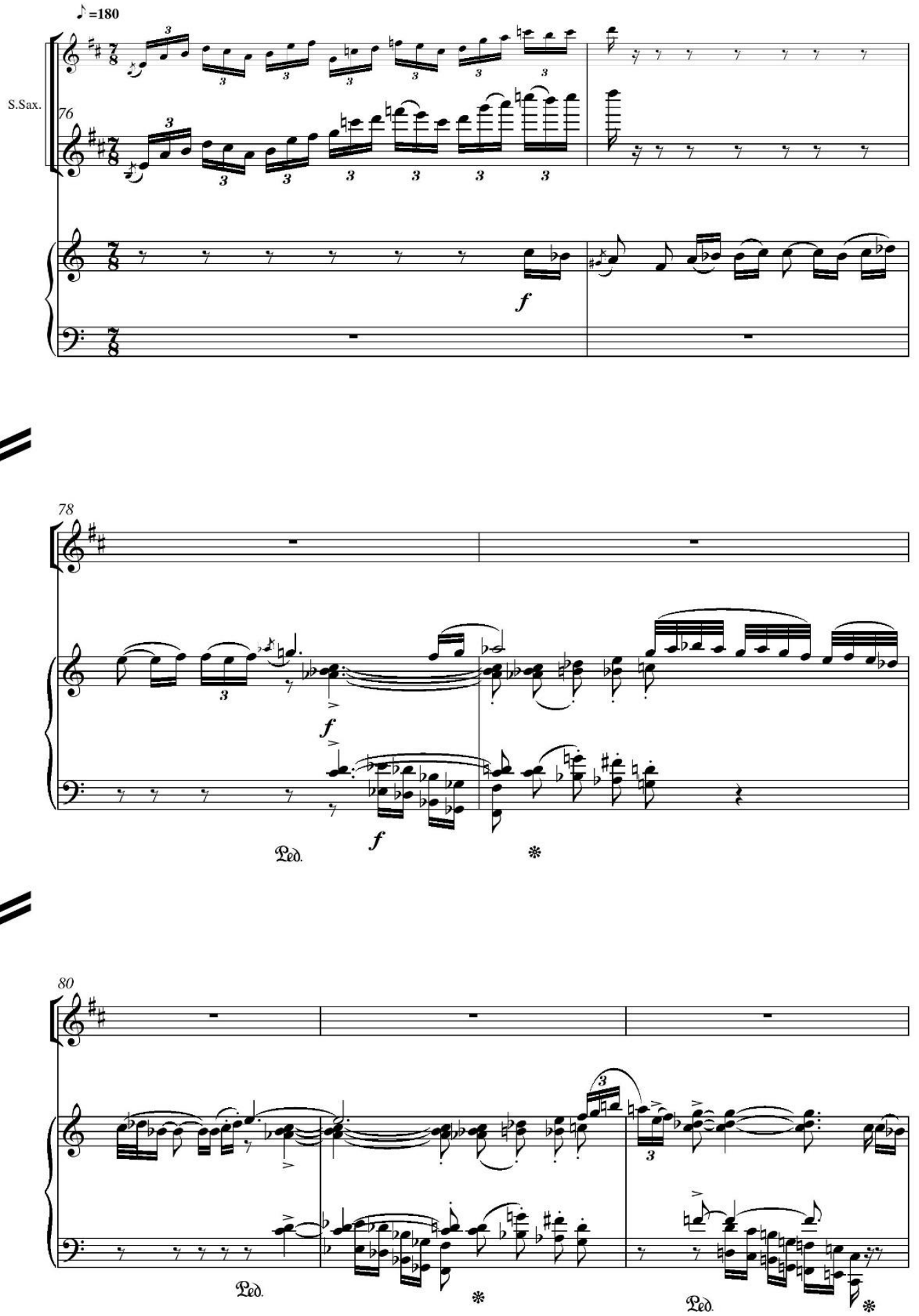

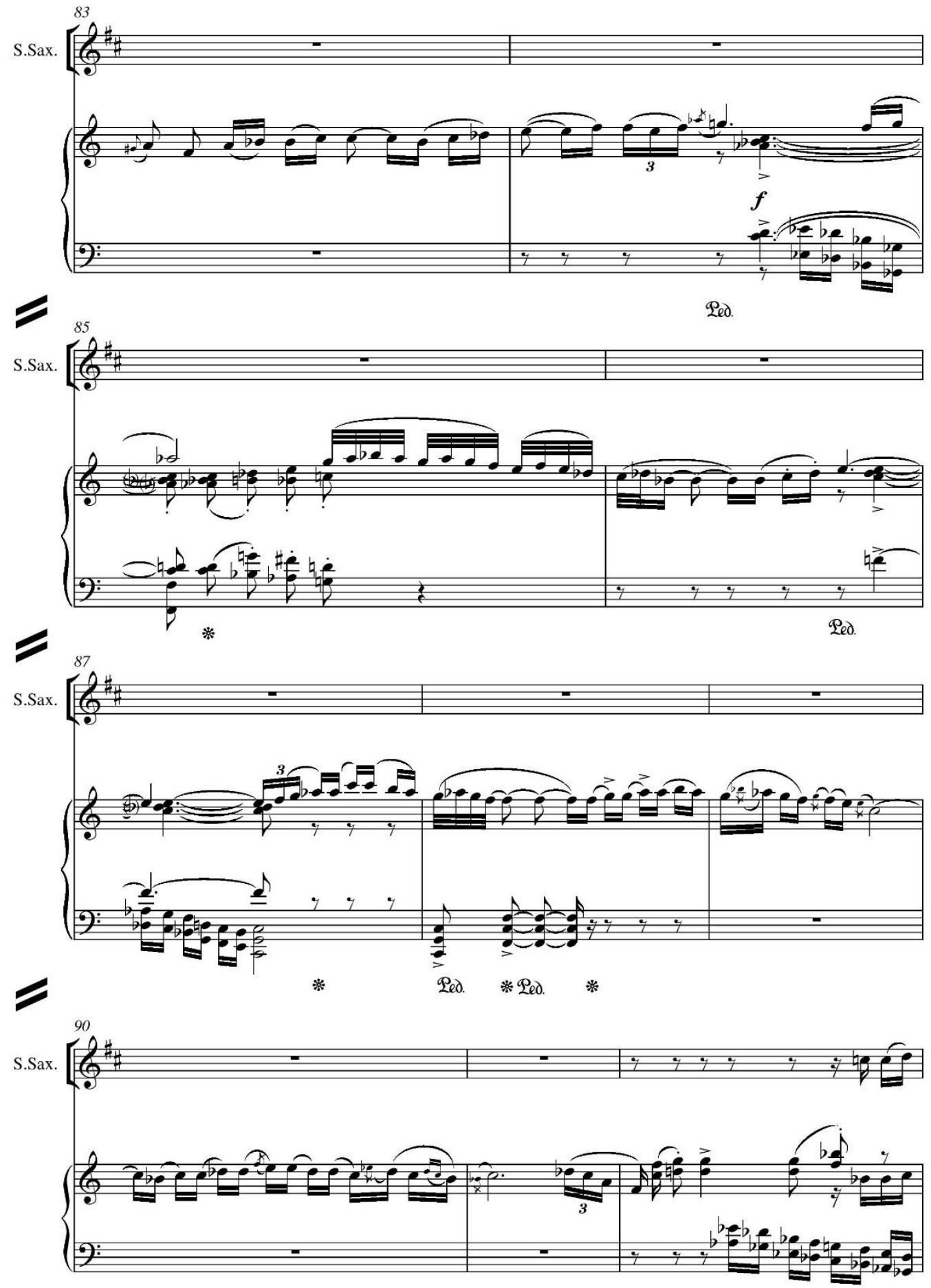
14
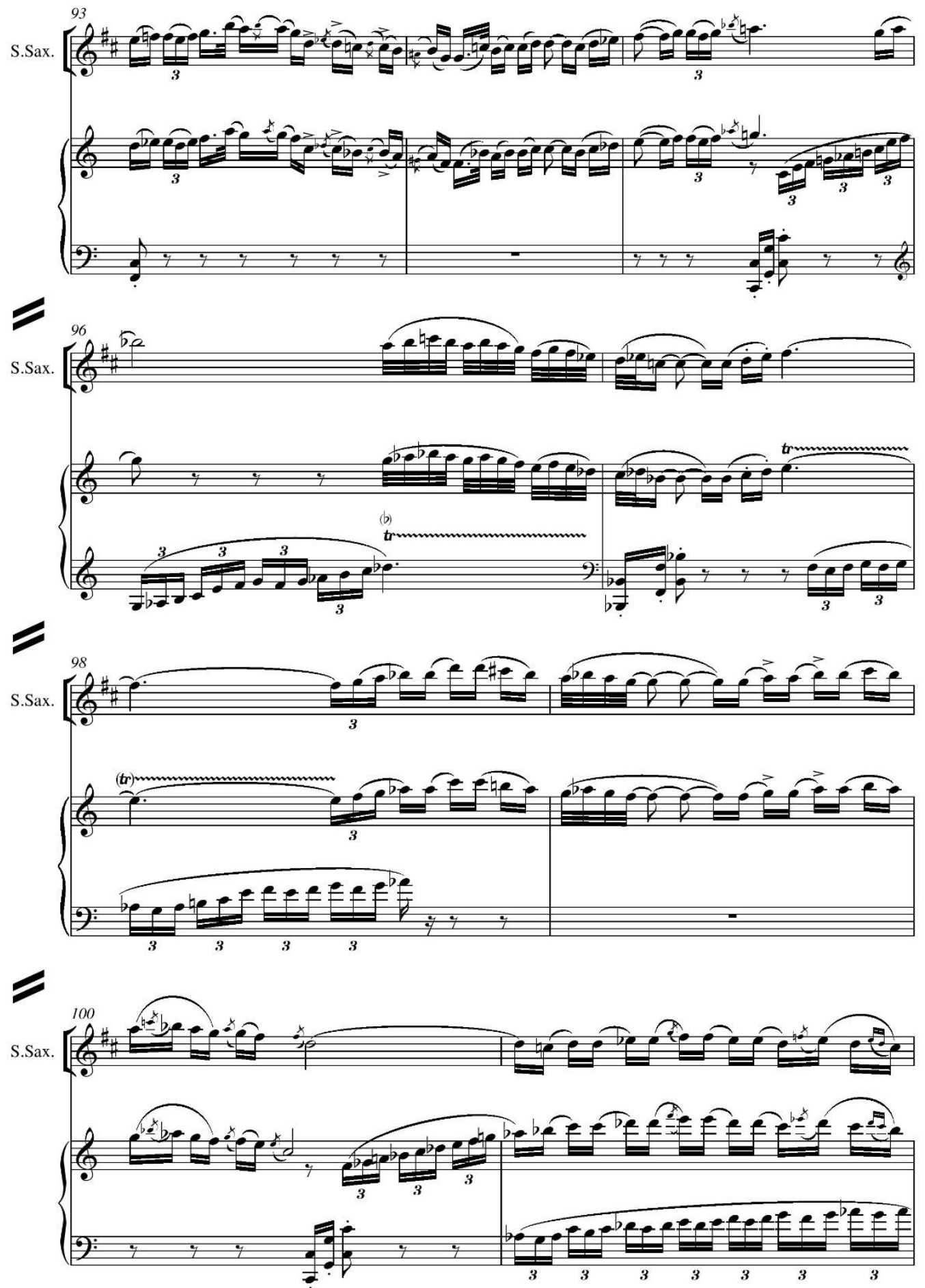

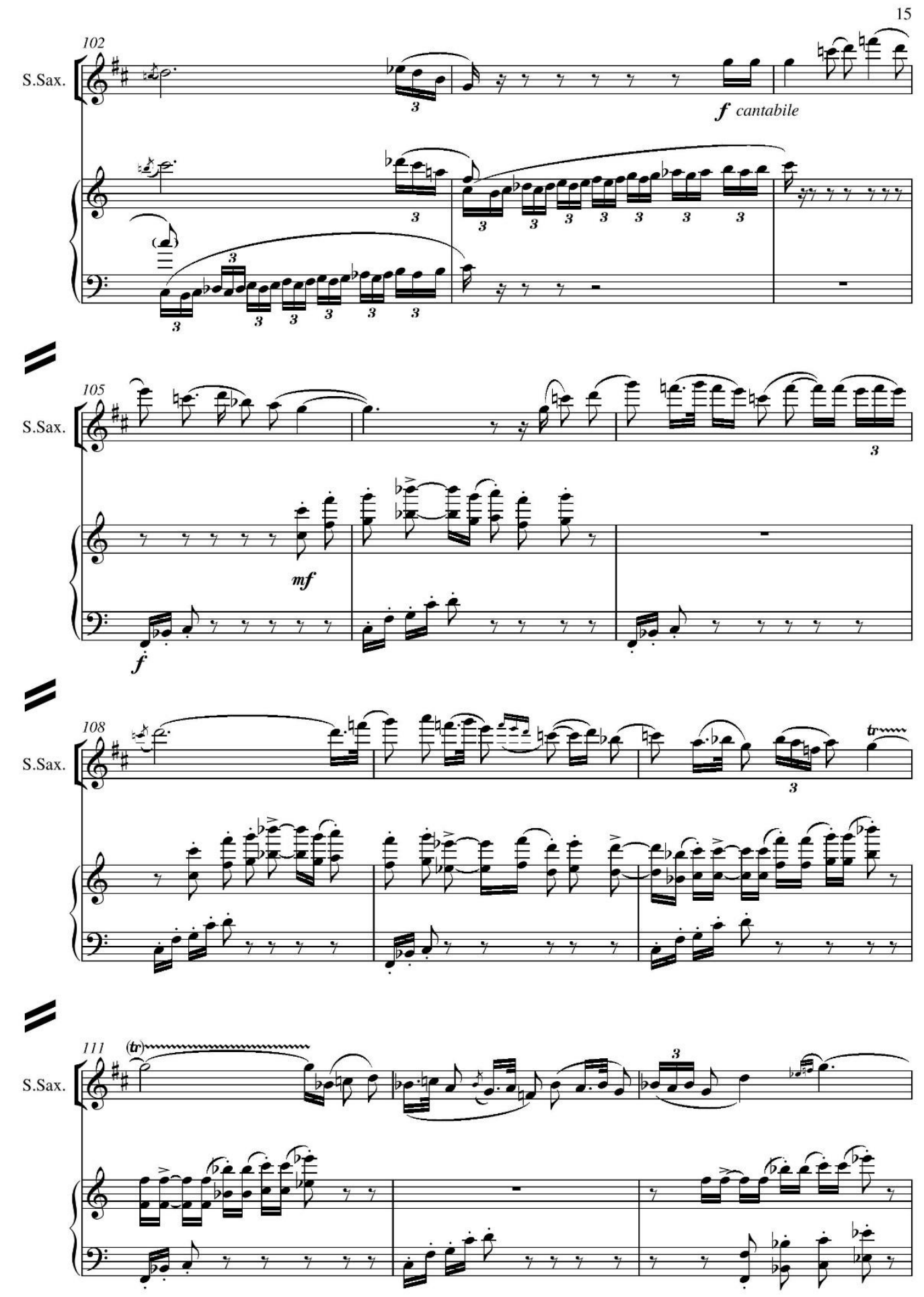


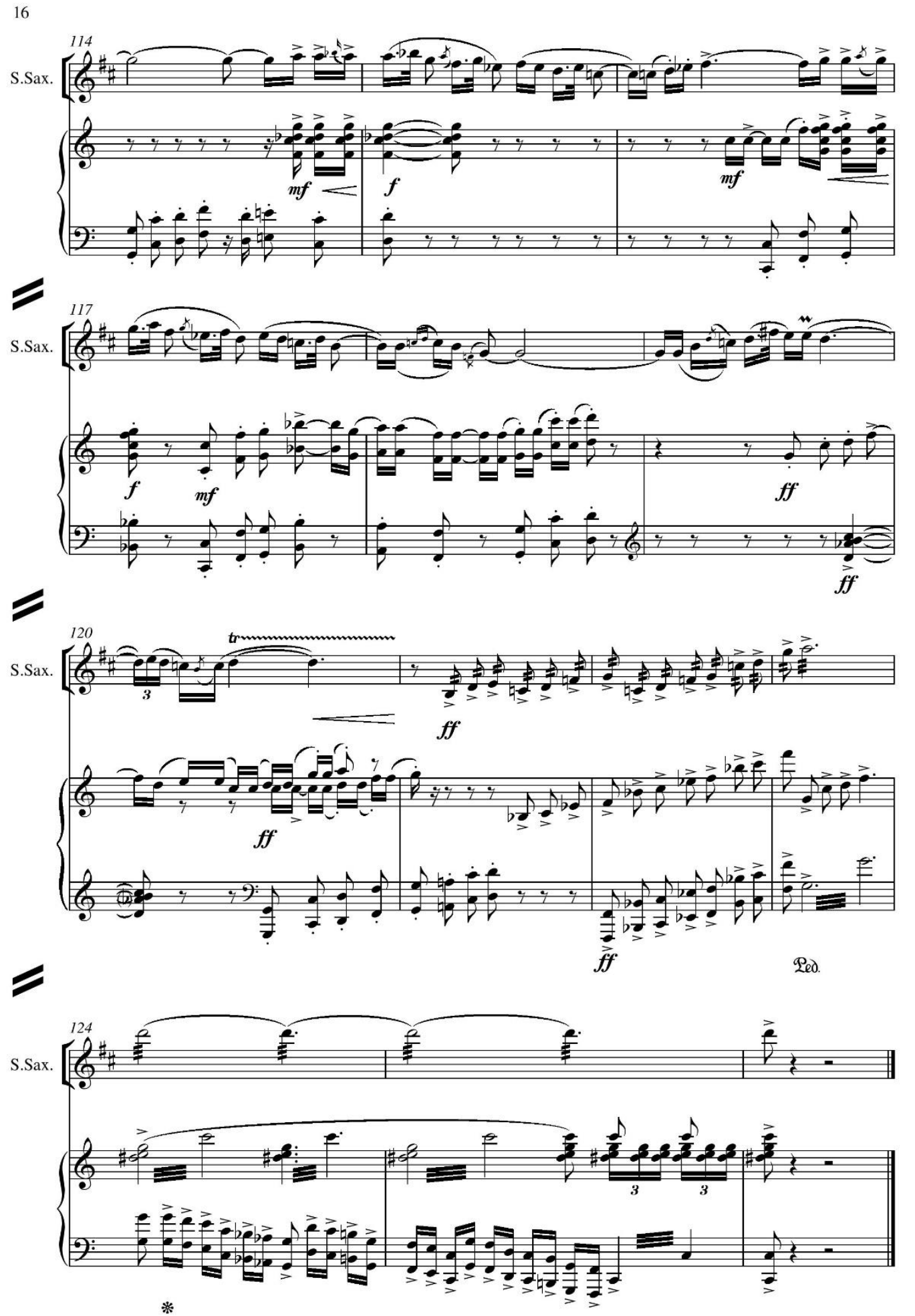




\section{CHAPTER 7}

\section{Conclusion}

This project was intended to create new repertoire for the saxophone by transcribing a suitable composition in a non-western aesthetic. Chen Yi's Chinese Folk Dance Suite was well-suited for this endeavor. A brief history of transcription was examined in the introductory chapter. The following two chapters investigated the biography and the music of Chen, including her general musical style, unique instrumentation, and works for the saxophone. The compositional background of Chinese Folk Dance Suite, including the quotations and origins of each movement, was examined in chapter four. The last two chapters have included a discussion of the methodology used in the transcription process and finally the transcription itself.

China is one of the oldest civilizations in the world, with written historical records dating as early as the Shang dynasty (c. 1600-1046 B.C.). Although the Han culture dominated the general tradition of China, cultural diversity did occur geographically within the country. Similarly, in music, common traditions such as the Chinese operas, the playing of common Chinese instruments, and pentatonic folk tunes are deeply rooted within Chinese culture. However, distinctive regional musical practices and styles exist throughout the country: for example, Cantonese music, Chaozhou xianshi music, and Xinjiang muqam music. The musical material in Chinese Folk Dance Suite draws upon this wide range of Chinese musics. None of the materials in Chinese Folk Dance Suite are direct quotations, and instead show an organic merging of Chen Yi's deep understanding and knowledge of these musical backgrounds and compositional techniques. This hybrid of 
musical styles goes deeper than the notation, and invites the performers to study the aesthetics of both Chinese culture and Western compositional traditions.

According to the bibliographical index, Londeix Guide to the Saxophone Repertoire, 1844-2012 by Jean-Marie Londeix and Bruce Ronkin, more than 29,000 works were written for the saxophone by 2012, excluding orchestral works which included one or more saxophone parts. ${ }^{102}$ In Chinese saxophonist Gao Xin's dissertation Project China: Resource of Contemporary Saxophone Music written by Chinese-born Composers, 97 works for the saxophone written by Chinese composers were documented, 88 of which were written before 2012. ${ }^{103}$ The number of saxophone works written by Chinese composers is surprisingly small when considering what an important new force Chinese composers have been since the second half of the twentieth century. Therefore, it is valuable to develop new saxophone literature from these composers for the stylistic diversity for the instrument.

This project is the only large-scale transcription of Chen Yi's works for saxophone. The solo part was adapted from the perspective of a saxophonist, creating choices for the performer to play with or without the altissimo register. The transcription of the original percussion parts in YangKo with unconventional piano techniques could serve as an example in other future piano reduction projects in imitating percussion. Most importantly, this project was completed under the guidance and approval of the composer.

Chinese Folk Dance Suite has been frequently performed and has become a popular work among violinists and orchestras. ${ }^{104}$ I hope this transcription will continue the success

\footnotetext{
102 Londeix, introduction, iv-v.

103 Xin Gao, "Project China: Resource of Contemporary Saxophone Music written by Chinese-born Composers" (DMA diss., University of North Carolina at Greensboro, 2016).

${ }^{104}$ Chen, phone interview by author.
} 
of the work, become a significant part of the saxophone literature, and encourage similar transcriptions and originals works to be written for the saxophone, especially by non-western composers. 


\section{BIBLIOGRAPHY}

“Awards." American Academy of Arts and Letters. Accessed December 18, 2016. http://artsandletters.org/awards.

“Chen Yi." New Music USA Online Library. Accessed February 16, 2017. http://library.newmusicusa.org/ChenYi.

“Chen Yi.” Theodore Presser Company. Accessed December 18, 2016. http://www.presser.com/composer/chen-yi.

“Chen Yi, Ba Yin.” New Music USA Online Library. Accessed February 16, 2017. http://library.newmusicusa.org/library/composition.aspx?CompositionID=345889.

"Chen Yi, Chinese Ancient Dances." New Music USA Online Library. Accessed February 16, 2017.

http://library.newmusicusa.org/library/composition.aspx?CompositionID=345895.

"Chen Yi, Monologue (Impressions on the True Story of Ah Q)." New Music USA Online Library. Accessed February 16, 2017.

http://library.newmusicusa.org/library/composition.aspx?CompositionID=345918.

“Chen Yi, Not Alone.” New Music USA Online Library. Accessed February 16, 2017. http://library.newmusicusa.org/library/composition.aspx?CompositionID=350488.

"Chen Yi, Septet for Erhu, Pipa, Percussion and Saxophone Quartet." New Music USA Online Library. Accessed February 16, 2017.

http://library.newmusicusa.org/library/composition.aspx?CompositionID=345933.

"Chen Yi, The Han Figurines." New Music USA Online Library. Accessed February 16, 2017. http://library.newmusicusa.org/library/composition.aspx?CompositionID=345908.

"Chen Yi, The Soulful and The Perpetual." New Music USA Online Library. Accessed February 16, 2017.

http://library.newmusicusa.org/library/composition.aspx?CompositionID= 349931 .

"Dr. Chen Yi." The University of Missouri-Kansas City. Accessed December 18, 2016. http://conservatory.umkc.edu/faculty.cfm?r=\%22\%2624\%20\%0A.

"Uyghur Muqam of Xinjiang." The United Nations Educational, Scientific and Cultural Organization. Accessed March 2, 2017.

http://www.unesco.org/culture/ich/en/RL/uyghur-muqam-of-xinjiang-00109.

Boyd, Malcolm. “Arrangement.” Oxford Music Online. Accessed February 9, 2017. http://www.oxfordmusiconline.com/subscriber/article/grove/music/01332. 
Brown, Howard Mayer. "Intabulation." Oxford Music Online. Accessed February 3, 2017. http://www.oxfordmusiconline.com/subscriber/article/grove/music/13823.

Broude, Ronald. "Arrangement, Transcription, Edition: Some Problems in Terminology." The Choral Journal 18, no. 1 (1977): 25-29. Accessed February 9, 2017. http://www.jstor.org/stable/23544286.

Burkholder, J. Peter. "Borrowing." Grove Music Online. Accessed March 11, 2017. http://www.oxfordmusiconline.com/subscriber/article/grove/music/52918pg1.

Burkholder, J. Peter. "The Uses of Existing Music: Musical Borrowing as a Field." Notes 50, no. 3 (1994): 851-70. Accessed March 11, 2017. doi:10.2307/898531.

Chen, Yi. Chinese Folk Dance Suite. King of Prussia: Theodore Presser Company, 2000.

Chen, Yi. Phone interview by author. February 26, 2017.

Chen, Yi. YangKo: for Solo Violin and 2 Percussionists. King of Prussia: Theodore Presser Company, 2006.

Dart, Thurston and Morehen, John and Rastall, Richard. "Tablature." Oxford Music Online. Accessed February 3, 2017.

http://www.oxfordmusiconline.com/subscriber/article/grove/music/27338.

Feeken, Qing Nadia. “The Complete Solo Piano Works of Chen Yi - A Recording, Analysis, and Interpretation.” DMA diss., Arizona State University, 2012.

Gao, Xin. "Project China: Resource of Contemporary Saxophone Music written by Chinese-born Composers." DMA diss., University of North Carolina at Greensboro, 2016.

Gray-Fisk, Clinton. "'Improving' the Classics." The Musical Times 69, no. 1026 (1928): 733-35. Accessed February 9, 2017. doi:10.2307/916657.

Guo, Xin. "Chinese Musical Language Interpreted by Western Idioms: Fusion Process in The Instrumental Works by Chen Yi.” PhD diss., Florida State University, 2010.

Han, Mei. “Zheng."” Oxford Music Online. Accessed February 20, 2017. http://www.oxfordmusiconline.com/subscriber/article/grove/music/46543.

Harris, Rachel and Muhpul, Yasin. "Music of the Uyghurs." London Uyghur Ensemble. Accessed March 2, 2017.

http://www.uyghurensemble.co.uk/en-html/nf-research-article1.html.

Howard-Jones, Evlyn. “Arrangements and Transcriptions.” Music \& Letters 16, no. 4 (1935): 305-11. Accessed February 7, 2017. http://www.jstor.org/stable/728727. 
Law, Po Kwan. “The A Cappella Choral Music of Chen Yi: 1985-2010.” DMA diss., University of Illinois at Urbana-Champaign, 2013.

Ledbetter, David and Harris, C., David. "D'Anglebert, Jean Henry.” Oxford Music Online. Accessed February 5, 2017.

http://www.oxfordmusiconline.com/subscriber/article/grove/music/07165.

Li, Guangming. "Onomatopoeia and Beyond: A Study of the Luogu Jing of the Beijing Opera." PhD diss., University of California, Los Angeles, 2001.

Li, Songwen. "East Meets West: Nationalistic Elements in Selected Piano Solo Works of Chen Yi." DMA diss., University of North Texas, 2001.

Liang, Ming-Yueh and Lam, Joseph S. C. "Qin." Oxford Music Online. Accessed February 20, 2017.

http://www.oxfordmusiconline.com/subscriber/article/grove/music/47071.

Liley, Thomas. "The Repertoire Heritage." In The Cambridge Companion to the Saxophone, edited by Richard Ingham, 51-64. Cambridge: Cambridge University Press, 1998.

Linda Wang. The Stream Flows. Recorded 2013. Scottsdale: Equilibrium. Compact Disc.

Londeix, Jean-Marie. Introduction to Londeix Guide to The Saxophone Repertoire 1844-2012, edited by Bruce Ronkin, iv-v. Glenmoore: Roncorp Publication, 2012.

Mao, Jizeng. "Wei wu er zu ren ming de jiao au: mu ka mu [The Pride of the Uyghurs Muqam].” Beishi GuoYue 193 (2003).

Mao, Jizeng and Jiang, Turghun. "Twelve Muqam.” Music Weekly (2007).

Meng, Fanqin. "A Research and Performance Guide of the Viola Concerto Xian Shi." DMA diss., University of Wisconsin-Madison, 2016.

Penrose, James F. "The Piano Transcriptions of Franz Liszt." The American Scholar 64, no. 2 (1995): 272-76. Accessed February 5, 2017.

http://www.jstor.org/stable/41212325.

Piñeiro, John de Clef. "An Interview with Chen Yi." The New Music Connoisseur 9, no. 4 (2001): 27-31.

Singapore Symphony Orchestra. Chen $Y i-M o m e n t u m$. Conducted by Lan Shui. Recorded 2002. Åkersberga: BIS. Compact Disc. 
Thrasher, Alan R. "China, §I: Introduction: Historical, regional and study perspectives." Oxford Music Online. Accessed February 26, 2017.

http://www.oxfordmusiconline.com/subscriber/article/grove/music/43141pg1.

Thrasher, Alan R. "Yangqin." Oxford Music Online. Accessed February 28, 2017. http://www.oxfordmusiconline.com/subscriber/article/grove/music/45375.

Wedemeyer, Dee. "Arts Abroad; A Chinese-Born Composer and Her Own Long March." New York Times, March 27, 2001. Accessed December 28, 2016.

http://www.nytimes.com/2001/03/27/arts/arts-abroad-a-chinese-born-composer-and-her-o wn-long-march.html.

Winemiller, John T. "Recontextualizing Handel's Borrowing." The Journal of

Musicology 15, no. 4 (1997): 444-70. Accessed February 5, 2017. doi:10.2307/764003.

Young, Robert W. "Terminology for Logarithmic Frequency Units." Journal of the Acoustical Society of America, 11, no. 1 (1939): 134-139. Accessed April 14, 2017. doi:10.1121/1.1916017. 


\title{
APPENDIX A
}

\author{
旱天雷
}

Han Tian Lei
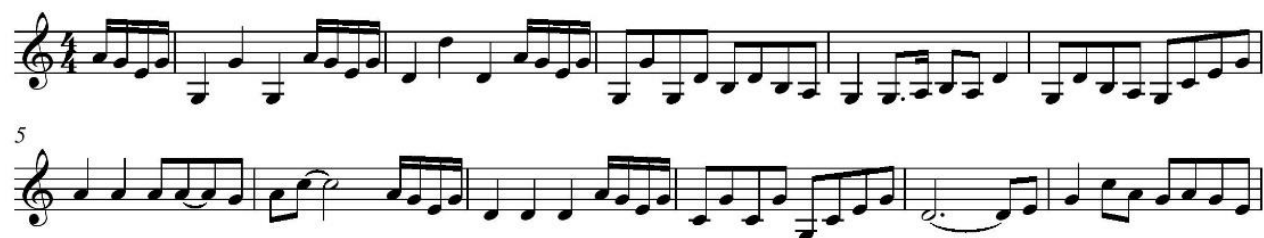

(a)
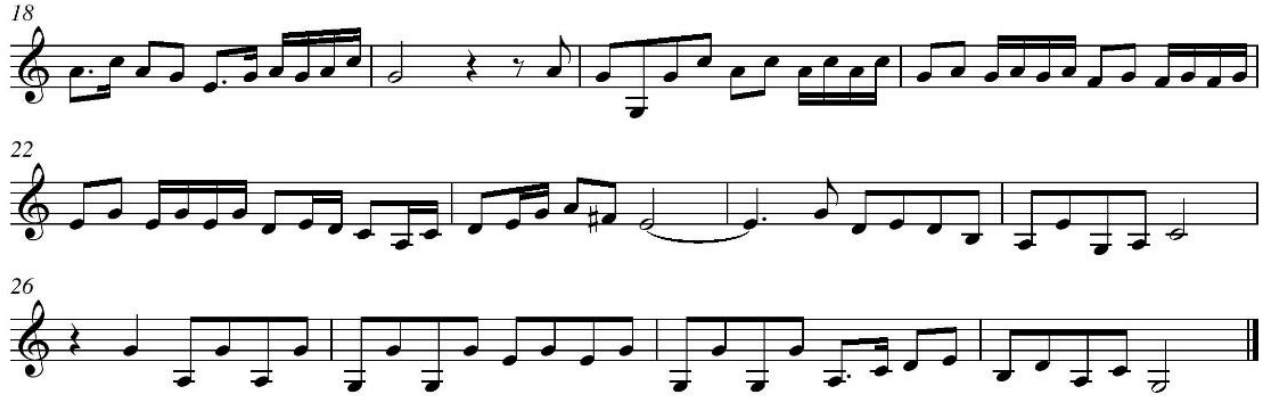

Transcribed by the author. 


\section{APPENDIX B}

獅子戲球

Shi Zi Xi Qiu
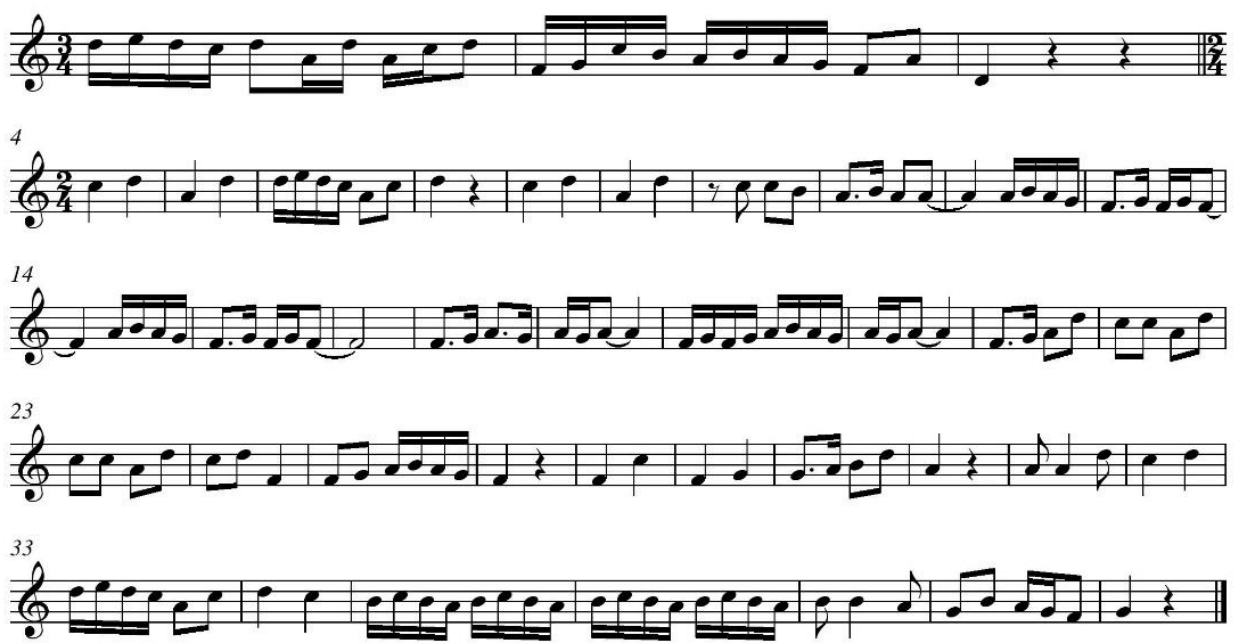

Transcribed by the author. 


\section{APPENDIX C}

阿瓦日古麗

Awaguli
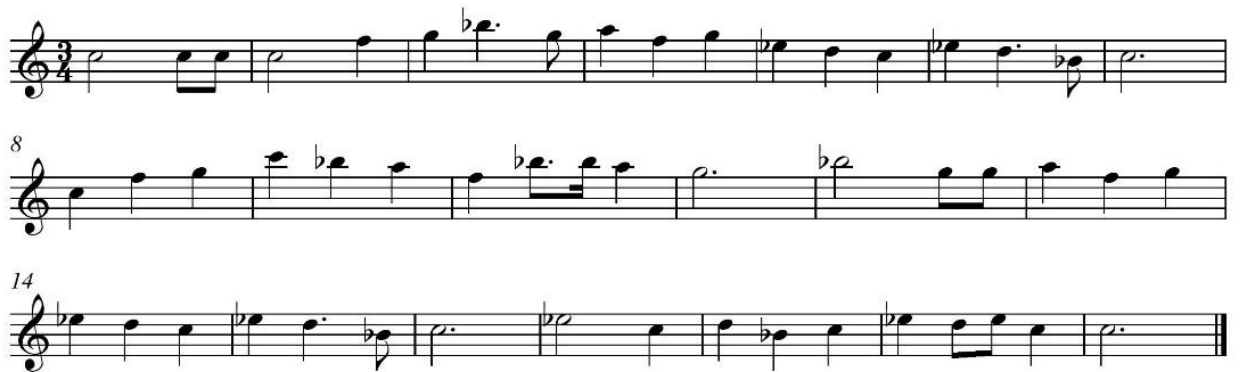

Transcribed by the author. 